\title{
A BAYESIAN APPROACH TO DYNAMIC EFFICIENCY AND PRODUCTIVITY MEASUREMENT
}

\author{
Dissertation \\ to obtain the Ph. D. degree \\ in the International Ph. D. Program for Agricultural Sciences in Göttingen \\ (IPAG) \\ at the Faculty of Agricultural Sciences, \\ Georg-August-University Göttingen, Germany
}

\author{
presented by \\ Ioannis Skevas \\ born in Alexandroupolis, Greece
}

Göttingen, December 2016 
D7

1. Name of supervisor: Prof. Dr. Bernhard Brümmer

2. Name of co-supervisor: Prof. Dr. Thomas Kneib

3. Name of $2^{\text {nd }}$ co-supervisor: Dr. Grigorios Emvalomatis

Date of dissertation: $9^{\text {th }}$ of February 2017 


\section{Summary}

The vast majority of the efficiency and productivity measurement literature has been based on the static viewpoint of the firm. Few studies have developed the dynamic analog of static efficiency measurement, introducing the notions of long-run efficiency and inefficiency persistence. The former is perceived as a flow that measures firms' failure to optimize their present production processes while taking into account their long-run objectives. The latter is based on the argument that adjustment costs prevent firms from altering the level of their quasi-fixed factors of production, and therefore inefficient firms are likely to remain partly inefficient in the future. This implies that their inefficiency may persist from one period to the next. However, the few existing dynamic efficiency studies have not provided any empirical evidence on the driving forces of firms' long-run efficiency and inefficiency persistence.

As far as productivity measurement is concerned, previous studies have exclusively employed static efficiency models that are inconsistent with the dynamic nature of firms' decision-making process. Additionally, these static efficiency models have either imposed a very restrictive or a non-existing time structure on efficiency. On the one hand, imposing a very restrictive time structure on efficiency scores may not reveal period-specific shocks on firms' efficiency. On the other hand, a specification that allows for the efficiency scores to evolve completely arbitrarily over time may capture period-specific efficiency shocks, but is also very likely to produce erratic results.

This dissertation departs from previous dynamic efficiency studies by shedding light on the drivers of long-run efficiency and inefficiency persistence. Additionally, a dynamic efficiency specification is used to calculate and decompose Total Factor Productivity (TFP) growth. Such a modelling approach not only recognizes that firms' decision-making processes are dynamic in nature, but also offers a more flexible time-structure for the efficiency component that can account for period-specific shocks without producing erratic results.

Three models for dynamic efficiency measurement are developed and applied to the case of German dairy farms. Estimation proceeds using Bayesian techniques. The first model is based on the argument that the efficiency levels achieved by farms in the long-run may vary due to their different characteristics and the varying degrees of their inefficiency persistence. The conventional dynamic stochastic frontier model is extended to allow for such heterogeneity in the long-run efficiency of farms. The results suggest that farms achieve different long-run efficiency levels mainly due to their different characteristics. In particular, economically larger farms are more technically efficient in the long-run, while farms that receive higher amounts of subsidies are less technically efficient in the long-run. 
The second model aims to provide empirical evidence on the driving forces of farms' inefficiency persistence. By assuming that inefficiency persistence arises due to the existence of pecuniary and non-pecuniary adjustment costs, the model tests whether financial aid and managers' experience have an impact on inefficiency persistence. The empirical findings reveal a high degree of inefficiency persistence through time, which increases with the amount of subsidies received. Older farmers exhibit higher inefficiency persistence as opposed to younger ones, presumably due to their lack of motivation to adopt state-of-the-art technologies.

The third model calculates and decomposes TFP growth of German dairy farms using a dynamic specification for the efficiency component. The results report a high TFP growth rate that is mostly attributed to technical progress. The model is also able to capture steep efficiency and TFP growth changes that may have been induced by the high milk price volatility which occurred in the German dairy sector. The dynamic efficiency model is favored by the data when tested against a model that imposes a very restrictive time structure on efficiency, and a model that imposes no time structure on efficiency scores. 


\section{Contents}

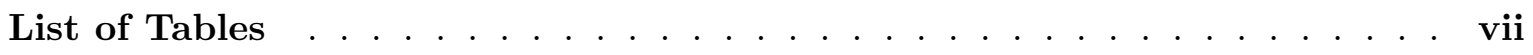

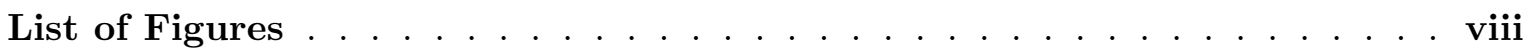

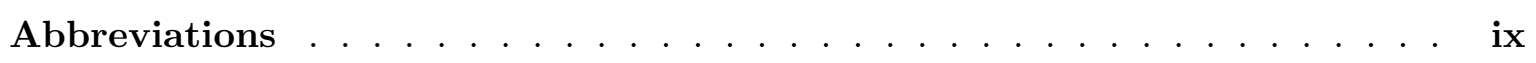

Acknowledgments .................... . . . .

Chapter 1: General Introduction . . . . . . . . . . . . . . . 1

1.1 Background on efficiency and productivity . . . . . . . . . . . . 1

1.2 Problem statement . . . . . . . . . . . . . . . . . . . . . 3

1.3 German dairy sector . . . . . . . . . . . . . . . . 4

1.4 Objectives and research questions .............. 6

1.5 Outline.......................... 7

Chapter 2: Heterogeneity of long-run technical efficiency of German dairy farms: a Bayesian approach . . . . . . . . . . . . . . 8

2.1 Introduction . . . . . . . . . . . . . . . . . . . . . . . . . . 9

2.2 Modelling Approach and Estimation . . . . . . . . . . . . . . 11

2.3 Data and empirical specification . . . . . . . . . . . . . 15

2.4 Results . . . . . . . . . . . . . . . . . . . . . . 18

2.5 Concluding remarks . . . . . . . . . . . . . . . . 21

Chapter 3: The effect of farm characteristics on the persistence of technical inefficiency: a case study in German dairy farming . . 23

3.1 Introduction . . . . . . . . . . . . . . . . . . . . . . . 24

3.2 Modelling approach . . . . . . . . . . . . . . . . 27

3.2.1 Modelling inefficiency persistence . . . . . . . . . . . . . . 29

3.2.2 Bayesian inference . . . . . . . . . . . . . . . . . . . . 29

3.2 .3 Alternative models . . . . . . . . . . . . . . . . 31

3.3 Data and empirical specification . . . . . . . . . . . . . . . . 32

3.4 Results . . . . . . . . . . . . . . . . . 36

3.5 Discussion and conclusions . . . . . . . . . . . . . . . . . 40

Chapter 4: Productivity growth under a dynamic inefficiency specification: the case of German dairy farms . . . . . . . . . . 42 
4.1 Introduction . . . . . . . . . . . . . . . . . . . . . 43

4.2 Modelling approach . . . . . . . . . . . . . . . . . 45

4.2.1 Distance function and efficiency . . . . . . . . . . . . 45

4.2.2 Alternative efficiency specifications . . . . . . . . . . . . 46

4.2.3 Measurement and decomposition of TFP growth . . . . . . . . . 48

4.3 Estimation approach . . . . . . . . . . . . . . . . . . . . . 48

4.3.1 Empirical specification . . . . . . . . . . . . . . 48

4.3.2 Bayesian inference ... . . . . . . . . . . . 49

4.3.3 Log-marginal likelihood and Bayes factors . . . . . . . . . . . 51

4.4 Data . . . . . . . . . . . . . . . . . . . . 52

4.5 Results and discussion . . . . . . . . . . . . . . . . 54

4.6 Conclusions . . . . . . . . . . . . . . . . . . . . . . 59

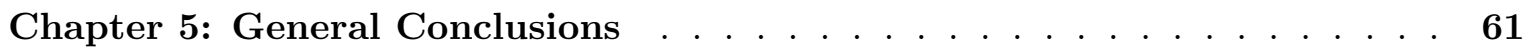

5.1 Summary of findings . . . . . . . . . . . . . . . . 61

5.2 Limitations . . . . . . . . . . . . . . . . . . . . . 63

5.3 Synthesized Results . . . . . . . . . . . . . . . . . . . . . 64

5.4 Policy Implications . . . . . . . . . . . . . . . . . . . . . 65

5.5 Suggestions for Future Research . . . . . . . . . . . . . . . . . . 67

Appendix A . . . . . . . . . . . . . . . . . . . . . . . 68

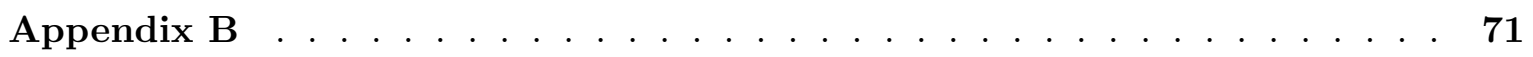

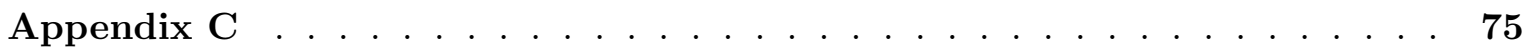

Bibliography . . . . . . . . . . . . . . . . . . 80 


\section{List of Tables}

2.1 Summary statistics of the models' variables . . . . . . . . . . . . . . . . 17

2.2 Posterior means, standard deviations and $95 \%$ credible intervals of the first-order terms and the structural parameters . . . . . . . . . . . . . . 19

2.3 Marginal effects of the variables in $\mathbf{z}$ on long-run technical efficiency (LRTE) . . . . . . . . . . . . . . . . . . . 21

3.1 Summary statistics of the models' variables . . . . . . . . . . . . . . 35

3.2 Posterior means, standard deviations and $95 \%$ credible intervals of the model's parameters . . . . . . . . . . . . . . . . . . . . . 37

3.3 Marginal effects of the variables in $\mathbf{z}$ on technical efficiency . . . . . . . 38

3.4 Marginal effects of the variables in $\mathbf{w}$ on inefficiency persistence . . . . 39

4.1 Summary statistics of the model's variables . . . . . . . . . . . . . . . 54

4.2 Posterior summaries of the first-order terms and the parameters in the three $\boldsymbol{\theta}$ vectors . . . . . . . . . . . . . . . . . . . . 55

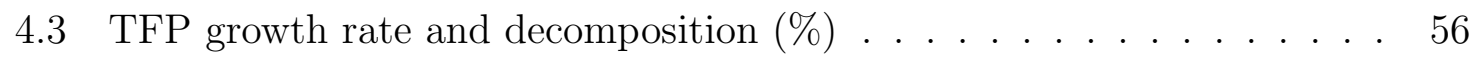

4.4 Marginal log-likelihoods and posterior model probabilities . . . . . . . . 59

5.1 Summary of average inefficiency persistence scores by chapters . . . . . 64

A.1 Parameterization of priors . . . . . . . . . . . . . 68

A.2 Estimates of the model's parameters . . . . . . . . . . . . . . . 69

A.3 Determinants of transformed efficiency s . . . . . . . . . . . . . . 70

B.1 Parameterization of priors . . . . . . . . . . . . . . 71

B.2 Parameter estimates from the three alternative inefficiency specifications 71

B.3 Estimates of the model's parameters . . . . . . . . . . . . . . . 71

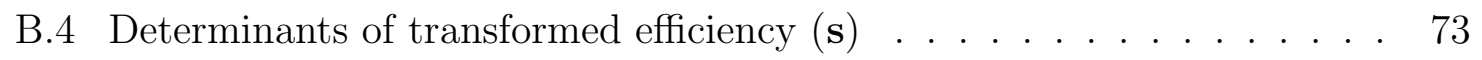

B.5 Determinants of transformed inefficiency persistence $(\mathbf{h}) \quad \ldots \ldots$. . . . 73

C.1 Estimates of the parameters from the Battese and Coelli (1992) model 75

C.2 Estimates of the parameters from the unstructured model . . . . . . . 76

C.3 Estimates of the parameters from the dynamic model . . . . . . . . . . 78

C.4 Determinants of efficiency in the unstructured model . . . . . . . . . . 79

C.5 Determinants of transformed efficiency $\mathbf{s}$ in the dynamic efficiency model 79 


\section{List of Figures}

1.1 Evolution of milk prices per 100kg in the German dairy sector from 2001 to 2009 . . . . . . . . . . . . . . . . . . . 5 5

2.1 Boxplot of inefficiency persistence parameter $\rho$ and LRTE . . . . . . 20

3.1 Posterior density and summary statistics of inefficiency persistence $\rho_{i} \quad . \quad 39$

4.1 Decomposition of TFP growth under the three alternative models . . . 58

A.1 Coefficient of variation for European Size Units and subsidies . . . . . . 68

B.1 Coefficient of variation for ESU, specialization, and density . . . . . . . 74

B.2 Coefficient of variation for received subsidies . . . . . . . . . . . . . . 74

C.1 Coefficient of variation for size, specialization and stock density . . . . 80 


\section{Abbreviations}

$\begin{array}{ll}\text { AMS } & \text { Automatic Milking System } \\ \text { CAP } & \text { Common Agricultural Policy } \\ \text { DEA } & \text { Data Envelopment Analysis } \\ \text { ESU } & \text { European Size Units } \\ \text { EU } & \text { European Union } \\ \text { FADN } & \text { Farm Accountancy Data Network } \\ \text { LRTE } & \text { Long-Run Technical Efficiency } \\ \text { MCMC } & \text { Markov Chain Monte Carlo } \\ \text { SFA } & \text { Stochastic Frontier Analysis } \\ \text { SPS } & \text { Single Payment Scheme } \\ \text { TFP } & \text { Total Factor Productivity }\end{array}$




\section{Acknowledgments}

Aristotle had once said: "The roots of education are bitter, but the fruit is sweet". The way that the word "bitter" is perceived is of course something subjective. In my view, it refers to a painful experience but not a tedious or an unpleasant one. How can one achieve his goals without sacrificing? Without sweating? Feelings like disappointment or anxiety are natural to arise, without, however, implying that one is unhappy. And this occurs when one strives for something that he really desires. This was exactly the case for myself during these 3 years. I am currently unaware of the "sweetness of the fruit" concerning my professional career. However, I am completely aware of something more important. And this is the life lesson that I got from this procedure. Learning how to think, respect and listen to alternative opinions, and keep on trying even when it seems impossible to achieve your target, are just some examples.

Upon the completion of my $\mathrm{PhD}$ dissertation, I need to acknowledge several people who helped, encouraged and guided me during this 3-year trip. I am highly indebted to my two supervisors from Göttingen, Prof. Bernhard Brümmer and Prof. Thomas Kneib. Bernhard thank you for trusting me for this position, your support in the initial stage of my $\mathrm{PhD}$, your constructive comments on my work even when I was in Scotland, and your patience when I was a bit late on the chair lunches. Thomas thank you for transferring parts of your wide statistical knowledge on me. Your way of teaching has made complicated concepts look like a piece of cake. Furthermore, I would like to thank Mrs. Dede Doërte from the Statistics department for facilitating the administrative work that I had to deal with. I would also like to express my gratitude to my colleagues both in the Agricultural Economics and the Statistics department. You made my stay in Germany easier and enjoyable. Particular thanks go to my colleagues Alberto Saucedo and Marwan Benali for being always there for me.

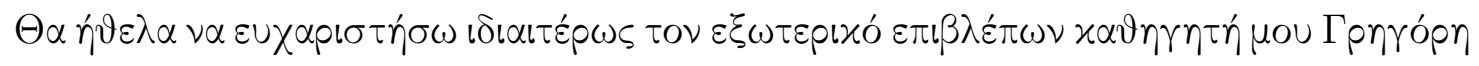

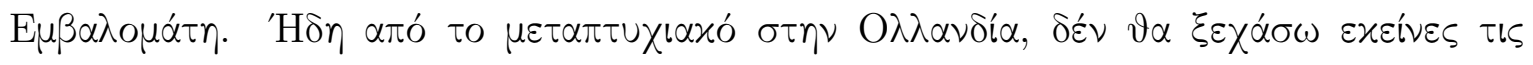

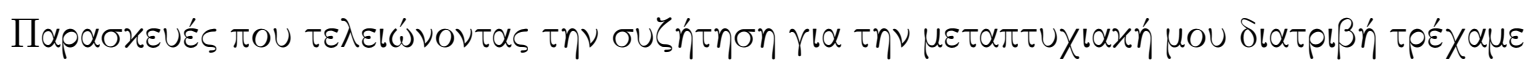

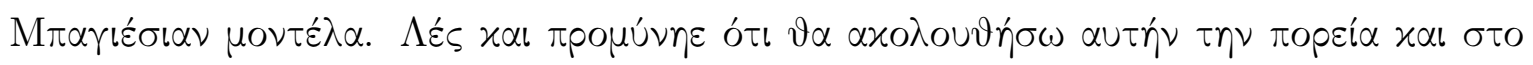

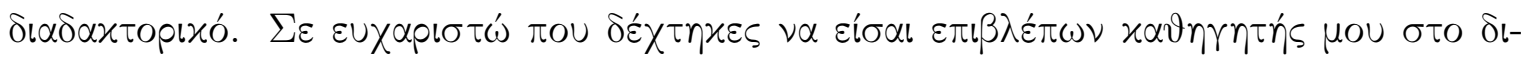

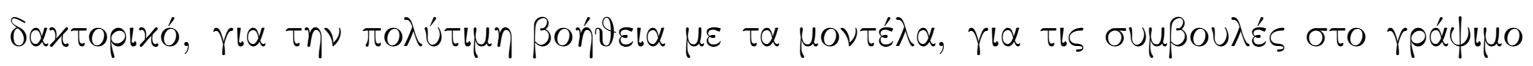

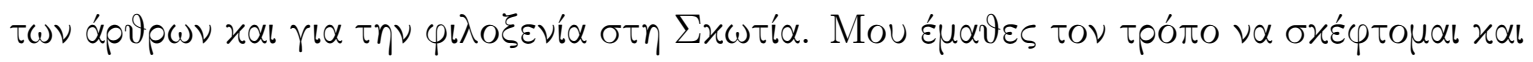

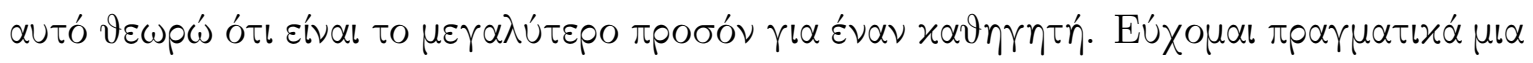

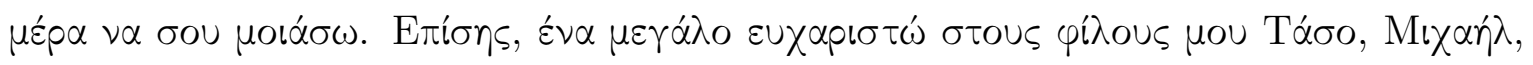

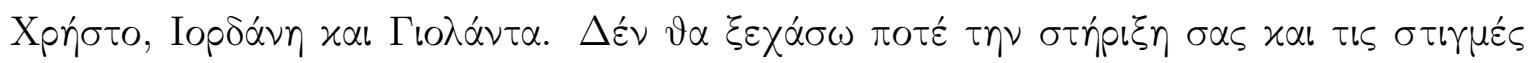




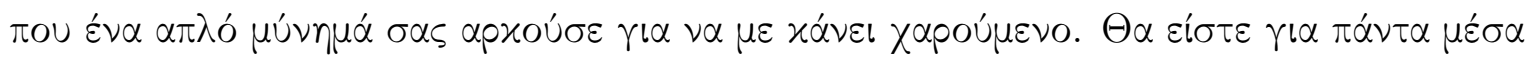

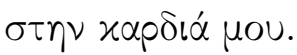

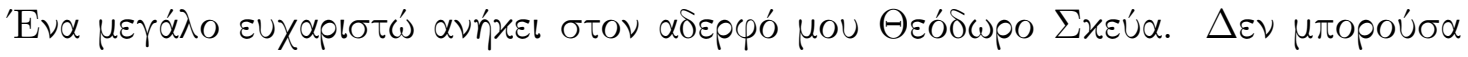

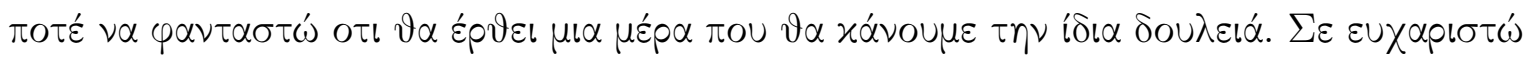

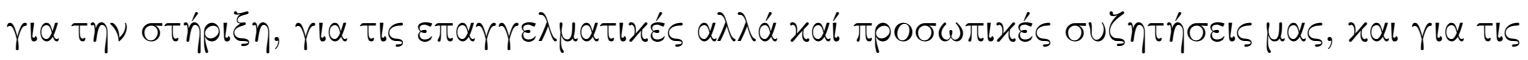

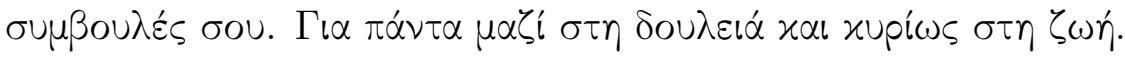

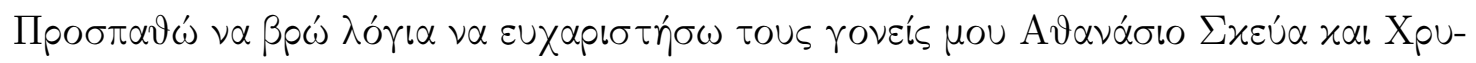

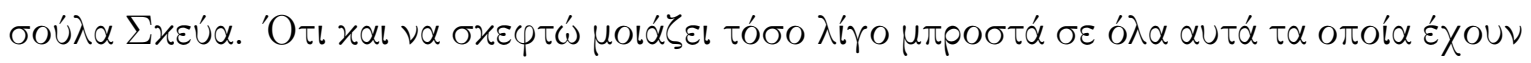

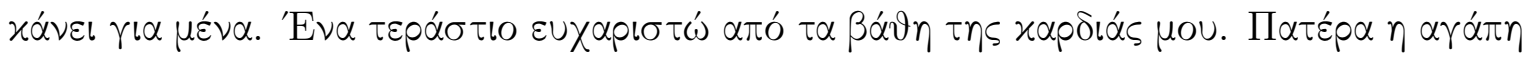

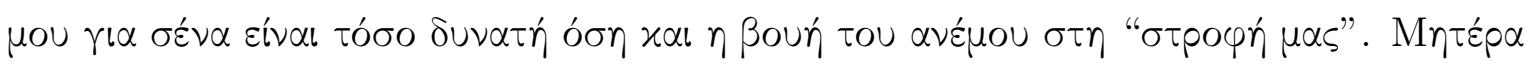

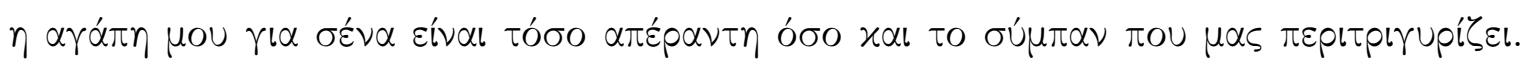

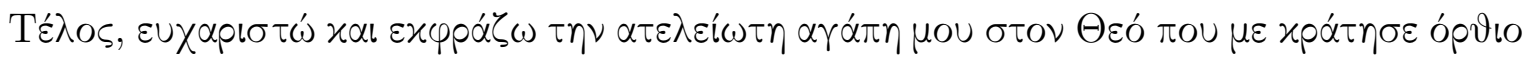

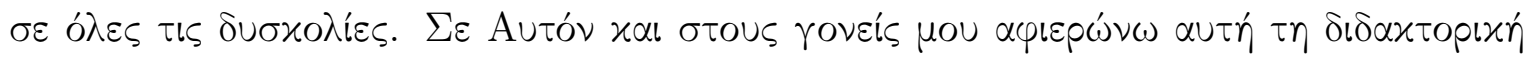

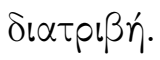




\section{Chapter 1}

\section{General Introduction}

\subsection{Background on efficiency and productivity}

According to production theory, firm managers are assumed to successfully optimize their production processes. The two main behavioral assumptions imposed on the decision-making units are those of cost minimization and profit maximization. The former maintains that production factors are employed in a way such that the cost of production is minimized, subject to the requirement that a certain level of output is produced. The latter claims that decision makers produce the amount of output that maximizes their profits. Of course, the aforementioned assumptions may not necessarily reflect the actual objectives of producers. For instance, a manager's actual objective may be to minimize his or her total debt, or maintain his or her existing market share. However, the majority of models used to represent producers' behavior are based on the assumptions of cost minimization and profit maximization. In particular, there is homophonous agreement that, irrespective of how output is determined, it will be produced at minimum cost. In other words, even if the level of output produced is not based on the criterion of profit maximization, the assumption of cost minimization should still hold.

However, in reality, producers are not necessarily successful optimizers. This may be due to governmental intervention that aims to protect them from market competition, and extreme weather conditions or disease outbreaks that can result in unexpected loses in output. If one is willing to accept that the decision-making units do not always meet their objectives, the discrepancy between optimal and observed production should be defined and quantified. Two early attempts to define efficiency in production are described in Debreu (1951) and Koopmans (1951). The former defines efficiency as the situation in which a level of "satisfaction", say output, is achieved with the minimum use of physical resources. The latter describes a producer as being efficient if he or she chooses the combination of productive activities that maximize the amount of output produced for a given quantity of production factors. The study of Farrell (1957) was the first to quantify efficiency. In particular, it provided a way to measure cost efficiency and decompose it into technical and allocative efficiency components. 
Based on the definitions of efficiency provided by Debreu (1951) and Koopmans (1951), and the pioneer applied work of Farrell (1957), a vast area of empirical research has been triggered that extends from providing alternative ways of measuring efficiency, to identifying its potential driving forces. Efficiency measurement and the identification of its determinants are important for better resource allocation and for the evaluation of particular policies. For instance, facilitation of economic planning can be achieved by knowing how much more a sector can produce by increasing its efficiency and not utilizing additional resources. Furthermore, by being able to identify the determinants of efficiency, one can evaluate the success of a particular policy instrument in increasing a firm's efficiency. However, to be able to measure efficiency and identify its driving forces, a modelling decision concerning a firm's objectives must be made. Measurement of profit or cost efficiency and the specification of an output or an input distance function are some examples of such a dilemma.

Once panel data are available and efficiency is estimated, one can proceed further and calculate the Total Factor Productivity (TFP) growth of a sector. Productivity analysis was first introduced in the work of Malmquist (1953), who developed a standard of living index defined as the ratio of two input distance functions. Shephard (1970) developed the analogous output index using output distance functions. These two studies have inspired researchers to develop a productivity index based on distance functions. Caves et al. (1982) were the first to define a productivity index based on ratios of output or input distance functions. This index is known as the Malmquist productivity index and has been extensively used in the productivity measurement literature. Subsequent research on productivity analysis has been focused on developing alternative decompositions for the Malmquist productivity index. TFP growth can be decomposed into the following components: (i) a technical change component which accounts for frontier shifts over time, (ii) an efficiency change component that quantifies firm-level efficiency changes over time, (iii) a scale effect component which accounts for firm-level changes in scale over time and (iv) allocative effects for outputs and inputs that concern the optimal output and input mix. The importance of calculating TFP growth stems from the fact that it serves as an indicator of the competitiveness of a sector. In particular, high TFP growth assures that a particular sector is able to survive both domestic and international competition and persist in a competitive environment. The most important decision that the researcher needs to take when calculating TFP growth concerns the specification of the time evolution of efficiency, as several different approaches exist for modelling time-varying efficiency. 


\subsection{Problem statement}

Empirical studies on efficiency measurement have been almost exclusively based on a static framework. However, firms' decision making processes are dynamic in nature; the decisions made today will not only affect present, but also future production possibilities. The minimization of discounted costs or the maximization of discounted cash flows are examples of firms' dynamic objectives. The major flaw associated with static efficiency analysis is that it may result in a producer being labeled as inefficient despite the fact that this may be an optimal strategy so that he meets his long-run objective. Besides the difference in firms' objectives under the two alternative contexts, another discrepancy between static and dynamic contexts is that capital is treated differently. In a static framework, capital is considered to be either fixed or freely adjusted. This implies that altering its level does not impose any penalty apart from the acquisition cost. In a dynamic context, capital is a quasi-fixed factor and not freely adjusted with its evolution depending on the depreciation rate of existing capital and investment in new capital (Stefanou, 2009).

Non-free adjustment implies that, beyond the acquisition cost, additional adjustment costs are associated with altering the level of certain production factors such as capital. Stefanou (2009) categorizes these adjustment costs into two major subcategories: external and internal adjustment costs. External adjustment costs are pecuniary in nature and refer to the lack of credit sources that would allow the firm to raise its capital stock. Internal adjustment costs are associated with learning and refer to the loss of physical output as a result of the time that the operator needs to spend in order to learn how to use his or her new resources.

Given that adjustment costs are responsible for the sluggish adjustment of quasifixed factors of production, the question that naturally arises is the following: can we argue that such a sluggish reaction could be used to label the producer as inefficient? This is what static efficiency measures argue, as they measure efficiency based on the distance of the observed quantities from the frontier. Nevertheless, in the presence of high adjustment costs, a certain degree of inertia in adjusting the level of quasi-fixed factors of production may be the most ideal decision of a producer. In other words, if a producer is inefficient at a certain point in time, his optimal strategy may be to remain inefficient in the short-run. This implies that inefficiency may persist from a period to the next. However, an efficiency measure that does not treat a sluggish reaction as inefficiency needs to be considered. Dynamic or long-run efficiency is such a candidate, as it measures a firm's failure to achieve optimality in the current period, where the firm operates. Nevertheless, the long-run objective of the firm is taken into account while defining optimality of the current period. 
The above arguments remain relevant when productivity analysis is conducted, as one of its major components is that of efficiency change. Several empirical studies that have attempted to measure TFP growth have relied on static efficiency measures that ignore the dynamic nature of producers' decisions. As TFP growth is a dynamic concept itself, modelling the dynamic behavior of the decision-making units is more appropriate. Additionally, numerous studies have considered the evolution of efficiency scores as a deterministic function of time. Consequently, these studies are not able to capture time-specific shocks in a firm's efficiency. Given the stochastic environment under which firms operate, shocks such as bad weather conditions or high price volatility should not be a rare phenomenon.

\subsection{German dairy sector}

The German dairy sector has recently experienced radical changes both in terms of its production and structure, and in terms of policy intervention. Milk production has steadily increased from $\sim 27$ million tons in 1999 to $\sim 28$ million tons in 2009, reaching a peak of $\sim 32$ million tons in 2015 . This increased production in milk has been accompanied by a continuous decline in the number of dairy cows. Specifically, the number of dairy cows has decreased from $\sim 4.8$ million in 1999 to $\sim 4.3$ million in 2015. Furthermore, the use of labor has declined and German dairy farms have become more capital intensive (EUROSTAT, 2016). Apart from the aforementioned production and structural changes, the dairy sector in Germany has also faced high milk price volatility, particularly between the years of 2001 and 2009. Figure 1.1 provides a graphical illustration of the evolution of milk prices per 100kg in the German dairy sector for the period 2001-2009. The graph reveals that slight changes in milk prices occur between 2001 and 2006, in both directions. More notably, steep milk price changes are observed from 2006 onwards. In particular, a large price increase occurs between 2006 and 2008 with milk prices rising from $25.25 € / 100 \mathrm{~kg}$ in 2006 to $35.01 € / 100 \mathrm{~kg}$ in 2008 . This milk price increase is followed by a rapid decline in 2009 , when milk prices sunk to a low of $25.25 € / 100 \mathrm{~kg}$.

Turning to policy intervention, by being a member of the European Union (EU), Germany's dairy sector has been extensively regulated by the Common Agricultural Policy (CAP) to meet objectives such as the reduction of milk production and sustainability. In 1984, the CAP introduced the milk quota system to reduce overporduction of milk and milk products. The quota regime in Germany has experienced several changes over the years that were mainly related to the transfer of quota rights. While milk quota transfers were initially realized by renting land, from 2000 onwards quota transfers were only possible through auctions at the regional level (Kleinhanß et al., 


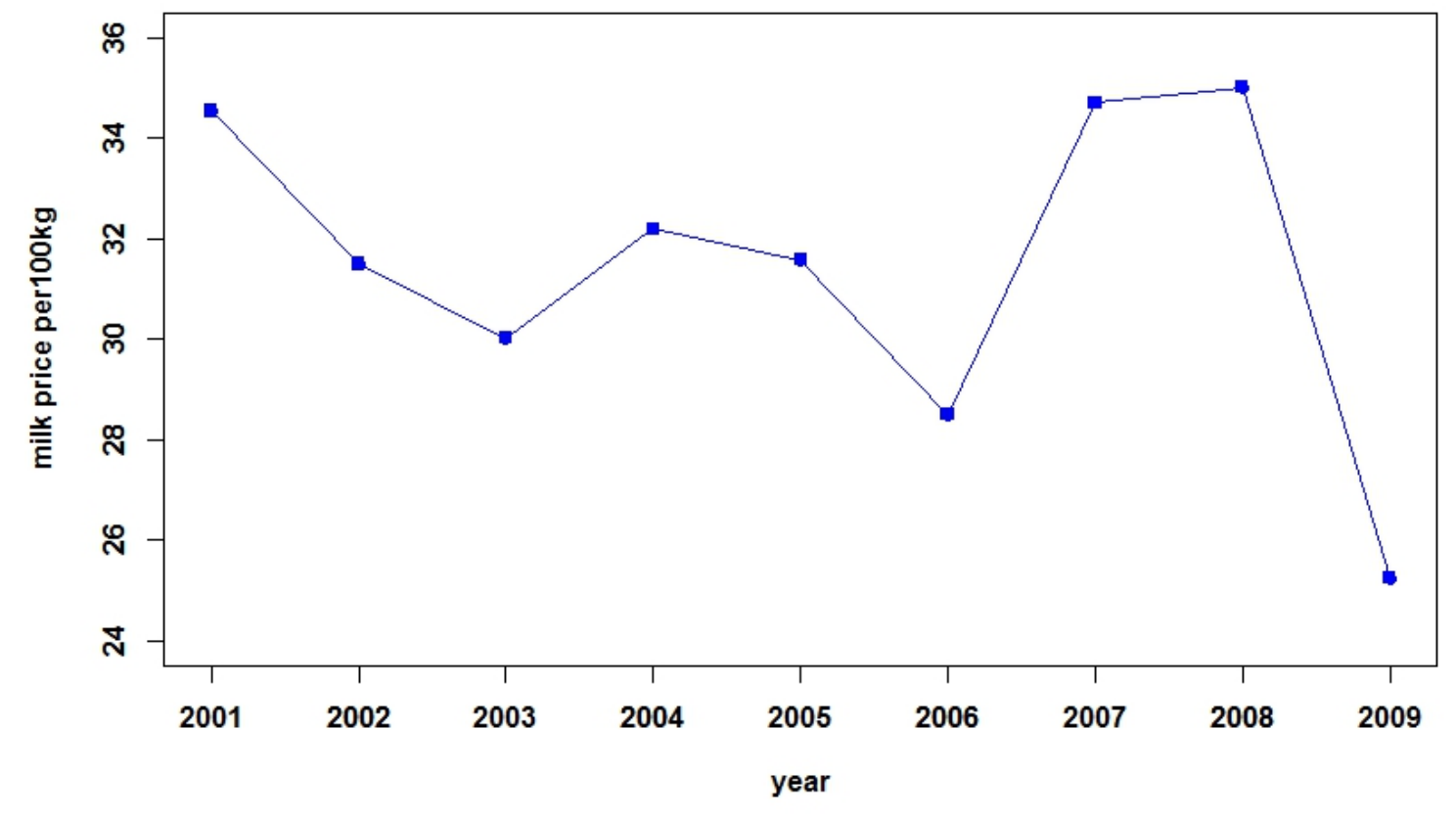

Figure 1.1: Evolution of milk prices per 100kg in the German dairy sector from 2001 to 2009 .

Source: EUROSTAT.

2010). In 2009, and with the intention of preparing a "soft landing" before the abolishment of the milk quota system in 2015, the CAP introduced the "Health Check" policy, which led to a 1\% increase in quotas for every year until 2015 (European Commission, 2016).

Dairy farms in Germany are also heavily subsidized. At first, subsidies took the form of direct support to farmers, who received a subsidy per unit of output. However, the 2003 decoupling reform of the CAP altered the way in which subsidies were granted. As its name suggests, the reform meant that subsidies became decoupled from production and were distributed based on a Single Payment Scheme (SPS) as well as cross-compliance conditions related to environmental, food safety, and animal welfare standards. Payments according to the SPS scheme could be regionalized, farmspecific, or both, with Member States of the EU being able to choose the way that the SPS is implemented. Germany chose a combination of regionalized and farm-specific payments (Brady et al., 2009).

In the particular case of decoupled payments, a large body of the efficiency measurement literature has concluded that the income support nature of these payments has reduced the motivation of farmers to work efficiently. Since German dairy farms have been heavily dependent on this policy instrument, the sector has become a good 
candidate for measuring its efficiency. Additionally, random shocks such as the aforementioned milk price volatility motivate the measurement of changes in both efficiency and TFP growth of farms. Finally, the fact that the German dairy sector is characterized by heavy use of capital stock and fast technological progress makes it likely that adjustment costs may influence producers' decisions and objectives. This motivates the transition from static to dynamic efficiency measurement.

\subsection{Objectives and research questions}

As far as parametric efficiency measurement is concerned, it is rather surprising that the majority of studies have assumed that firms' decision-making processes are static in nature. The most likely reason is that moving to dynamic efficiency analysis involves complex estimation techniques, intensive coding and a lot of computing power. That is why dynamic efficiency studies have been primarily conducted in non-parametric settings. Recently, a few attempts have been made to model the dynamic behavior of decision-making units in parametric settings. Such attempts have revealed this to be a brand new field of research, one that allows us to extend the few existing models in order to relax some of their assumptions or, indeed, to add relevant information that can explain some key concepts.

The main objective of this study is to extend and estimate parametric dynamic efficiency and TFP growth models. These models are applied to the case of German dairy farms. Firstly, the dynamic efficiency model is extended to allow for heterogeneity in the long-run technical efficiency of farms. Long-run technical efficiency is allowed to differ across farms not only based on varying degrees of inefficiency persistence, but also due to farm-specific characteristics. Additionally, an alternative way of modelling inefficiency persistence is used. Secondly, a model that accounts for the impact of farm-specific characteristics on the persistence of technical inefficiency is developed. These farm-specific characteristics are closely related to the aforementioned types of adjustment costs, which, according to theory, are responsible for the sluggish adjustment of quasi-fixed factors of production. Finally, a dynamic efficiency specification is used to measure and decompose farms' TFP growth. Given the stochastic nature of the production environment, the last study tests whether the dynamic efficiency specification is able to capture time-specific shocks on farms' technical efficiency and, therefore, TFP growth.

The research questions associated with the study include the following:

- Is there heterogeneity in the long-run technical efficiency of German dairy farms?

- Are there any farm-specific characteristics that can help explaining the persis- 
tence of German dairy farms' technical inefficiencies?

- Is the dynamic efficiency specification able to capture time-specific technical efficiency and TFP growth shocks in German dairy farming?

To provide answers to the aforementioned research questions, three models are used and estimation proceeds in a Bayesian framework. By using the technique of data augmentation, Bayesian methods have been proved to be particularly useful in estimating models that involve latent data, with models for efficiency measurement falling in this category. Additionally, interpretation of the results and particularly hypothesis testing and construction of credible intervals is much more straightforward when compared to frequentist techniques, while the results obtained are valid in finite samples.

\subsection{Outline}

This dissertation focuses on extending the already existing parametric dynamic efficiency models to provide answers to the formulated research questions. The next chapter extends the dynamic efficiency model in a way such that it can account for heterogeneity in the long-run technical efficiency of German dairy farms. Heterogeneity is permitted due to both farm-specific characteristics and farm-specific inefficiency persistence. In addition, a novel method for modelling inefficiency persistence is proposed. Chapter 3 aims to provide empirical evidence on the factors that may influence farms' inefficiency persistence. Particular emphasis is given to the modelling approach of the inefficiency persistence parameter and the motivation behind the selection of its determinants.

Chapter 4 examines the TFP growth of German dairy farms by using a dynamic efficiency specification. The main focus of this chapter is to test whether the dynamic efficiency model can reveal abrupt changes in technical efficiency and TFP growth that may be due to the high milk price volatility that took place in the German dairy sector. The results from the dynamic efficiency specification are compared with those of two static efficiency specifications and a formal model comparison is performed. Finally, Chapter 5 summarizes the main findings of this dissertation, discusses its limitations, synthesizes the results, presents some policy implications and offers suggestions for future research. 


\title{
Chapter 2
}

\section{Heterogeneity of long-run technical efficiency of German dairy farms: a Bayesian approach}

\begin{abstract}
In parametric efficiency studies, two alternative approaches exist that can provide an estimate of the long-run efficiency of firms: the dynamic stochastic frontier model and the generalized true random-effects model. We extend the former in order to allow for heterogeneity in the long-run technical efficiency of firms. This model is justified by drawing on potential differences in firm-specific characteristics and in firms' inefficiency persistence. The model is applied to an unbalanced micro-panel of German dairy farms that covers the period from 1999 to 2009. Estimation of long-run technical efficiency and inefficiency persistence is based on an output distance function representation of the production technology and performed in a Bayesian framework. The results suggest that heterogeneity in long-run technical efficiency of farms is mostly attributed to discrepancies in farm-specific factors rather than differences in farms' inefficiency persistence. Farm size is positively related to long-run technical efficiency while subsidies exert a negative effect on the long-run technical efficiency of farms. Inefficiency persistence is found to be very high, but heterogeneity in this persistence is low.
\end{abstract}

Keywords: Dynamic stochastic frontier; long-run technical efficiency; inefficiency persistence; heterogeneity; dairy farms.

JEL Classification: C11, C23, D21, D24 


\subsection{Introduction}

Agricultural investment is often referred to as the main engine of farm productivity improvement and considered to be necessary for farms to catch up with frontier shifts in order to avoid being driven out of business. In a capital-intensive agricultural environment, such investment is associated with the replacement of existing capital, the increase in the capital stock or the adoption of technological innovations (Kapelko et al., 2015). Hence, continuous agricultural investment can assure frequent changes in firms' production process, facilitating the use of existing knowledge or the generation of new technology. However, the adjustment cost hypothesis described by Penrose (1959) and Eisner et al. (1963), states that the existence of adjustment costs prevents the decision-making units from instantaneously adjusting their quasi-fixed inputs to their long-run equilibrium values. Examples of adjustment costs are expansion-related expenses, constraints on credit sources and learning and training costs that are related to the time spent by the operator to acquire knowledge and experience using the new resources (Stefanou, 2009). This costly adjustment provides firm operators with an incentive to remain partly inefficient in the short-run, resulting in persistence of their inefficiency over time. Besides, inefficiency persistence may differ among firms because of discrepancies in the speed that technological innovations are adopted. For instance, disparities in the managerial skills and motivation of the firm operators may affect the speed of the introduction of a new technology (Gardebroek and Oude Lansink, 2004). In addition, discrepancies in the cognitive capacity and experience of firm operators may result in less/more time devoted to becoming familiar with the new technology. Hence, differences in adjustment costs across firms may result in varying degrees of inefficiency persistence among them.

The adjustment cost hypothesis can also provide the basis for the distinction between short and long-run inefficiency. The difference between these two concepts is illustrated by an example. Suppose that a system is currently in equilibrium when a new technology arises. If there were no adjustment costs present, firm operators would instantaneously adopt the new technology and would reach their desirable efficiency levels in the short-run. However, if adjustment costs exist, the optimal strategy for firm operators would be to remain inefficient in the short-run and reach their targeted efficiency levels in the long-run. Dependent on the level of adjustment costs and on firm-specific characteristics, firms may consider different reactions to the shock introduced by the new technology. Despite reacting differently, decision makers will take into account their long-run objective (which may differ among firms) in their current production plans. Hence, long-run inefficiency is perceived as a flow that measures the failure to optimize in the current period where firms always operate. The term 
"long-run" stems from the fact that firms' decisions are made in the short-run but with a view in the future. On the other hand, short-run inefficiency completely ignores the presence of adjustment costs and that current production decisions may affect future outcomes. It simply takes a snapshot of the current position of the production frontier, and quantifies the deviation of firms from this frontier.

Two alternative approaches exist that take into account adjustment costs and distinguish between short-run and long-run inefficiency using the parametric technique of Stochastic Frontier Analysis (SFA) introduced by Aigner et al. (1977) and Meeusen and van den Broeck (1977) ${ }^{1}$. The first approach, is based on the generalized true random effects model introduced by Tsionas and Kumbhakar (2014) in a Bayesian framework, and involves the specification of an one-sided time-invariant error term and an one-sided time-varying error term in the production frontier. The first error term aims to capture the so-called persistent or long-run inefficiency while, the latter, aims to capture the so-called transient or short-run inefficiency. Identification of these two inefficiency components, in the presence of time-invariant firm characteristics (i.e. unobserved heterogeneity) and time-varying statistical noise, is achieved through the use of one-sided distributions for the two inefficiency components. Since its introduction, this novel approach has been used by several other empirical studies. For instance, Filippini and Hunt (2015) and Filippini and Greene (2016), present the frequentist way to estimate the generalized true random effects model using the method of simulated maximum likelihood, while, Badunenko and Kumbhakar (2016), examine the robustness of the model due to concerns related mainly to the identification of the four error components.

The second approach, accounts in a more comprehensive way for the consequences of costly adjustment of quasi-fixed inputs, and the resulting persistence of inefficiency. More precisely, Ahn and Sickles (2000) specified an autoregressive process on firmspecific efficiency scores to account for persistence of shocks in firms-level efficiency. In the presence of the aforementioned adjustment costs, this model recognizes that inefficiency is not likely to disappear over time. Criticism related to the specification of an autoregressive process on a non-negative variable, has led Tsionas (2006) to specify an autoregressive process on transformed efficiency that can take any value on the real line. The same approach was followed by Emvalomatis et al. (2011), Emvalomatis (2012a) and Galán et al. (2015). This model, as in the case of the generalized true random effects model, can provide an estimate of both the short- and long-run firmlevel efficiency. The short-run efficiency is derived based on the distance of the firms from the production possibilities frontier, while, long-run efficiency corresponds to the

\footnotetext{
${ }^{1}$ For non-parametric dynamic efficiency studies that have used the technique of Data Envelopment Analysis (DEA), see Fallah-Fini et al. (2014).
} 
steady-state value of efficiency from the specification of the autoregressive process.

The study of Tsionas (2006) fails to derive the long-run efficiency of firms due to the specification of time-varying covariates in the autoregressive process. Emvalomatis et al. (2011) and Emvalomatis (2012a) provide estimates for the long-run efficiency scores assuming that all firms reach a common long-run efficiency level. Unlike the aforementioned studies, the study of Galán et al. (2015) recognizes that differences in firms' adjustment costs may result in different degree of their inefficiency persistence, but, as in Tsionas (2006), the specification of time-varying variables in the autoregressive process does not allow them to derive long-run measures of efficiency. The only exception that combines the specification of heterogeneity in inefficiency persistence and the derivation of firm-specific long-run efficiency scores, is the work of Ahn and Sickles (2000). However, heterogeneity in firm-specific long-run efficiency occurs only due to differences in firms' (unobserved) management and different speed of adoption of a new technology, without taking into account any observable firm-specific factors. However, as the effect of firm-specific factors on short-run efficiency is well documented, surprisingly, their impact on long-run efficiency has been completely disregarded. Particularly in agriculture, heterogeneity in farm size and the high extent of regulation may be responsible for differences in the long-run efficiency of farms.

In this paper we propose a dynamic stochastic frontier model that, as in the case of the generalized true random effects model, can provide an estimate of firm-specific long-run efficiency. However, our model allows for firm-specific long-run inefficiency to be dependent on firm-specific characteristics, which is an issue that has been completely ignored by both the generalized true random effects and the dynamic stochastic frontier models. Furthermore, an alternative specification for modeling heterogeneity in inefficiency persistence over time is proposed, that maintains the assumption of positive autocorellation of efficiency scores. In the next section, the modeling approach is described and Bayesian techniques are detailed. The model is applied to a micro-panel of German dairy farms and Section 2.3 describes the data used and the empirical specification of the model. Section 2.4 presents the results, while concluding remarks are provided in Section 2.5.

\subsection{Modelling Approach and Estimation}

We consider the typical stochastic frontier model and employ an output distance function to account for the multi-output nature of the production technology. Assuming that a vector of outputs $\tilde{\mathbf{y}} \in R_{+}^{M}$ is produced by a vector of inputs $\tilde{\mathbf{x}} \in R_{+}^{N}$, the output distance function is defined as: 


$$
D_{o}(\tilde{\mathbf{x}}, \tilde{\mathbf{y}}, t)=\min \left\{\theta: \frac{\tilde{\mathbf{y}}}{\theta} \text { can be produced by in period } \mathrm{t}\right\}
$$

The output distance function gives the minimum amount by which the output vector can be deflated given the input vector. It assumes values in the unit interval and the locus of points for which $D_{o}(\tilde{\mathbf{x}}, \tilde{\mathbf{y}}, t)=1$ defines the boundary of the production possibilities set. The technical efficiency of firm $i$ in period $t$ is defined as $T E_{i t}=D_{o}\left(\tilde{\mathbf{x}}_{i t}, \tilde{\mathbf{y}}_{i t}, t\right)$. Taking the logarithm of both sides of this expression, imposing the condition of linear homogeneity in outputs of the output distance function, and appending an error term leads to the econometric version of the distance function:

$$
-\log \tilde{y}_{i t}^{m}=\log D_{o}\left(\tilde{\mathbf{x}}_{i t}, \frac{\tilde{\mathbf{y}}_{i t}}{\tilde{y}_{i t}^{m}}, t\right)+v_{i t}-\log \left(T E_{i t}\right)
$$

where $\tilde{y}_{i t}^{m}$ is the normalizing output and $v_{i t}$ is an error term that captures statistical noise. Letting $y_{i t}$ be the dependent variable in equation (2.2) and the logarithm of the distance function a linear function of parameters and functional transformations of its arguments, the estimable form of the distance function can be written as:

$$
y_{i t}=\mathbf{x}_{i t}^{\prime} \boldsymbol{\beta}+v_{i t}-\log \left(T E_{i t}\right), \quad v_{i t} \sim \mathscr{N}\left(0, \sigma_{v}^{2}\right)
$$

where $y_{i t}$ is minus the logarithm of the normalizing output, $\mathbf{x}_{i t}^{\prime}$ is a vector of covariates, $\boldsymbol{\beta}$ is a vector of parameters to be estimated, $v_{i t}$ is a two-sided error term that accounts for statistical noise, and $T E_{i t}$ is the technical efficiency of firm $i$ in period t. For estimation purposes, equation (2.3) can be seen as a typical cost stochastic frontier. Following Tsionas (2006), Emvalomatis et al. (2011), Emvalomatis (2012a) and Galán et al. (2015), we consider a dynamic stochastic frontier model that specifies an autoregressive process on firm-specific technical efficiency. However, in this study, as in Galán et al. (2015) we allow for firm-specific inefficiency persistence and recognize that heterogeneity in terms of the adjustment costs and the managerial characteristics of farms may affect the degree of persistence. We define a latent-state variable, $s_{i t}=\log \left(\frac{T E_{i t}}{1-T E_{i t}}\right)$, as the logistic transformation of technical efficiency so that we project $T E_{i t}$ from the unit interval to the real line and we assume the following autoregressive process on $s_{i t}$ :

$$
\begin{gathered}
s_{i t}=\mathbf{z}_{i}^{\prime} \boldsymbol{\delta}+\rho_{i} s_{i, t-1}+\xi_{i t}, \quad \xi_{i t} \sim \mathscr{N}\left(0, \sigma_{\xi}^{2}\right) \\
s_{i 0}=\frac{\mathbf{z}_{i}^{\prime} \boldsymbol{\delta}}{1-\rho_{i}}+\xi_{i 0}, \quad \xi_{i 0} \sim \mathscr{N}\left(0, \sigma_{\xi 0}^{2}\right)
\end{gathered}
$$

where $\mathbf{z}$ is a vector of time-invariant covariates, $\boldsymbol{\delta}$ and $\rho_{i}$ are parameters to be esti- 
mated, $\xi_{i t}$ is a two-sided error term that captures statistical noise, and $\sigma_{\xi 0}^{2}=\frac{\sigma_{\xi}^{2}}{1-\rho_{i}^{2}}$, is due to stationarity. Based on this modelling approach $\rho_{i}$ is an elasticity that measures the firm-specific percentage change in the efficiency to inefficiency ratio that is transferred from one period to the next. Stationarity of the s series ensures that the expected value of $\mathbf{s}$ does not diverge to either positive or negative infinity and therefore, technical efficiency will not approach unity or zero. Using functional transformations, the firm-specific inefficiency persistence parameter is restricted on the unit interval. A value of $\rho_{i}$ close to one indicates high inefficiency persistence and that high adjustment costs result in sluggish adjustment of quasi-fixed factors. Besides, given the one-to-one transformation from $\mathbf{s}$ to $\mathrm{TE}$, the steady-state value of $\mathbf{s}$ is directly interpreted as the expected value of Long-Run Technical Efficiency (LRTE). In this case, the expected value of LRTE corresponds to the expectation of $\left[1+\exp \left\{\mathbf{z}_{i}^{\prime} \boldsymbol{\delta} / 1-\rho_{i}\right\}\right]^{-1}$ and is interpreted as the expected value of efficiency that will prevail in the sector in the long-run. Besides, this value will be firm-specific due to differences in firm-specific characteristics and potential heterogeneity in firms' inefficiency persistence.

Moving to the modeling of firm-specific inefficiency persistence, Galán et al. (2015) used a hierarchical structure allowing the inefficiency persistence parameter $\rho_{i}$ to take values between -1 and 1 . More specifically, they assumed that $\rho_{i}=2 k_{i}-1$ and sampled $k_{i}$ from a Beta distribution. However, we argue that it is rather unlikely to observe negative autocorrelations of efficiency in the adjustment towards the long-run equilibrium, while sampling from a Beta distribution can be computationally troublesome. With the intention to restrict the inefficiency persistence parameter, $\rho_{i}$, on the unit interval, we specify $\rho_{i}=\frac{\exp \left(h_{i}\right)}{1+\exp \left(h_{i}\right.}$ and we assume the following relationship:

$$
h_{i}=\mu+\omega_{i}, \quad \omega_{i} \sim \mathscr{N}\left(0, \sigma_{\omega}^{2}\right)
$$

In this framework, $h_{i}$ is a draw from a Normal distribution with common mean $\mu$, and variance $\sigma_{\omega}^{2}$. Hence, our modeling approach not only restricts inefficiency persistence on the unit interval but also specifies a less computationally demanding sampling distribution for $\rho_{i}$. According to this transformation, $h_{i}$ follows a logit-Normal distribution with negative values of $\mu$ resulting in very low inefficiency persistence, positive and low values (e.g. from 2 to 4 ) in high inefficiency persistence, while, positive and high values imply that inefficiency persistence approaches unity. Finally, given that the variables in $\mathbf{z}$ capture part of firm's unobserved heterogeneity, we do not include random effects in the production frontier. We use Bayesian techniques to estimate the model described in equations $(2.3-2.6)$. We define $s_{i}$ to be a $T_{i} \times 1$ vector of the latentstate variable of the transformed technical efficiency for firm $i$ and $\mathbf{h}$ to be an $N \times 1$ vector of the latent-state variables of the transformed inefficiency persistence. Finally, 
we collect all structural parameters to be estimated to a vector $\boldsymbol{\theta}=\left[\boldsymbol{\beta}, \sigma_{v}, \boldsymbol{\delta}, \sigma_{\xi}, \mu, \sigma_{\omega}\right]^{\prime}$. The complete data likelihood of the structural parameters and latent states is:

$$
\begin{aligned}
p\left(\mathbf{y},\left\{\mathbf{s}_{i}\right\}, \mathbf{h} \mid \boldsymbol{\theta}, \mathbf{X}, \mathbf{Z}\right)=p\left(\mathbf{y} \mid\left\{\mathbf{s}_{\mathbf{i}}\right\}, \boldsymbol{\beta}, \sigma_{v}, \mathbf{X}\right) \times p\left(\left\{\mathbf{s}_{\mathbf{i}}\right\} \mid \mathbf{h}, \boldsymbol{\delta}, \sigma_{\xi}, \mathbf{Z}\right) \times p\left(\mathbf{h} \mid \mu, \sigma_{\omega}\right) \\
=\frac{1}{\left(2 \pi \sigma_{v}^{2}\right)^{\sum_{i=1}^{N} \frac{T_{i}}{2}}} \exp \left\{-\sum_{i=1}^{N} \sum_{t=0}^{T_{i}-1} \frac{\left(y_{i t}-\mathbf{x}_{i t}^{\prime} \boldsymbol{\beta}+\log T E_{i t}\right)^{2}}{2 \sigma_{v}^{2}}\right\} \\
\times \frac{1}{\left(2 \pi \sigma_{\xi 0}^{2}\right)^{\frac{N}{2}}} \exp \left\{-\sum_{i=1}^{N} \frac{\left(s_{i 0}-\mathbf{z}_{i}^{\prime} \boldsymbol{\delta}\right)^{2}}{2 \sigma_{\xi 0}^{2}}\right\} \\
\times \frac{1}{\left(2 \pi \sigma_{\xi}^{2}\right)^{\sum_{i=1}^{N} \frac{\left(T_{i}-1\right)}{2}}} \exp \left\{-\sum_{i=1}^{N} \sum_{t=1}^{T_{i}-1} \frac{\left(s_{i t}-\mathbf{z}_{i}^{\prime} \boldsymbol{\delta}-\rho_{i} s_{i, t-1}\right)^{2}}{2 \sigma_{\xi}^{2}}\right\} \\
\times \frac{1}{\left(2 \pi \sigma_{\omega}^{2}\right)^{\frac{N}{2}}} \exp \left\{-\sum_{i=1}^{N} \frac{\left(h_{i}-\mu\right)^{2}}{2 \sigma_{\omega}^{2}}\right\}
\end{aligned}
$$

where $\mathbf{y}$ is the stacked vector of the values of the dependent variable over $i$ and $t$, $\mathbf{X}$ is the matrix of covariates in equation (2.3) and $\mathbf{Z}$ is the matrix of covariates in equations (2.4) and (2.5).

Using Bayes' rule the joint posterior density of the model's parameters and latent states is:

$$
\pi\left(\boldsymbol{\theta},\left\{\mathbf{s}_{\mathbf{i}}\right\}, \mathbf{h} \mid \mathbf{y}, \mathbf{X}, \mathbf{Z}\right) \propto p\left(\mathbf{y},\left\{\mathbf{s}_{i}\right\}, \mathbf{h} \mid \boldsymbol{\theta}, \mathbf{X}, \mathbf{Z}\right) \times p(\boldsymbol{\theta})
$$

where $p\left(\mathbf{y},\left\{\mathbf{s}_{i}\right\}, \mathbf{h} \mid \boldsymbol{\theta}, \mathbf{X}, \mathbf{Z}\right)$ is given by equation (2.7) and $p(\boldsymbol{\theta})$ corresponds to the product of all the prior densities. We use proper and rather flat priors for the structural parameters $^{2}$. Normal priors are used for $\boldsymbol{\beta}, \boldsymbol{\delta}$, and $\mu$, while inverted-Gamma priors are used for all variance parameters. We use Markov Chain Monte Carlo (MCMC) simulations (see Koop et al. (1995) for an application to stochastic frontier models) to sample from the posterior. To draw samples from the posterior for the latent states, $\left\{\mathbf{s}_{i}\right\}$ and $\mathbf{h}$, data augmentation techniques are also used (Tanner and Wong, 1987). The priors specified for $\boldsymbol{\beta}, \boldsymbol{\delta}$, and $\mu$, and the variances are conjugate and, therefore, Gibbs updates are used. The complete conditionals for $\left\{\mathbf{s}_{i}\right\}$ and $\mathbf{h}$ do not belong to any known distributional family and, therefore, Metropolis-Hastings updates are used. The MCMC techniques used involve 10 chains and 130,000 iterations with a burn-in phase of 50,000 iterations being used to remove the influence of the initial values. Since the Metropolis-Hastings algorithm has the potential of generating highly correlated draws, every one in 10 draws were retained to reduce autocorrelation in the samples. Hence, every chain contributes 8,000 draws, resulting in a total of 80,000

\footnotetext{
${ }^{2}$ Table A.1 in Appendix A provides details on the parameterization of priors.
} 
retained draws from the posterior.

\subsection{Data and empirical specification}

The data used for this application are provided by the Farm Accountancy Data Network $(\mathrm{FADN})^{3}$. The accounting data that FADN provides are collected regionally using a common questionnaire across all EU Member States. The dataset contains farmlevel information on physical and structural data of farms, such as farms' location, milk output, livestock units, as well as economic and financial data, such as production costs, subsidies and quotas. FADN uses a stratified random sampling scheme in which farms remain in the panel for a period of four to five years on average, although there are cases where farms remain for more than ten years.

The part of the dataset used here contains such information for German dairy farms and covers the period from 1999 to 2009. This study focuses on farms engaged primarily in dairy production, and for this purpose we have selected farms whose revenue from sales of cow's milk, beef and veal comprise at least $66 \%$ of their total revenues for every year the farm is observed. Additionally, considering the dynamic nature of our model, we have selected farms that are observed for at least four consecutive years. The final dataset consists of an unbalanced panel of 1,691 farms with a total of 13,384 observations.

The output distance function in equation (2.2) is specified in two outputs:

1. Deflated revenues from sales of cow's milk and milk products (milk)

2. Deflated revenues plus change in valuation of beef and veal, pigmeat, sheep and goats, and poultry meat, plus deflated revenues from sales of other livestock and products (other)

The reported revenues are deflated with price indices obtained from EUROSTAT, using 2000 as the base year.

Six inputs are specified in equation (2.2):

1. Buildings and machinery $(\mathrm{K})$ are measured in deflated book value ${ }^{4}$. A Törnqvist index was constructed using price indices for each of the two components. The total reported value was then deflated using the Törnqvist index.

2. Total labor (L) is measured in man-hours and consists of family, as well as hired labor.

\footnotetext{
${ }^{3}$ Data source: EU-FADN - DG AGRI.

${ }^{4}$ Brümmer et al. (2002) have included livestock units in their capital index. We decided to specify livestock units as a separate input to identify its individual effect on production.
} 
3. Total utilized agricultural area (A) is measured in hectares and includes owned and rented land.

4. Materials and services (M) are measured in deflated value. This input consists of ten categories of inputs: seeds and plants, fertilizers, crop protection, energy, other livestock-specific costs, other crop-specific costs, forestry-specific costs, feed for pigs and poultry, contract work and other direct inputs. A Törnqvist index was constructed using expenditure and price indices for each input. The total reported value was then deflated using the Törnqvist index.

5. Total livestock units $(\mathrm{S})$ is measured in livestock units and includes equines, cattle, sheep, goats, pigs and poultry that are present at the holding.

6. Purchased feed $(\mathrm{F})$ is measured in deflated value. It includes concentrated feedingstuffs for grazing stock and coarse fodder for grazing stock. The value of feed produced within the farm is excluded.

Dummy variables for eastern, western, northern and southern (base category) Germany are used to capture discrepancies in technology and climatic conditions. Finally, the $\mathbf{z}$ vector in equations (2.4)-(2.5) includes two variables ${ }^{5}$ : the economic size of farms expressed in hundreds of European Size Units (ESU) and the total amount of subsidies $^{6}$ that farms receive in thousands of euros. Farms with large economic farm size are more business/market oriented and may put more managerial effort in terms of the use of mental labor in the production process compared to those with smaller economic farm size. This may be reflected in differences in their efficiency. For instance, Latruffe et al. (2004), Latruffe et al. (2008), Bojnec and Latruffe (2011) and Zhu et al. (2012), find that bigger farm size is associated with higher efficiency levels. The effect of subsidies on efficiency is more disputable. On the one hand, subsidies may affect efficiency negatively as, their income effect nature, may reduce the motivation of farm operators to work efficiently (Hadley, 2006; Bojnec and Latruffe, 2009; Zhu and Oude Lansink, 2010; Zhu et al., 2011; Zhu et al., 2012; Bojnec and Latruffe, 2013). On the other hand, if subsidies act as an investment tool, they may increase the efficiency of farms (Rizov et al., 2013). In our case, decoupled payments comprise approximately $65 \%$ of the total amount of subsidies that farms receive. Hence, we expect that subsidies will negatively affect efficiency, since, decoupled payments are independent from production quantities and therefore, may be simply seen as an additional income source.

\footnotetext{
${ }^{5}$ Inclusion of additional variables is possible but time-invariant $\mathbf{z}$ variables needed to be considered to be able to derive long-run efficiency scores. Hence, we were unable to include additional relevant variables that vary significantly over time.

${ }^{6}$ This variable consists of subsidies on crops, livestock, other subsidies (related to forestry, environmental programs etc.), subsidies on intermediate consumption and external factors, and decoupled payments.
} 
The two aforementioned variables are specified as time-invariant for two main reasons. First, the interpretation of LRTE would have no meaning if the variables were changing over time. Second, the size of the farms and the amount of subsidies that farms receive change slightly across time and therefore a time-invariant specification can be representative of the actual behavior of farms ${ }^{7}$. Summary statistics of the models' variables appear in Table 2.1 .

Table 2.1: Summary statistics of the models' variables

\begin{tabular}{lcccc}
\hline Variable & Mean & Std. dev. & $\mathbf{5 \%}$ & $\mathbf{9 5 \%}$ \\
\hline Cow's milk $(1,000 €)$ & 144.47 & 213.84 & 32.43 & 350.98 \\
Other output $(1,000 €)$ & 26.20 & 30.44 & 4.36 & 70.23 \\
Capital $(1,000 €)$ & 195.83 & 249.13 & 28.96 & 485.38 \\
Labor (1,000 man-hours) & 3.97 & 5.99 & 1.80 & 7.20 \\
Land (hectares) & 77.41 & 132.29 & 19.08 & 173.47 \\
Materials (1,000€) & 60.25 & 98.55 & 13.08 & 142.79 \\
Livestock (livestock units) & 108.17 & 130.41 & 32.06 & 241.81 \\
Purchased feed (1,000€) & 27.63 & 55.76 & 2.28 & 73.38 \\
ESU (100 ESU) & 0.89 & 1.25 & 0.25 & 1.98 \\
Subsidies (100,000€) & 0.31 & 0.64 & 0.04 & 0.72 \\
\hline
\end{tabular}

We use an output distance function for the following reasons. First, despite the milk quota system restricting milk production, farms still have the opportunity to lease and purchase milk quota. Second, given the main argument of the paper concerning sluggish adjustment of quasi-fixed factors of production, inputs like capital and labor are restricted to immediate changes. The distance function is specified as translog in inputs $(\mathbf{x})$, outputs $(\mathbf{y})$, and time trend $(t)$. Using the estimable form of equation $(2.2)$, the distance function is written as:

\footnotetext{
${ }^{7}$ We compute farm-specific coefficients of variation for ESU and subsidies by dividing every farm's standard deviation in the respective variable by the farm's mean. Figure A.1 in Appendix A presents histograms of the coefficient of variation for ESU and subsidies.
} 


$$
\begin{aligned}
-\log y_{i t}^{m} & =\alpha_{0}+\sum_{k} \alpha_{k} \log x_{i t}^{k}+\sum_{l} \beta_{l} \log \left(\frac{y_{i t}^{l}}{y_{i t}^{m}}\right) \\
& +\frac{1}{2} \sum_{l} \sum_{p} \alpha_{k p} \log x_{i t}^{k} \log x_{i t}^{p} \\
& +\frac{1}{2} \sum_{l} \sum_{q} \beta_{l q} \log \left(\frac{y_{i t}^{l}}{y_{i t}^{m}}\right) \log \left(\frac{y_{i t}^{l}}{y_{i t}^{m}}\right) \\
& +\frac{1}{2} \sum_{k} \sum_{l} \zeta_{k l} \log x_{i t}^{k} \log \left(\frac{y_{i t}^{l}}{y_{i t}^{m}}\right) \\
& +\eta_{1} t+\eta_{2} t^{2}+\sum_{k} \lambda_{k} t \log x_{i t}^{k} \\
& +\sum_{l} \xi_{l} t \log \left(\frac{y_{i t}^{l}}{y_{i t}^{m}}\right)+v_{i t}-\log \left(T E_{i t}\right)
\end{aligned}
$$

Unlike the Cobb-Douglas function, the translog is a flexible functional form that does not impose any restrictions on substitution possibilities between inputs and outputs. Time and its interaction with inputs and outputs is included to capture, possibly biased, technological progress. The data for inputs and outputs are normalized by their geometric mean allowing us to interpret the parameters associated with the first-order terms directly as distance elasticities, evaluated at the geometric mean of the data.

\subsection{Results}

The complete set of results is provided in Table A.2 in Appendix A. Table 2.2 reports the posterior means, standard deviations and $95 \%$ credible intervals of the first-order terms of the distance function and the structural parameters. All of the distance function elasticities are statistically significant, as their respective credible intervals do not contain zero (capital is significant only at the $90 \%$ credible interval).

The distance elasticity with respect to output reflects a measure of the curvature of the frontier and implies that a $1 \%$ increase in output other than milk will lead to a $0.12 \%$ increase in the distance function, meaning that farms will move closer to the frontier. The negative distance elasticities with respect to inputs state that increases in inputs push the frontier outwards and farms become less efficient, with livestock units having the highest effect. The scale elasticity is 0.88 and reveals that farms operate under decreasing returns to scale. The German dairy sector experiences technological progress as the frontier moves outwards with time. Finally, the value of $\mu$ is 3.03 and suggests that inefficiency persistence, $\rho$, of German dairy farms is rather 
Table 2.2: Posterior means, standard deviations and $95 \%$ credible intervals of the first-order terms and the structural parameters

\begin{tabular}{lccc}
\hline Variable & Mean & Std. dev. & 95\% Credible Interval \\
\hline intercept & -0.464 & 0.030 & {$[-0.542,-0.415]$} \\
log_other & 0.121 & 0.003 & {$[0.116,0.127]$} \\
log_capital & -0.007 & 0.004 & {$[-0.015,0.000]$} \\
log_labor & -0.053 & 0.008 & {$[-0.068,-0.038]$} \\
log_land & -0.078 & 0.009 & {$[-0.097,-0.060]$} \\
log_materials & -0.114 & 0.007 & {$[-0.128,-0.100]$} \\
log_units & -0.446 & 0.012 & {$[-0.469,-0.422]$} \\
log_feed & -0.180 & 0.004 & {$[-0.188,-0.172]$} \\
trend & -0.022 & 0.001 & {$[-0.023,-0.020]$} \\
\hline$\sigma_{v}$ & 0.089 & 0.001 & {$[0.087,0.091]$} \\
$\sigma_{\xi}$ & 0.148 & 0.008 & {$[0.132,0.162]$} \\
$\sigma_{\omega}$ & 0.380 & 0.030 & {$[0.321,0.439]$} \\
$\mu$ & 3.032 & 0.075 & \\
\hline
\end{tabular}

high. Moving to the parameters associated with the hidden-state process, Figure 2.1 presents boxplots ${ }^{8}$ of the inefficiency persistence parameter $\rho$ and LRTE.

The mean value of the inefficiency persistence parameter $\rho$ across farms is $95 \%$ while, most farms are concentrated around this mean as can been seen on the left panel of Figure 2.1. This result is in accordance with the high inefficiency persistence in German dairy farming reported by Emvalomatis et al. (2011). Very few farms exhibit values of inefficiency persistence lower than $90 \%$, while, a few more attain extremely high values of $98 \%$. Hence, despite these small differences, all farms face high adjustment costs that force them to remain inefficient in the future. Moreover, given that the $\mathbf{s}$ process is stationary, the average value of LRTE is $63 \%^{9}$ and most of the variation between farms is attributed to their different characteristics (ESUs and subsidies), and, to a lesser extent, to heterogeneity in their inefficiency persistence.

The right panel of Figure 2.1 shows that most observations are concentrated in the area between the $1^{\text {st }}$ and $3^{\text {rd }}$ quartiles while outliers are found only above the $3^{\text {rd }}$ quartile. The fact that most farms' LRTE is concentrated around $60-80 \%$ should not be surprising. Recalling that LRTE reflects the value of efficiency that each farm will attain in the long-run, one should not expect to observe values below $50 \%$ since these farms would probably drop out of the market by attaining such a low level of efficiency in the long-run. In contrast, we should expect to find farms to be partly inefficient but in a competitive level such that of $60-80 \%$, while cases of farms' exhibiting a higher level of efficiency in the long-run may occur. The average value of short-run efficiency

\footnotetext{
${ }^{8}$ We first calculate the mean of all the draws from the posterior for every farm and then we plot these farm-specific means.

${ }^{9}$ Note that the expectation of LRTE was defined as $\left[1+\exp \left\{z_{i}^{\prime} \delta / 1-\rho_{i}\right\}\right]^{-1}$.
} 


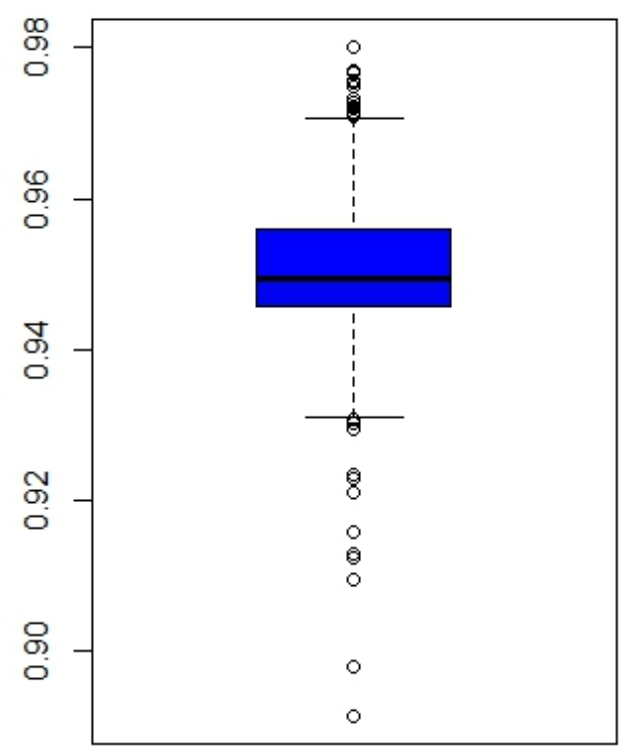

$\rho$

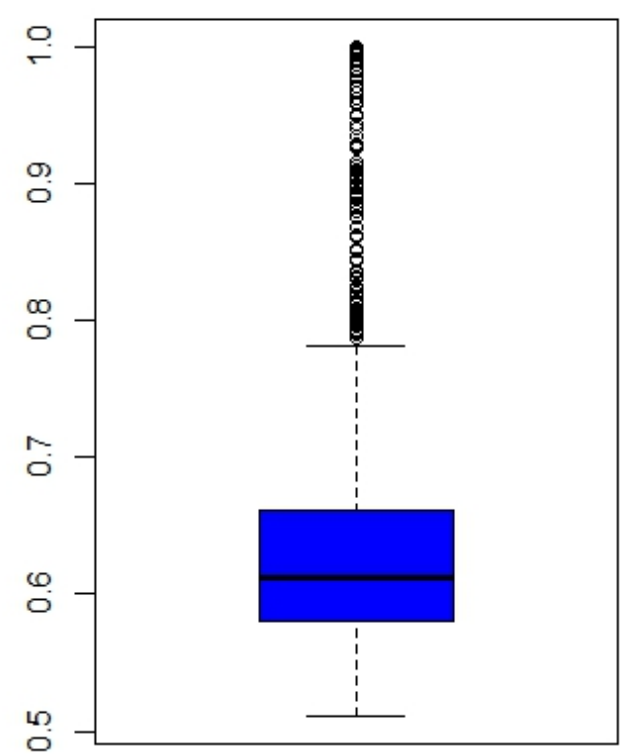

LRTE

Figure 2.1: Boxplot of inefficiency persistence parameter $\rho$ and LRTE

across years and farms is $65 \%$ meaning that farms can, on average, increase their production by $35 \%$, by still using the same amount of inputs. Besides, the values of short-run efficiency and LRTE are very close to each other meaning that the time-span captured by the data is close to the equilibrium.

Differences in the LRTE of farms can be attributed to farm-specific characteristics. Table A.3 in Appendix A, reports the determinants of transformed technical efficiency s. However, since the main contribution of this paper lies on the explanation of LRTE heterogeneity due to farm-specific characteristics, we derive the marginal effects of the variables in $\mathbf{z}$ on $\operatorname{LRTE}^{10}$. These marginal effects were calculated at the mean values of the variables in $\mathbf{z}$ and are presented in Table 2.3. All marginal effects are statistically significant.

The marginal effect with respect to farm size is positive and implies that an 1 unit (100 ESU) increase in farm size causes a $0.9 \%$ increase in LRTE. This result suggests that larger farms are more likely to attain higher efficiency scores in the long run, possibly because they tend to be more business oriented and make use of more mental

${ }^{10}$ The derivative of LRTE with respect to the $k^{t h}$ explanatory variable in $\mathbf{z}$ is given by: $\frac{\partial L R T E_{i}}{\partial z_{k}}=$ $\frac{\left(\frac{z_{k}}{\rho_{i}}\right) \times \exp \left\{z_{i}^{\prime} \delta\right\}}{\left(1+\exp \left\{z_{i}^{\prime} \delta\right\}\right)^{2}}$. 
Table 2.3: Marginal effects of the variables in $\mathbf{z}$ on long-run technical efficiency (LRTE).

\begin{tabular}{lccc}
\hline Variable & Mean & Std. dev. & 95\% Credible Interval \\
\hline ESU & 0.009 & 0.001 & {$[0.007,0.012]$} \\
subsidies & -0.009 & 0.001 & {$[-0.011,-0.006]$} \\
\hline
\end{tabular}

labor. Subsidies have a negative marginal effect on LRTE with an 1 unit $(100,000 €)$ increase in subsidies leading to a $0.9 \%$ decrease in LRTE. This negative effect can be attributed to the decrease in farmers' motivation to work efficiently when subsidies are seen as an additional source of income. This result is in accordance with the findings of Hadley (2006), Bojnec and Latruffe (2009), Zhu and Oude Lansink (2010), Zhu et al. (2011), Zhu et al. (2012), and Bojnec and Latruffe (2013).

\subsection{Concluding remarks}

This article developed a model that accounts for heterogeneity in long-run technical efficiency. A dynamic stochastic frontier model is used, which, as an alternative to the generalized true random effects model, can provide a value of the long-run efficiency of farms. However, our model recognizes that long-run technical efficiency may be affected by firm-specific characteristics, which is an issue that has been completely ignored in previous studies that have used either the dynamic stochastic frontier or the generalized true random effects model. Furthermore, it also accounts for potential differences in firms' inefficiency persistence using a novel approach that maintains the assumption of positive autocorellation of efficiency under the presence of high adjustment costs. Hence, our modeling approach allows the long-run expected value of technical efficiency to differ among firms based on two components: differences in firm-specific factors and potentially different degrees of inertia of firms in adjusting their quasi-fixed factors under the presence of high adjustment costs. The model is applied to an unbalanced panel dataset of German dairy farms that covers the period from 1999 to 2009 and a Bayesian estimation approach is proposed.

Our results confirm the presence of highly autocorellated inefficiency as the model produces an estimate of average inefficiency persistence of $95 \%$. Governmental regulation and unpredictable changes in economic conditions force farms to remain inefficient and this inefficiency does not disappear as time progresses. Credit access problems or time-consuming learning-by-doing procedures suggest that the convergence towards more efficient use of resources is costly and, therefore, gradual. Heterogeneity in inefficiency persistence is found to be low, suggesting that farmers exhibit a similar degree of sluggish adjustment towards more efficient production plans. High risk-aversion 
when it comes to the adoption of a new technology in combination with adjustment costs may be responsible for such similarities in inefficiency persistence.

The average value of long-run technical efficiency is $63 \%$, confirming that the presence of high adjustment costs provides farmers with an incentive to remain partly inefficient at a given point in time. Most farms attain long-run efficiency scores of $60-80 \%$, while few of them reach higher efficiency levels in the long-run. The fact that there exist no farms that attain long-run efficiency scores below $60 \%$ is anticipated based on the argument that very inefficient farms should not be able to survive in the long-run due to market competition. One should rather expect that most farms would reach a high level of efficiency in the long-run that can allow them to continue operating. Differences in long-run technical efficiency of farms are attributed, to a large extent, to farm-specific factors and, to a lesser extent, to heterogeneity in inefficiency persistence.

European size units are positively related with long-run technical efficiency, suggesting that larger farms, in terms of economic size units, are more efficient in the long-run. This result is justified based on the fact that larger farms are more business/market oriented and more prone to the use of mental labor that can increase their efficiency. Subsidies are negatively associated with long-run technical efficiency. Several studies have shown that when subsidies are perceived as an additional source of income, they lead to lower motivation of farm operators to improve the efficiency of their farms. This income effect is particularly true for the period under study, since, after the 2003 CAP reform, subsidies were disbursed in the form of decoupled payments which were independent from production quantities. 


\title{
Chapter 3
}

\section{The effect of farm characteristics on the persistence of technical inefficiency: a case study in German dairy farming}

\begin{abstract}
This paper provides a way to include explanatory variables that may impact the persistence of farms' technical inefficiency by extending the conventional parametric dynamic efficiency model. Estimation of the model is performed using Bayesian techniques. The empirical findings reveal a high degree of inefficiency persistence through time, which is increasing in the amount of subsidies received. Older farmers exhibit higher inefficiency persistence, as opposed to younger ones, presumably due to their lack of motivation to adopt state-of-the-art technologies.
\end{abstract}

Keywords: dairy farms; inefficiency persistence; dynamic stochastic frontier.

JEL Classification: C11, C23, Q12 


\subsection{Introduction}

The adoption of technical innovation in farming is necessary to ensure that farms remain productive and competitive in an evolving sector. The technological treadmill theory introduced by Cochrane (1958) states that early adopters of new technologies enjoy high returns, which are gradually eliminated as more and more farmers adopt the new technology. This is a consequence of an increase in supply and the associated fall in prices. As a result, farmers are trapped on a treadmill, with initial high returns and the need to keep up with the evolution of technology providing strong incentives for continuous investment in new technologies. However, empirical evidence has shown that investment in new equipment takes place at irregular intervals, often referred to as investment spikes (Geylani and Stefanou, 2013). Investment is irregular because inputs such as capital are not freely adjusted. However, certain adjustment costs do exist, such as those associated with altering production levels (Stefanou, 2009).

The adjustment cost hypothesis described by Penrose (1959) maintains that it is costly for the decision maker to rapidly adjust the level of quasi-fixed factors of production to their optimal levels. Therefore, the decision making unit exhibits a certain degree of inertia when it comes to the adoption of a new technology when high adjustment costs are present. These adjustment costs are due to financial constraints and costs associated with learning. In efficiency analysis, this sluggish adjustment of quasi-fixed factors of production and the associated lag in technology adoption have implications on the dynamic evolution of farms' efficiency scores. Considering a farm which operates in a dynamic environment, governmental regulation or unpredictable events (i.e. extreme weather conditions, pest outbreaks etc.) may force the farm to be inefficient at a certain point in time. In order to become efficient and stay viable, the farm will need to reorganize its production process. However, when adjustment costs are high, immediate adjustment may not be optimal. Therefore, the decision making unit may have an incentive to remain inefficient in the short-run. As a result, this implies that inefficiency will persist ${ }^{1}$ from one period to the next (Emvalomatis et al., 2011).

Inefficiency persistence is, therefore, the result of high adjustment costs that slow down the adjustment of some production factors. Stefanou (2009) provides a description and categorizes adjustment costs in two major subcategories, external and internal adjustment costs. On the one hand, external adjustment costs are pecuniary in nature and involve the lack of credit sources that prevent farms from raising their capital

\footnotetext{
${ }^{1}$ Since inefficiency is defined as one minus efficiency, if most farms are fully efficient or close to being fully efficient, one should refer to efficiency persistence and not inefficiency persistence. However, the term inefficiency persistence is used as we expect that only few farms will be fully efficient or close to that.
} 
stock beyond the level that is currently in use. Examples of external adjustment costs include expansion planning fees such as architects and legal costs, as well as imperfect capital markets. Besides, information asymmetries may result in low selling prices of used equipment, even if it has been only minimally used. In dairy farming, an example of an external adjustment cost is the following: consider a farmer who has just bought an Automatic Milking System (AMS). Soon after, an advanced AMS that incorporates udder cleaning and the removal of milking equipment from dairy cows becomes available on the market. While the farmer will observe some of his neighbors milking their cows more efficiently using the advanced AMS, it will probably not be optimal for him to sell his newly bought AMS to buy the advanced AMS, as this will entail high costs due to the low selling price of his newly bought AMS (even though he only used it minimally). This implies that the optimal decision for the farmer would be to exploit the full potential of his AMS and buy the new machine when its value depreciates enough. However, this also implies that his optimal strategy is to remain inefficient in comparison to his peers using the advanced AMS.

On the other hand, internal adjustment costs do not involve financial constraints but are perceived as learning costs. A manager who invests in a new technology needs to devote a certain amount of time to learning how to use the new equipment efficiently. New skills and experience must first be developed before the farmer is able to take advantage of his newly bought equipment. Following the previous example of the availability of an advanced AMS on the market, the farmer should devote a particular amount of time to learning how to use the computer that programs the new milking procedure. This implies that more efficient milking will not start immediately after the purchase of the new AMS, but only when the farmer becomes familiar with using it. This is an example of an internal adjustment cost.

Based on the aforementioned types of adjustment costs, the degree of inefficiency persistence is expected to be influenced by financial constraints/aid, as well as by managers' experience. In terms of the former, farms facing credit constraints (external adjustment costs) have limited access to external funding because of being unable to offer adequate guarantees to lenders and, as a result, tend to invest less (Kumbhakar and Bokusheva, 2009). Subsidies may play a key role in ameliorating access to external funding, since they can induce credit access and lower the cost of borrowing (Ciaian and Swinnen, 2009; Kumbhakar and Bokusheva, 2009; Rizov et al., 2013). However, subsidies may also act as an additional source of income that provides farmers with less motivation to invest in new technologies (Zhu et al., 2012; Rizov et al., 2013). Hence, the effect of subsidies on inefficiency persistence depends on the way farmers perceive subsidies. If farmers view subsidies as a credit access tool, they may induce investment in new technologies and result in lower inefficiency persistence. Neverthe- 
less, if subsidies are viewed simply as an additional income source, farmers may invest in subsidy-seeking activities instead of investing in new technologies; this would imply higher inefficiency persistence.

On the subject of internal adjustment costs, Luh and Stefanou (1993), argue that learning plays a key role in facilitating the adjustment of quasi-fixed inputs to their optimal levels, in the sense that knowledge accumulation accelerates the familiarization of farm operators with using new equipment. Stefanou and Saxena (1988), state that managers with more experience have a greater ability to learn. Hence, older farmers are expected to learn quicker than younger ones and as a result, farms owned by older managers may adjust faster and exhibit lower inefficiency persistence. However, very old farmers may not be willing to invest in new technologies in comparison with younger ones due to a lack of motivation (Hadley, 2006; Abdulai and Tietje, 2007), especially in the absence of a successor. Accordingly, farms owned by young or middle-aged operators may adopt easier new technologies compared to very old operators. This would result in lower inefficiency persistence.

The main objective of this paper is to incorporate particular farm-specific characteristics that are related to adjustment costs. These can then be tested to determine whether they have an impact on the persistence of technical inefficiency of German dairy farms. The concept of inefficiency persistence has been tackled in both nonparametric and parametric settings. In a non-parametric framework, Nemoto and Goto (1999), Nemoto and Goto (2003) and Silva and Stefanou (2007) account for inefficiency persistence by assuming intertemporal cost-minimizing behavior and making use of price information ${ }^{2}$. Parametrically, the method of SFA, introduced by Aigner et al. (1977) and Meeusen and van den Broeck (1977), has undergone several changes before it was considered as being truly dynamic. With the availability of panel data, early attempts to describe the evolution of efficiency scores over time considered inefficiency as a deterministic function of time (Cornwel et al., 1990; Kumbhakar, 1990; Battese and Coelli, 1992; Lee and Schmidt, 1993), ignoring firms' dynamic behavior.

A more recent generation of SFA models that are truly dynamic has emerged with the innovative work of Ahn and Sickles (2000). The research specified an autoregressive process on firm-specific efficiency scores to account for persistence of shocks in firms' efficiency. Subsequent criticism relating to the formulation of an autoregressive process on non-negative variables, led Tsionas (2006) to specify an autoregressive process on transformed efficiency that can take any value on the real line. Since then, several studies have considered this type of model, including Emvalomatis et al. (2011), Emvalomatis (2012a) and Galán et al. (2015). All these models, irrespective of the

${ }^{2}$ For a thorough literature review on non-parametric dynamic efficiency studies see Fallah-Fini et al. (2014). 
way efficiency is transformed, recognize that under the presence of high adjustment costs, inefficient firms are likely to remain inefficient in the future, or, in other words, exhibit high inefficiency persistence. All studies find very high inefficiency persistence, thus adding credibility to the adjustment cost theory.

However, in this dynamic SFA framework, none of the aforementioned studies allow for firm characteristics to impact inefficiency persistence. In this study, we extend the dynamic SFA model in a way that it can accommodate factors that may influence inefficiency persistence. Such a modelling approach allows one not only to test the adjustment cost theory as previous studies do, but also include and test whether particular farm-specific characteristics affect inefficiency persistence. In the next section we describe the modelling approach and the Bayesian techniques used to estimate the model. A description of the data used and the empirical specification follows. Then, an application of the model to a panel of German dairy farms is presented. The final section provides some discussion on the implications of the study and offers some concluding remarks.

\subsection{Modelling approach}

An output distance function is used to measure efficiency in a multi-output production technology ${ }^{3}$. Assuming that a vector of inputs $\tilde{\mathbf{x}} \in R_{+}^{N}$ is used to produce a vector of outputs $\tilde{\mathbf{y}} \in R_{+}^{M}$, the output distance function is defined as:

$$
D_{o}(\tilde{\mathbf{x}}, \tilde{\mathbf{y}}, t)=\min \left\{\theta: \frac{\tilde{\mathbf{y}}}{\theta} \text { can be produced by } \tilde{\mathbf{x}} \text { in period } t\right\}
$$

The output distance function takes an output-expanding approach to measure the distance of a producer to the boundary of the production possibilities set, and gives the minimum amount by which the output vector can be deflated to reach this boundary. It assumes values in the unit interval and the locus of points for which $D_{o}(\tilde{\mathbf{x}}, \tilde{\mathbf{y}}, t)=1$ defines the boundary of the production possibilities set. The technical efficiency of a firm $i$ in period $t$ is then defined as $T E_{i t}=D_{o}\left(\tilde{\mathbf{x}}_{i t}, \tilde{\mathbf{y}}_{i t}, t\right)$. Taking the logarithm of both sides, imposing the condition of linear homogeneity on the outputs of the distance function, and then appending an error term, all lead to the following econometric version of the output distance function:

$$
-\log \tilde{y}_{i t}^{m}=\log D_{o}\left(\tilde{\mathbf{x}}_{i t}, \frac{\tilde{\mathbf{y}}_{i t}}{\tilde{y}_{i t}^{m}}, t\right)+v_{i t}-\log \left(T E_{i t}\right)
$$

\footnotetext{
${ }^{3}$ The model can also be applied to an input or a hyperbolic distance function. However, the output distance function makes sense for the application that follows.
} 
where $\tilde{y}_{i t}^{m}$ is the normalizing output and $v_{i t}$ is a linear error term that accounts for random noise. Notice that the left hand-side variable is negative and $\log \left(T E_{i t}\right)$ is subtracted from the right hand-side. Hence, the distance elasticities with respect to inputs should be negative and the skewness of the efficiency term suggests that we should estimate the frontier as if it is a cost frontier. Letting $y_{i t}$ be the dependent variable in equation (3.2), and the logarithm of the distance function representing a linear function of parameters and monotonic transformations of its arguments, the estimable form of the distance function can be written as:

$$
y_{i t}=\mathbf{x}_{i t}^{\prime} \boldsymbol{\beta}+v_{i t}-\log \left(T E_{i t}\right), \quad v_{i t} \sim \mathscr{N}\left(0, \sigma_{v}^{2}\right)
$$

where $y_{i t}$ is the negative of the logarithm of the normalizing output, $\mathbf{x}_{i t}^{\prime}$ is a vector of time-varying covariates, $\boldsymbol{\beta}$ is a vector of parameters to be estimated, $v_{i t}$ is a two-sided error term that captures statistical noise, and $T E_{i t}$ is the technical efficiency of firm $i$ in time $t$.

We follow Tsionas (2006) and consider a dynamic stochastic frontier model by specifying an autoregressive process on firm-specific technical efficiency. $T E_{i t}$ is treated as a random variable that lies on the unit interval $T E_{i t} \in(0,1]$. To avoid criticism related to the specification of an autoregressive process on a nonnegative variable, a one-to-one transformation of $T E_{i t}$ is used to project it from the unit interval to the real line. Following Emvalomatis (2012a), we use the inverse of the logistic function for this transformation. We define $s_{i t}=\log \left(\frac{T E_{i t}}{1-T E_{i t}}\right)$ as the latent-state variable and assume the following autoregressive process on $s_{i t}$ :

$$
\begin{gathered}
s_{i t}=\mathbf{z}_{i}^{\prime} \boldsymbol{\delta}+\rho_{i} s_{i, t-1}+\xi_{i t}, \quad \xi_{i t} \sim \mathscr{N}\left(0, \sigma_{\xi}^{2}\right) \\
s_{i 1}=\frac{\mathbf{z}_{i}^{\prime} \boldsymbol{\delta}}{1-\rho_{i}}+\xi_{i 1}, \quad \xi_{i 1} \sim \mathscr{N}\left(0, \sigma_{\xi 1}^{2}\right)
\end{gathered}
$$

where $\mathbf{z}$ is a vector of time-invariant covariates, $\boldsymbol{\delta}$ and $\rho_{i}$ are parameters to be estimated, $\xi_{i t}$ is a two-sided error term that accounts for statistical noise and $\sigma_{\xi 1}^{2}=\frac{\sigma_{\xi}^{2}}{1-\rho_{i}^{2}}$, is due to stationarity. Imposing stationarity on the s series, and therefore time-invariant covariates in the $\mathbf{z}$ vector, is necessary both from an econometric point of view and theoretically. Econometrically, since $\mathbf{s}$ is an unobserved quantity, a distribution in the initial period expressed by equation (3.5) needs to be defined. This is possible if we impose stationarity on the s series (Wooldridge, 2005). Theoretically, if the s series is not stationary, then its expected value will approach either positive or negative infinity depending on the sign of the term $\mathbf{z}_{i}^{\prime} \boldsymbol{\delta}$. This implies that technical efficiency will approach either unity or zero. Observing fully efficient or fully inefficient firms in 
efficiency analysis is something quite rare.

\subsubsection{Modelling inefficiency persistence}

Based on the modelling approach presented in equation (3.4), the inefficiency persistence parameter $\rho_{i}$ can be viewed as an elasticity that measures the firm-specific percentage change in the efficiency to inefficiency ratio that is carried out from one period to the next. Stationarity of the series requires that the inefficiency persistence parameter, $\rho_{i}$, remains between -1 and 1 . However, we restrict $\rho_{i}$ to the unit interval since we do not expect negative adjustment towards the long-run equilibrium. For interpretation purposes, a value of $\rho_{i}$ close to 1 implies that inefficiency persistence is very high and firms find it difficult to adjust their quasi-fixed inputs to their optimal levels. Conversely, lower values for $\rho_{i}$ suggest that the adjustment towards optimal conditions is faster. When it comes to the modelling approach, we transform the inefficiency persistence parameter in a way that not only restricts it to the unit interval, but also, exposes it to firm-effects and allows them to have an impact. Therefore, we consider the following transformation ${ }^{4}$ for the inefficiency persistence parameter:

$$
\rho_{i}=\frac{\exp \left\{h_{i}\right\}}{1+\exp \left\{h_{i}\right\}}
$$

where $h_{i}$ is a firm-specific latent-state variable that is assumed to exhibit the following relationship:

$$
h_{i}=\mathbf{w}_{i}^{\prime} \boldsymbol{\eta}+\lambda_{i}, \quad \lambda_{i} \sim \mathscr{N}\left(0, \sigma_{\lambda}^{2}\right)
$$

where $\mathbf{w}_{i}^{\prime}$ is a vector of time-invariant covariates, $\boldsymbol{\eta}$ is a vector of parameters to be estimated, and $\lambda_{i}$ is a linear error term that captures random noise. Hence, $h_{i}$ is a continuous variable that can take any value on the real line while, based on our transformation in equation (3.6), $\rho_{i}$ lies on the unit interval. Firm-specific factors can be incorporated into the vector $\mathbf{w}$ that will have a non-linear impact on the inefficiency persistence parameter $\rho_{i}$ as equation (3.6) implies. This modelling approach allows us to include firm-specific factors and test whether they have an impact on inefficiency persistence.

\subsubsection{Bayesian inference}

Bayesian techniques are used to estimate the model in equations $(3.3-3.7)$. We define $\mathbf{s}_{i}$ to be a $T_{i} \times 1$ vector of the latent-state variable of the transformed technical efficiency

\footnotetext{
${ }^{4}$ Note that we use the inverse of the logistic function again for the transformation and we define a latent-state variable $h_{i}=\log \left(\frac{\rho_{i}}{1-\rho_{i}}\right)$. Solving for $\rho_{i}$ yields equation (3.6).
} 
for firm $i$, where $T_{i}$ represents farm-specific time periods, and $\mathbf{h}$ is an $N \times 1$ vector of the latent state variable of the transformed inefficiency persistence. All structural parameters to be estimated are collected in a vector, $\boldsymbol{\theta}=\left[\boldsymbol{\beta}, \sigma_{v}, \boldsymbol{\delta}, \sigma_{\xi}, \boldsymbol{\eta}, \sigma_{\lambda}\right]^{\prime}$. The complete data likelihood and the latent states is:

$$
\begin{aligned}
p\left(\mathbf{y},\left\{\mathbf{s}_{i}\right\}, \mathbf{h} \mid \boldsymbol{\theta}, \mathbf{X}, \mathbf{Z}, \mathbf{W}\right)=p\left(\mathbf{y} \mid\left\{\mathbf{s}_{\mathbf{i}}\right\}, \boldsymbol{\beta}, \sigma_{v}, \mathbf{X}\right) \times p\left(\left\{\mathbf{s}_{\mathbf{i}}\right\} \mid \mathbf{h}, \boldsymbol{\delta}, \sigma_{\xi}, \mathbf{Z}\right) \times p\left(\mathbf{h} \mid \boldsymbol{\eta}, \sigma_{\lambda}, \mathbf{W}\right) \\
=\frac{1}{\left(2 \pi \sigma_{v}^{2}\right)^{\sum_{i=1}^{N} \frac{T_{i}}{2}}} \exp \left\{-\sum_{i=1}^{N} \sum_{t=0}^{T_{i}} \frac{\left(y_{i t}-\mathbf{x}_{i t}^{\prime} \boldsymbol{\beta}+\log T E_{i t}\right)^{2}}{2 \sigma_{v}^{2}}\right\} \\
\times \frac{1}{\left(2 \pi \sigma_{\xi}^{2}\right)^{\sum_{i=1}^{N} \frac{\left(T_{i}-1\right)}{2}}} \exp \left\{-\sum_{i=1}^{N} \sum_{t=1}^{T_{i}-1} \frac{\left(s_{i t}-\mathbf{z}_{i}^{\prime} \boldsymbol{\delta}-\rho_{i} s_{i, t-1}\right)^{2}}{2 \sigma_{\xi}^{2}}\right\} \\
\times \frac{1}{\left(2 \pi \sigma_{\xi 1}^{2}\right)^{\frac{N}{2}}} \exp \left\{-\sum_{i=1}^{N} \frac{\left(s_{i 1}-\mathbf{z}_{i}^{\prime} \boldsymbol{\delta}\right)^{2}}{2 \sigma_{\xi 1}^{2}}\right\} \\
\quad \times \frac{1}{\left(2 \pi \sigma_{\lambda}^{2}\right)^{\frac{N}{2}}} \exp \left\{-\sum_{i=1}^{N} \frac{\left(h_{i}-\mathbf{w}_{i}^{\prime} \boldsymbol{\eta}\right)^{2}}{2 \sigma_{\lambda}^{2}}\right\}
\end{aligned}
$$

where $\mathbf{y}$ is the stacked vector of the dependent variable over firms and time periods, $\mathbf{X}$ is the matrix of covariates in equation (3.3), $\mathbf{Z}$ is the matrix of covariates in equations $(3.4-3.5)$, and $\mathbf{W}$ is the matrix of covariates in equation (3.7).

The first line of equation (3.8) is due to the normality assumption of $\sigma_{v}$. The second and third lines are due to equations $(3.4-3.5)$. These assumptions state that transformed inefficiency $\mathbf{s}$ depends on the covariates in $\mathbf{z}$ and $\mathbf{w}$ (since $\mathbf{s}$ depends on $\rho_{i}$, which is a function of the covariates in $\mathbf{w}$ ), but not on the inputs $\mathbf{x}$. This is a standard assumption in the frontier literature and a convenient one since, if it fails, the covariates in $\mathbf{x}$ should also appear in the inefficiency component, making identification potentially weak (as these variables will appear in the model twice). This is what non-neutral stochastic frontiers do (Karagiannis and Tzouvelekas, 2005). The fourth line of equation (3.8) is due to equation (3.7) and states that inefficiency persistence is independent of the inputs $\mathbf{x}$, and of the covariates in $\mathbf{z}$. The first assumption is somewhat straightforward since inefficiency persistence depends on investment decisions which are related to farm characteristics rather than input volumes. The second assumption states that the variables that affect efficiency should not affect inefficiency persistence. This assumption stems from the fact that farm characteristics that may affect the efficiency of farms do not necessarily affect their ability to change the efficiency levels as a response to a shock (i.e. introduction of a new technology). An important issue here is that this holds for farm characteristics that are not related to adjustment costs. 
Back to our econometric formulation and using Bayes' rule, the joint posterior density of the model's parameters and latent-states can be written as:

$$
\pi\left(\boldsymbol{\theta},\left\{\mathbf{s}_{\mathbf{i}}\right\}, \mathbf{h} \mid \mathbf{y}, \mathbf{X}, \mathbf{Z}, \mathbf{W}\right) \propto p\left(\mathbf{y},\left\{\mathbf{s}_{i}\right\}, \mathbf{h} \mid \boldsymbol{\theta}, \mathbf{X}, \mathbf{Z}, \mathbf{W}\right) \times p(\boldsymbol{\theta})
$$

where $p(\boldsymbol{\theta})$ is the product of all prior densities. Proper, but rather vague priors are used for the structural parameters ${ }^{5}$. We use normal priors for $\boldsymbol{\beta}, \boldsymbol{\delta}$ and $\boldsymbol{\eta}$, while invertedGamma priors are used for the three variance parameters. Such prior specification has the desirable property of resulting in posteriors of the same distributional form. We estimate the posterior moments of the model's parameters using MCMC techniques (Koop et al. (1995) illustrate an application of MCMC in stochastic frontier models). Drawing samples from the posterior for the latent-state variables requires data augmentation techniques (see Tanner and Wong, 1987). Finally, Metropolis-Hastings updates are used for $\mathbf{s}_{i}$ and $\mathbf{h}$ as their complete conditionals do not belong to any known distributional family.

\subsubsection{Alternative models}

Since we extend previously applied models, we compare our results with two base models: (i) the most popular panel-data stochastic frontier specification introduced by Battese and Coelli (1992). The inefficiency component is defined as $u_{i}{ }^{t}=\gamma(t) \cdot u_{i}$, with $u_{i}$ being a firm-specific effect that captures technical inefficiency and is assumed to follow a one-sided distribution (in our specification an exponential distribution), and $\gamma(t)=\exp (\eta\{T-t\})$. This model has been used extensively in the stochastic frontier literature as it relaxes the assumption of time-invariant inefficiency by estimating only one additional parameter $(\eta)$. However, this model fails to capture firms' dynamic behavior as it considers inefficiency as a deterministic function of time, (ii) the dynamic efficiency model used by Emvalomatis et al. (2011), where (transformed) inefficiency $\mathbf{s}$ is defined as $s_{i}{ }^{t}=\delta+\rho s_{i, t-1}+w_{i t}$. This model, in contrast to the Battese and Coelli specification, is able to capture firm-level dynamic behavior by specifying an autoregressive process on firm-specific efficiency scores. However, it does not allow for firm-specific characteristics to impact efficiency and it restricts the inefficiency persistence parameter to be the same across firms. The results under the two aforementioned specifications and the specification used in this paper are similar and are presented in Table B.2 in Appendix B.

${ }_{5}^{5}$ Table B.1 in Appendix B presents the parameterization of priors. 


\subsection{Data and empirical specification}

The data used in this application are provided by the $\mathrm{FADN}^{6}$. The dataset contains farm-level information on physical units such as outputs and inputs, economic and financial data such as production costs, subsidies and debts, geographical information that allows one to distinguish different regions, as well as characteristics of the farm's primary operator such as age. The accounting data that FADN provides are collected regionally using a common questionnaire across all EU Member States. FADN uses stratified random sampling and farms remain in the panel on average for a period of 4-5 years, although there are cases where farms remain for more than ten years.

The part of the dataset that is used here contains such information for German dairy farms and covers a period from 1999 to 2009. This study focuses on farms primarily engaged in dairy production, and for this purpose we have selected farms whose revenues from sales of cow's milk, beef, and veal comprise at least $66 \%$ of their total revenues for every year the farm is observed. Furthermore, given the dynamic nature of our modelling approach, we retained farms that are observed for at least four consecutive years. Our final dataset consists of an unbalanced panel of 1,625 farms with a total of 12,965 observations.

The output distance function in equation (3.2) is specified in two outputs:

1. Deflated revenues from sales of cow's milk (milk)

2. Deflated revenues plus change in valuation of beef and veal, pigmeat, sheep and goats, and poultry meat, plus deflated revenues from sales of other livestock and products (other)

The reported revenues are deflated with price indices obtained from EUROSTAT, using 2000 as the base year. Deflation of milk was based on its own price index, while, an aggregate price index of agricultural products was used to deflate outputs other than milk.

Six categories of inputs are specified in equation (3.2):

1. Buildings and machinery $(\mathrm{K})$ are measured in deflated book value. For each input subcategory (buildings and machinery), its own price index was obtained from EUROSTAT and a Törnqvist index was constructed. The total reported value was deflated using the Törnqvist index.

2. Total labor (L) is measured in man-hours and consists of family and hired labor.

${ }^{6}$ Data source: EU-FADN - DG AGRI. 
3. Total utilized agricultural area (A) is measured in hectares and includes owned, as well as rented land.

4. Materials and services (M) are measured in deflated value. This input consists of ten subcategories of inputs: seeds and plants, fertilizers, crop protection, energy, other livestock-specific costs, other crop-specific costs, forestry-specific costs, feed for pigs and poultry, contract work and other direct inputs. For each of the aforementioned subcategories, the relevant price indices were obtained from EUROSTAT and a Törnqvist index was constructed. The total reported value was deflated using the Törnqvist index.

5. Total livestock units $(\mathrm{S})$ is measured in livestock units and includes the total number of equines, cattle, sheep, goats, pigs and poultry of the holding.

6. Purchased feed $(\mathrm{F})$ is measured in deflated value. It includes concentrated feedingstuffs for grazing stock and coarse fodder for grazing stock. The value of feed produced within the farm is excluded. This variable was deflated using its own price index from EUROSTAT.

We further account for differences in technology and climatic conditions across regions in Germany by including dummy variables for eastern, western, northern and southern (base category) Germany. Recognizing that several factors may affect technical efficiency, the $\mathbf{z}$ vector in equations $(3.4-3.5)$ includes the following variables: the economic size of farms measured in hundreds of ESU, specialization in milk production captured by the ratio of revenues that come from milk production to total revenues, and stock density defined as livestock units per hectare. The criteria for choosing the aforementioned covariates are based on theoretical arguments that their validity has been examined by several empirical studies. For instance, farm size is expected to exert a positive effect on efficiency due to the higher managerial effort by the operators of big farms (Davidova and Latruffe, 2007; Latruffe et al., 2008; Zhu et al., 2012). Specialization may affect efficiency either positively, because of farmers' experience when they are engaged in a single production activity (Latruffe et al., 2005; Zhu et al., 2012; Sauer and Latacz-Lohmann, 2015), or negatively, when economies of scope arise (Brümmer, 2001; Coelli and Fleming, 2004). Finally, stock density is associated with intensive production techniques and it can positively impact efficiency (Alvarez and Corral, 2010). The variables in $\mathbf{z}$ are specified as time-invariant because stationarity on the $\mathbf{s}$ series needs to be imposed so that we are able to estimate equation (3.5). Besides, such a specification is not very restrictive since the covariates in $\mathbf{z}$ do not vary 
significantly over time ${ }^{7}$.

The $\mathbf{w}$ vector in equation (3.7) that directly examines the variation in the transformed inefficiency persistence parameter $h_{i}$ and, indirectly, the variation in the inefficiency persistence $\rho_{i}$ through equation (3.6), consists of the following covariates: (i) the total amount of subsidies per hectare that farms receive. This variable consists of subsidies on crops, livestock, other subsidies (related to forestry, environmental programs etc.), subsidies on intermediate consumption and external factors, and decoupled payments, (ii) a dummy variable that captures the effect of the primary operators' age on inefficiency persistence. As a base category, we use those farms whose primary operator is aged 65 years or older ${ }^{8}$. The reasoning behind these choices is twofold: (i) subsidies are included in order to test whether financial support is perceived as an investment tool that could lower inefficiency persistence, or as an additional source of income that could lower farmers' motivation to work efficiently and therefore, increase their inefficiency persistence, (ii) the dummy variable for age examines whether very old farmers exhibit higher inefficiency persistence compared to young and middle-aged farmers due to their lack of motivation to invest in new technologies ${ }^{9}$. Since inefficiency persistence does not change over time, the covariates in $\mathbf{w}$ are specified as time-invariant ${ }^{10}$.

The selection of the covariates in $\mathbf{z}$ and $\mathbf{w}$ is solely based on their connection with adjustment costs and how likely it is that they play a role in farmers' investment decisions as a response to a shock (i.e. introduction of a new technology). Farm size, milk specialization and stock density (covariates in $\mathbf{z}$ ) may affect the efficiency of farms but not the ability to change efficiency as a response to a shock (i.e. the introduction of a new technology) if we control for human capital. For instance, higher specialization in milk production may allow the farmer to do better on a daily basis and be efficient. However, if a new technology arises, being more specialized in milk production should not affect his decision whether or not to invest. Such a decision would probably be made based on the farmer's experience (age) or his financial situation. Besides, robustness checks with respect to the inclusion of all covariates in both the $\mathbf{z}$ and

\footnotetext{
${ }^{7}$ We derive farm-specific coefficients of variation for ESU, specialization and stock density in the following way: for each variable, we calculate each farm's mean and mean standard deviation over the years that is observed. Then, for every variable, we divide each farm's standard deviation by each farm's mean. Figure B.1 in Appendix B present histograms of the coefficient of variation for ESU, specialization, and stock density.

${ }^{8}$ Note that $25 \%$ of the farms in our sample are managed by primary operators who are aged 65 or above on average. Age was initially specified as a continuous variable, and then by using 3 categories (young, middle-aged and old). All specifications resulted in insignificant coefficient estimates.

${ }^{9}$ Financial indicators such as debt-to-asset ratio and liabilities-to-asset ratio were also included, resulting in highly insignificant coefficient estimates. Note that these indicators were very close to 0 for most farms with extremely low variation across farms and time.

${ }^{10}$ We again compute the farm-specific coefficient of variation for subsidies. Figure B.2 in Appendix $B$ presents a histogram of the coefficient of variation for subsidies.
} 
w vectors were performed, resulting in weak identification due to poor mixing of chains and many insignificant coefficient estimates. Summary statistics of the models' variables are presented in Table 3.1.

Table 3.1: Summary statistics of the models' variables

\begin{tabular}{lcccc}
\hline Variable & Mean & Std. dev. & $\mathbf{5 \%}$ & $\mathbf{9 5 \%}$ \\
\hline Revenues from cow's milk $(1,000 €)$ & 125.52 & 126.29 & 32.24 & 311.13 \\
Revenues from other output $(1,000 €)$ & 24.37 & 25.14 & 4.31 & 63.06 \\
Capital (1,000€) & 176.53 & 162.16 & 28.77 & 444.71 \\
Labor (1,000 man-hours) & 3.36 & 2.01 & 1.80 & 6.30 \\
Land (hectares) & 64.79 & 56.77 & 19.00 & 156.83 \\
Materials (1,000€) & 51.02 & 53.60 & 13.01 & 125.45 \\
Livestock (livestock units) & 96.40 & 76.56 & 31.95 & 214.79 \\
Purchased feed (1,000€) & 22.76 & 26.48 & 2.25 & 64.39 \\
Size (100 ESU) & 0.78 & 0.66 & 0.25 & 1.75 \\
Specialization (milk revenues/total revenues) & 0.72 & 0.12 & 0.52 & 0.89 \\
Density (livestock units/hectare) & 2.01 & 0.67 & 1.10 & 3.15 \\
Subsidies (1,000€/hectare) & 0.04 & 0.02 & 0.01 & 0.06 \\
Age (years) & 56.89 & 9.19 & 41.00 & 71.00 \\
\hline
\end{tabular}

Moving to the empirical specification of the model, since German dairy farms use multiple inputs to produce multiple outputs (milk, meat etc.), an appropriate representation of the production technology can be achieved using a distance function. The criteria for selecting an output distance function instead of an input distance function are summarized as follows. First, despite production of milk being restricted under the milk quota system, dairy farms in Germany are able to lease and purchase milk quota and, therefore, relax their output restrictions. Second, considering the main argument of the paper, inputs such as capital are considered to be quasi-fixed and consequently, an input distance function may be an inappropriate specification tool.

We use a translog specification of the output distance function because, as opposed to the Cobb-Douglas functional form, the translog is more flexible without imposing any restrictions on substitution possibilities between inputs and outputs. Hence, the output distance function is specified as translog in inputs $(\mathbf{x})$, outputs $(\mathbf{y})$, and time trend $(t)$. Using the estimable form of equation (3.2), the output distance function can be written as: 


$$
\begin{aligned}
-\log y_{i t}^{m} & =\alpha_{0}+\sum_{k} \alpha_{k} \log x_{i t}^{k}+\sum_{l} \beta_{l} \log \left(\frac{y_{i t}^{l}}{y_{i t}^{m}}\right) \\
& +\frac{1}{2} \sum_{k} \sum_{r} \alpha_{k r} \log x_{i t}^{k} \log x_{i t}^{r} \\
& +\frac{1}{2} \sum_{l} \sum_{m} \beta_{l m} \log \left(\frac{y_{i t}^{l}}{y_{i t}^{m}}\right) \log \left(\frac{y_{i t}^{l}}{y_{i t}^{m}}\right) \\
& +\frac{1}{2} \sum_{k} \sum_{l} \zeta_{k l} \log x_{i t}^{k} \log \left(\frac{y_{i t}^{l}}{y_{i t}^{m}}\right) \\
& +\mu_{1} t+\mu_{2} t^{2}+\sum_{k} \gamma_{k} t \log x_{i t}^{k} \\
& +\sum_{l} \phi_{l} t \log \left(\frac{y_{i t}^{l}}{y_{i t}^{m}}\right)+v_{i t}-\log \left(T E_{i t}\right)
\end{aligned}
$$

A time trend is included to capture technological progress, while its interaction with inputs and outputs allows it to be nonneutral. The data for outputs and inputs are normalized by their respective geometric means, so that the parameters associated with the first-order terms are directly interpretable as distance function elasticities, evaluated at the geometric mean of the data.

\subsection{Results}

The results reported below are based on the following sampling scheme: we use 10 chains and after a long burn-in of 50,000 iterations, each chain contributes 80,000 draws from the posterior. With the intention to remove potential autocorrelation induced by the Metropolis-Hastings updates, in each chain, every one in 10 draws is retained so that we end up with a total of 80,000 draws from the posterior. The complete set of results is provided in Table B.3 in Appendix B. Table 3.2 presents the parameter estimates of the first-order terms of the distance function for output and inputs, the trend estimate, the scale elasticity, and the three variance parameters. All of the distance function elasticities have the expected signs and are statistically significant, as the corresponding credible intervals do not contain zero.

The distance function elasticity with respect to the other output is a measure of the curvature of the frontier and implies that a $1 \%$ increase in output, other than milk, will result in a $0.125 \%$ increase in the distance function, implying that farms will move closer to the frontier. The negative signs of the distance function elasticities with respect to inputs state that potential increases in inputs push the frontier outwards 
Table 3.2: Posterior means, standard deviations and $95 \%$ credible intervals of the model's parameters

\begin{tabular}{lccc}
\hline Variable & Mean & Std. dev. & 95\% Credible Interval \\
\hline intercept & -0.417 & 0.029 & {$[-0.480,-0.370]$} \\
log_other & 0.125 & 0.003 & {$[0.119,0.130]$} \\
log_K & -0.017 & 0.004 & {$[-0.024,-0.010]$} \\
log_L & -0.051 & 0.007 & {$[-0.064,-0.037]$} \\
log_A & -0.087 & 0.010 & {$[-0.106,-0.067]$} \\
log_M & -0.162 & 0.007 & {$[-0.175,-0.148]$} \\
log_S & -0.422 & 0.012 & {$[-0.445,-0.399]$} \\
log_F & -0.175 & 0.004 & {$[-0.182,-0.167]$} \\
trend & -0.020 & 0.000 & {$[-0.021,-0.019]$} \\
& & & \\
scale & 0.913 & 0.013 & {$[0.886,0.937]$} \\
& & & \\
$\sigma_{v}$ & 0.105 & 0.001 & {$[0.103,0.107]$} \\
$\sigma_{\xi}$ & 0.086 & 0.010 & {$[0.282,0.395]$} \\
$\sigma_{\lambda}$ & 0.340 & 0.029 & \\
\hline
\end{tabular}

and farms become less efficient, with livestock units having the highest effect. There is also evidence that German dairy farms experience technological progress as the frontier moves outwards with time. We also derive the scale elasticity by adding the distance function elasticities with respect to inputs and multiplying them by minus 1 . The scale elasticity is 0.91 , indicating that German dairy farms operate, on average, on the decreasing returns to scale part of the technology ${ }^{11}$.

Moving to the technical efficiency scores, the average value of technical efficiency across farms and years is $0.7^{12}$. This means that farms are producing, on average, $70 \%$ of what is feasible using the observed amount of inputs. The reported score is a bit lower than that reported by Emvalomatis et al. (2011), and can be attributed to the fact that their sample consists of farms which are more specialized in milk production. Turning to the determinants of transformed technical efficiency (s), Table B.4 in Appendix B presents the corresponding parameter estimates. Since $\mathbf{s}$ is a monotonic transformation of efficiency, we are able to interpret the signs but not the magnitude of the estimates on technical efficiency. For this purpose, we derive the marginal effects of the variables in $\mathbf{z}$ on technical efficiency by calculating the derivative of technical

\footnotetext{
${ }^{11}$ Empirically, we observe that studies who have used higher thresholds for farms' milk specialization tend to report higher returns to scale in contrast to those who have applied lower thresholds. For instance, Emvalomatis (2012b) reports a scale elasticity of 0.9 applying a threshold of $50 \%$ milk specialization, while Brümmer (2001) and Emvalomatis et al. (2011) use a threshold of $80 \%$ milk specialization and report a unit elasticity. Based on these empirical facts, the scale elasticity reported in this paper is, as expected, closer to the one of Emvalomatis (2012b).

${ }^{12}$ Technical efficiency is obtained as $\frac{\exp \left\{s_{i t}\right\}}{1+\exp \left\{s_{i t}\right\}}$.
} 
efficiency with respect to the covariates in $\mathbf{z}^{13}$. The marginal effects were calculated at the mean values of the variables and are reported in Table 3.3. All marginal effects are statistically significant.

Table 3.3: Marginal effects of the variables in $\mathbf{z}$ on technical efficiency

\begin{tabular}{lccc}
\hline Variable & Mean & Std. dev. & 95\% Credible Interval \\
\hline size & 0.003 & 0.001 & {$[0.002,0.004]$} \\
specialization & 0.022 & 0.005 & {$[0.013,0.034]$} \\
density & 0.001 & 0.000 & {$[0.001,0.002]$} \\
\hline
\end{tabular}

The marginal effect with respect to size is positive and implies that a 1 unit (100 ESU) increase in size causes a $0.3 \%$ increase in technical efficiency. Hence, bigger economic farm size is associated with higher efficiency levels. This may be due to the fact that large (in economic size) farms are more business/market oriented and use more mental labor that can lead to higher efficiency. This conclusion was highlighted in the work of both Latruffe et al. (2008) and Zhu et al. (2012). Specialization in milk production has a positive marginal effect on technical efficiency, with a $1 \%$ increase in specialization leading to a $2.2 \%$ increase in technical efficiency, as a result of the high experience levels of managers that are engaged in a single production activity. Finally, stock density is also positively related to technical efficiency. A 1 unit (livestock/ha) increase in stock density leads to a $0.1 \%$ increase in technical efficiency, suggesting that farms which adopt intensive production techniques are more technically efficient. This result is consistent with the findings of Alvarez and Corral (2010) in their study on dairy farms.

Turning to the inefficiency persistence $\rho_{i}$ estimates, Figure 3.1 presents the posterior density along with summary statistics ${ }^{14}$. Inefficiency persistence is found to be very high with a mean value across farms of 0.97 , verifying that inefficiency scores are very highly autocorrelated due to the presence of high adjustment costs. This result is very similar to the research of Emvalomatis et al. (2011) in the case of German dairy farms. Furthermore, inefficiency persistence exhibits very little variation around the mean, implying that all farms face high adjustment costs, which lead them to remain inefficient in the future. In terms of the covariates affecting inefficiency persistence, Table B.5 in Appendix B reports the determinants of transformed inefficiency persistence $\mathbf{h}$. However, since the main interest of the paper lies in determining the effect of certain covariates on inefficiency persistence, we derive the marginal effects of the

\footnotetext{
${ }^{13}$ The derivative of technical efficiency with respect to the $l^{\text {th }}$ explanatory variable in $\mathbf{z}$ is given by: $\frac{\partial T E_{i t}}{\partial z_{l}}=\frac{\delta_{l} \times \exp \left\{z_{i}^{\prime} \delta\right\}}{\left(1+\exp \left\{z_{i}^{\prime} \delta\right\}\right)^{2}}$.

${ }^{14}$ The inefficiency persistence parameter $\rho_{i}$ presented in Figure 3.1 is obtained as follows: we first calculate the mean of all the draws for each farm and then plot these means using a kernel density plot.
} 


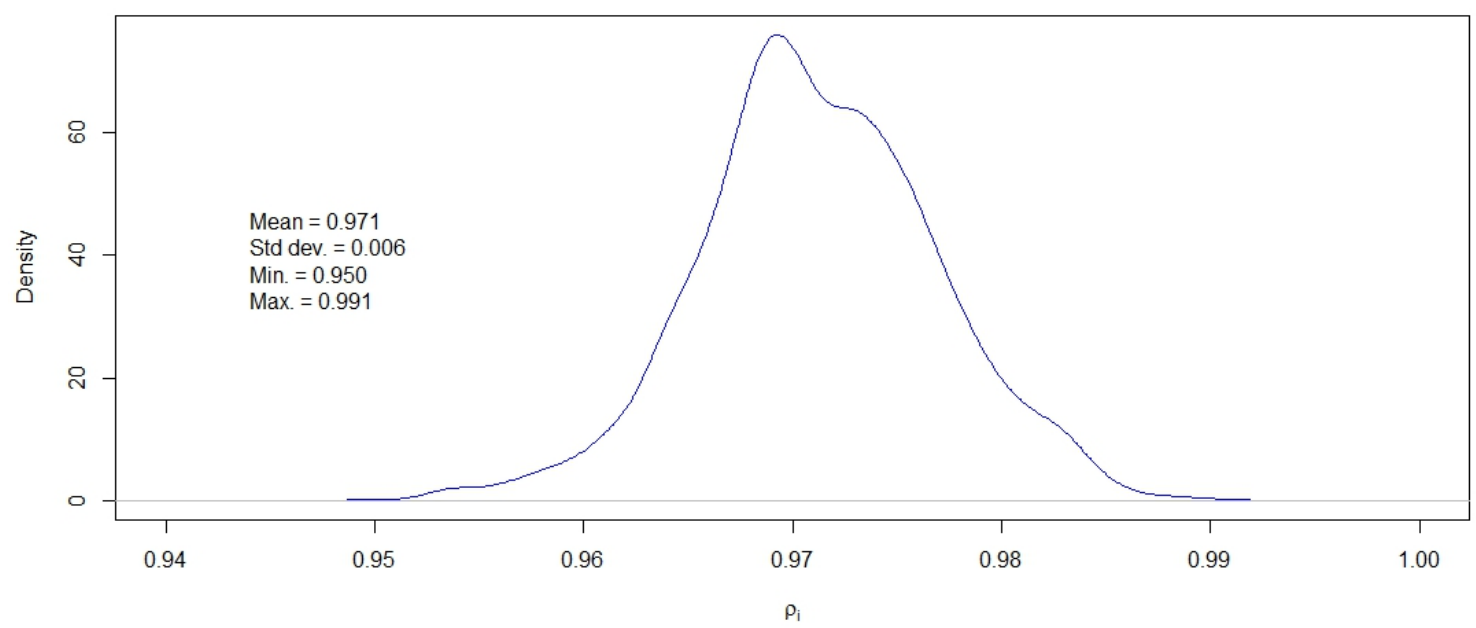

Figure 3.1: Posterior density and summary statistics of inefficiency persistence $\rho_{i}$

variables in $\mathbf{w}$ on inefficiency persistence ${ }^{15}$. These marginal effects were calculated at the mean values of the variables in $\mathbf{w}$ and are presented in Table 3.4. All marginal effects are statistically significant.

Table 3.4: Marginal effects of the variables in $\mathbf{w}$ on inefficiency persistence

\begin{tabular}{lccc}
\hline Variable & Mean & Std. dev. & 95\% Credible Interval \\
\hline subsidies & 0.002 & 0.001 & {$[0.001,0.004]$} \\
age $<65$ & -0.003 & 0.001 & {$[-0.005,-0.001]$} \\
\hline
\end{tabular}

Subsidies have a positive marginal effect on inefficiency persistence with a 1 unit $(1000 /$ ha) increase in subsidies leading to a $0.2 \%$ increase in inefficiency persistence. This result implies that subsidies are most probably not used for investment purposes, but are rather perceived by farmers as an additional source of income. Since farmers themselves do not view subsidies as a credit provision tool for investing in new technologies, their inefficiency persistence increases slightly with subsidies. Furthermore, based on our dataset, governmental intervention does not facilitate the distribution of part of the subsidies for investment purposes, as the share of subsidies for investment to total subsidies is negligible. Hence, external adjustment costs persist as subsidies do not ameliorate access to external funding that can be used for investment in new equipment. Farms whose primary operator is younger than 65 years old exhibit lower inefficiency persistence compared to those managed by older ones. This finding suggests that very old farmers are probably less motivated to adopt state-of-the-art

\footnotetext{
${ }^{15}$ The derivative of inefficiency persistence with respect to the $m^{\text {th }}$ explanatory variable in $\mathbf{w}$ is given by: $\frac{\partial \rho_{i}}{\partial w_{m}}=\frac{\eta_{m} \times \exp \left\{w_{i}^{\prime} \boldsymbol{\eta}\right\}}{\left(1+\exp \left\{w_{i}^{\prime} \boldsymbol{\eta}\right\}\right)^{2}}$.
} 
technologies, as opposed to young or middle-aged farmers, resulting in slightly higher inefficiency persistence. Even though increasing age offers more experience to farmers and a higher ability to manage new resources, as Stefanou and Saxena (1988) and Luh and Stefanou (1993) point out, there exists a point where a lack of motivation to invest in new technologies prevails over a farmer's advantage from experience.

\subsection{Discussion and conclusions}

In this article, we provided a way to include and test for the effect of farm characteristics on inefficiency persistence. Previous studies on dynamic stochastic frontier analysis have taken for granted the fact that high adjustment costs result in high inefficiency persistence, without allowing for farm-specific factors to influence this persistence. Our model, aside from testing the hypothesis that inefficiency is highly autocorrelated through time, also allows us to test whether a set of farm-specific characteristics have an effect on inefficiency persistence. In order to quantify the persistence of inefficiency, we specify an autoregressive process on transformed technical efficiency, while the inefficiency persistence parameter is also transformed to allow for farm-specific effects to have an impact on it. The model is applied to an unbalanced micro-panel of German dairy farms that covers a period from 1999 to 2009. Bayesian techniques are used for the estimation.

The model's results are quite similar when compared with different efficiency specifications such as those of Battese and Coelli (1992) and Emvalomatis et al. (2011); this certainly strengthens the robustness of our model. Our results suggest a high degree of inefficiency persistence, which implies that inefficiency does not disappear with time due to the presence of high adjustment costs. This result is in line with the adjustment cost hypothesis described by Penrose (1959), which suggests that high adjustment costs provide farmers with an incentive to remain partly inefficient in the short-run. In terms of the determinants of inefficiency persistence, despite being statistically significant, their economic significance is negligible. However, one could argue that since inefficiency persistence lacks units of measurement (it is an elasticity that measures the ratio of efficiency to inefficiency that is carried from one period to the next), a more reasonable approach would be to focus on the sign of the effect rather than its magnitude. Furthermore, the lack of variation in our financial indicators and the lack of additional potential variables such as education or the presence of a successor, did not allow as to examine the impact of further important covariates that could explain inefficiency persistence. However, this paper has presented a way to empirically look for the factors that may influence this persistence, opening an array

for future research. 
Subsidies are shown to not relieve the external adjustment costs that farms face. They rather act as an additional source of income and not as a source of credit that can be used for technology adoption purposes. Faster adjustment can be achieved if subsidies are provided on the basis of investment in new technologies and not as a compensation for income loss. Besides, if subsidies are provided for investment purposes, an income gain is already implied as a result of increased productivity related to the use of advanced technology. However, considering the variety of subsidies that dairy farmers receive, one could expect different effects on inefficiency persistence for different types of subsidies. Hence, a more analytical tool to assess the impact of subsidies on inefficiency persistence would be to split them into multiple subcategories. Nevertheless, given that inefficiency persistence is time-invariant, this approach would be rather problematic as we would introduce significant variation over time. For instance, decoupled payments would vary significantly over time given that they were introduced in the middle of the time span that our dataset considers.

Furthermore, despite being unable to directly test the theory of Stefanou and Saxena (1988) and Luh and Stefanou (1993) by modelling the different stages of the farm's life cycle, our study revealed that technology adoption also depends on farmers' perceptions, as these evolve with ageing. Our results confirm that very old farmers are less keen on adopting new technologies compared to their younger counterparts, presumably due to a lack of motivation. This result does not imply that very old farmers invest less than younger ones, but rather suggests that they invest more in the replacement of existing capital and not in new equipment (productive investment) that could make them more competitive in the long-run. Furthermore, the fact that $25 \%$ of farms in our sample are managed by primary operators that are, on average, 65 years old or above, provides a warning that several German dairy farms may be left behind in terms of technology adoption. Hence, incentives should be provided to young people to undertake the management of farms, as our results reveal that they are more motivated to adopt state-of-the-art technologies that can increase the productivity of farms and make them more competitive. 


\title{
Chapter 4
}

\section{Productivity growth under a dynamic inefficiency specification: the case of German dairy farms}

\begin{abstract}
A dynamic inefficiency specification is used to measure and decompose total factor productivity growth of German dairy farms for the period 2001-2009. The average total factor productivity growth rate is estimated approximately at $2.4 \%$ with high variation observed towards the end of the study period. Given that this period is characterized by high volatility in milk prices, the dynamic inefficiency specification is able to capture the associated sharp efficiency and total factor productivity growth changes. The dynamic inefficiency model is favored by the data when compared with a model that imposes a very restrictive time structure on inefficiency, and a model that does not impose any time structure on inefficiency scores.
\end{abstract}

Keywords: productivity growth; German dairy farms; dynamic inefficiency

JEL Classification: C11, C23, D24, Q12 


\subsection{Introduction}

The evaluation of the competitiveness of a sector has traditionally been based on the measurement of TFP growth, defined as the ratio of output growth rate to input growth rate. In agriculture, TFP growth is used as an indicator of the ability of farms to generate high income and factor employment levels while being exposed to both domestic and international competition (Newman and Matthews, 2007). High productivity growth is, therefore, essential to assure that a country's agricultural sector survives competitive pressure from abroad but also from other sectors within the country. The critical role that TFP growth plays in determining whether a sector will survive or perish in a competitive environment requires precise estimates to be obtained. Given that TFP growth is a dynamic concept, the modelling approach followed should be able to capture potential shocks that may be due to bad weather conditions, pest outbreaks, or high price volatility. For instance, in the specific context of dairy farms, Germany (as well as most EU countries), has experienced large changes in milk price during the first decade of the $21^{\text {st }}$ century. More specifically, milk prices have steeply increased from 2006 to 2008 , reaching a peak of $35.01 € / 100 \mathrm{~kg}$ in 2008 , while in 2009 they sunk to $25.25 € / 100 \mathrm{~kg}$ (EUROSTAT, 2016). All the aforementioned price changes make German dairy farms an interesting case for measuring changes in farm efficiency and, more generally, TFP growth.

Detecting efficiency changes that can result in TFP growth volatility depends on the specification of inefficiency. In a parametric setting, measurement and decomposition of TFP growth relies on the estimation of the production frontier using the technique of SFA, introduced by Aigner et al. (1977) and Meeusen and van den Broeck (1977). The most challenging task while measuring the efficiency of the decision making units concerns the assumptions made for the inefficiency component. In a crosssectional setting, one should only be concerned with the distributional assumptions made. However, when panel data are available, the assumptions of time-invariant versus time-varying inefficiency become the focus of attention. Since the assumption of time-invariant inefficiency is very restrictive, several models have been developed that relax this assumption. For instance, Cornwel et al. (1990) and Kumbhakar (1990) specified inefficiency as a quadratic function of time, while Battese and Coelli (1992) assumed that time-invariant inefficiency is scaled by a simple function of time. Specification of inefficiency as a quadratic function of time turns out to be more flexible than the Battese and Coelli model, which allows inefficiency to be either always increasing or decreasing with the passage of time. However, parametric efficiency studies that have attempted to measure and decompose TFP growth have mostly considered the Battese and Coelli (1992) approach. For instance, Newman and Matthews (2007) and 
Emvalomatis (2012b) used the aforementioned inefficiency specification to measure and decompose the productivity growth of Irish agricultural enterprises and German dairy farms, respectively. This is primarily due to the fact that the approach proposed by Cornwel et al. (1990) requires a large number of parameters to be estimated and consistency can only be met if the time dimension of the panel goes to infinity. On the other hand, the model of Kumbhakar (1990) may be problematic as the identification of two parameters from a latent process is questionable. Furthermore, the major flaw of all the aforementioned specifications is that inefficiency is considered to be a deterministic function of time and can't capture abrupt shocks in the environment in which firms operate. This implies that these modelling approaches may be unable to capture potential changes in efficiency and TFP growth that could result from the steep milk price changes mentioned above.

An alternative specification for time-varying inefficiency that does not impose any time structure on inefficiency assumes that, for each time period, inefficiency is a random draw from a one-sided distribution. This specification offers also the option to examine the potential drivers of inefficiency by allowing the mean of the distribution to be a function of firm-specific characteristics. For instance, Battese and Coelli (1995) assumed that for each time period, inefficiency is a random draw from a truncated normal distribution, while Koop et al. (1997) use an exponential distribution, as it behaves better when Bayesian techniques are considered. In the productivity measurement literature, this approach has been used by Brümmer et al. (2002), Alvarez and Corral (2010), and Sauer and Latacz-Lohmann (2015), who evaluated the productive performance of dairy farms. Meanwhile, Cechura et al. (2016) used it to perform TFP country comparisons for the European dairy sector. Such a specification, in contrast to the Battese and Coelli (1992) model that imposes a very restrictive time structure of inefficiency, has the potential of capturing time-specific shocks in firmlevel efficiency. However, it may also produce very erratic results due to the complete absence of a time structure for inefficiency.

A more flexible specification for the inefficiency component that does not lie on the extremes of either imposing a very restrictive or a non-existing time structure on inefficiency, is one that allows for autocorrelation in firm-specific efficiency scores. This specification is justified on the grounds of the adjustment cost theory, which maintains that it is costly for decision makers to rapidly adjust the level of quasi-fixed factors of production (i.e. capital) to their optimal levels (Penrose, 1959). Costly adjustment implies that inefficient firms may find it optimal to remain inefficent in the short-run, resulting in persistence of their inefficiency over time (Emvalomatis et al., 2011). The first study that attempted to account for persistence shocks in firms' efficiency is the study of Ahn and Sickles (2000), who specified an autoregressive process on firm- 
specific efficiency scores. To overcome the flaw of specifying an autoregressive process on a non-negative variable, Tsionas (2006) has specified an autoregressive process on transformed efficiency that can take any value on the real line. Subsequent studies on dynamic efficiency have followed the latter approach, with minor adjustments concerning the way that efficiency is transformed (Emvalomatis et al., 2011; Emvalomatis, 2012a; Galán et al., 2015). All studies find strong autocorrelation in efficiency scores, adding credibility to the adjustment cost theory. In contrast to the restrictive time structure for inefficiency that the Battese and Coelli (1992) model assumes, the dynamic efficiency specification offers a less restrictive time structure that can capture abrupt changes in firm-level efficiency and TFP growth. On the other hand, since it does not allow for the time evolution of efficiency scores to be completely arbitrary, the results should be more stable compared to models that do not impose any time structure on inefficiency scores.

The main objective of this paper is to measure and decompose TFP growth of German dairy farms for the period 2001-2009, while accounting for persistent shocks in farm-level efficiency. Given that the time period under consideration is characterized by high price volatility, the dynamic efficiency specification could reveal abrupt changes in efficiency and TFP growth as it can capture (persistent) time-specific efficiency shocks. The results from the dynamic efficiency specification are compared with those from a model that imposes the time structure of Battese and Coelli (1992), and a model that imposes no time structure on efficiency. Additionally, formal model comparisons are performed to infer which of the models fit the data better. The remainder of the paper proceeds as follows: the next section describes the modelling approach, while Section 4.3 provides details on the estimation of the models. Section 4.4 describes the data, and Section 4.5 presents and discusses the results. Finally, Section 4.6 offers some conclusions.

\subsection{Modelling approach}

\subsubsection{Distance function and efficiency}

We use an output distance function to measure efficiency in a multi-output production technology. Assuming that a vector of inputs $\tilde{\mathbf{x}} \in R_{+}^{N}$ is used to produce a vector of outputs $\tilde{\mathbf{y}} \in R_{+}^{M}$, the output distance function is defined as:

$$
D_{o}(\tilde{\mathbf{x}}, \tilde{\mathbf{y}}, t)=\min \left\{\theta: \frac{\tilde{\mathbf{y}}}{\theta} \text { can be produced by } \tilde{\mathbf{x}} \text { in period } t\right\}
$$


The output distance function assumes values in the unit interval and the locus of points for which $D_{o}(\tilde{\mathbf{x}}, \tilde{\mathbf{y}}, t)=1$ defines the boundary of the production possibilities set. The technical efficiency of a firm $i$ in period $t$ is then defined as:

$$
\mathrm{TE}_{i t}=D_{o}\left(\tilde{\mathbf{x}}_{i t}, \tilde{\mathbf{y}}_{i t}, t\right)
$$

Taking the logarithm of both sides, imposing the condition of linear homogeneity in the outputs of the distance function, and appending an error term, all leads to the following econometric version of the output distance function:

$$
-\log \tilde{y}_{i t}^{m}=\log D_{o}\left(\tilde{\mathbf{x}}_{i t}, \frac{\tilde{\mathbf{y}}_{i t}}{\tilde{y}_{i t}^{m}}, t\right)+v_{i t}-\log \left(T E_{i t}\right)
$$

where $\tilde{y}_{i t}^{m}$ is the normalizing output, and $v_{i t}$ is a linear error term that accounts for statistical noise. Letting $y_{i t}$ be the dependent variable in equation (4.3) and the logarithm of the distance function a linear function of its arguments, the estimable form of the distance function can be written as:

$$
y_{i t}=\mathbf{x}_{i t}^{\prime} \boldsymbol{\beta}+v_{i t}-\log \left(T E_{i t}\right), \quad v_{i t} \sim \mathscr{N}\left(0, \sigma_{v}^{2}\right)
$$

where $y_{i t}$ is the negative value of the logarithm of the normalizing output, $\mathbf{x}_{i t}^{\prime}$ is a vector of time-varying covariates, $\boldsymbol{\beta}$ is a vector of parameters to be estimated and $T E_{i t}$ is the technical efficiency of firm $i$ in time $t$.

\subsubsection{Alternative efficiency specifications}

The most popular efficiency specification in a static context and when panel data are available was introduced by Battese and Coelli (1992). Following the conventional way that this specification is presented in the literature, it would be convenient to define $u_{i t}=-\log T E_{i t}$. The structure proposed by Battese and Coelli has the following form:

$$
u_{i t}=\gamma(t) \cdot u_{i}
$$

where $u_{i}$ is the time-invariant inefficiency component that is assumed to follow a onesided distribution and $\gamma(t)=\exp \{\eta(T-t)\}$. In our case, we assume that $u_{i}$ follows an exponential distribution with rate parameter $\lambda$. The popularity of this model stems from the fact that it relaxes the assumption of time-invariant inefficiency by estimating only one additional parameter $(\eta)$. However, it imposes a very restrictive time structure as inefficiency can either be only increasing or decreasing, depending on the sign of $\eta$. Additionally, it does not allow for time-specific shocks to be taken 
into account as inefficiency is specified as a deterministic function of time.

The second model that we consider was used by Koop et al. (1997) and assumes that for each time-period inefficiency is a random draw from an exponential distribution with rate parameter $\lambda$ :

$$
u_{i t} \sim \operatorname{Exp}\left(\lambda_{i t}\right)
$$

The following relationship is assumed for $\lambda_{i t}$ :

$$
\lambda_{i t}=e^{\mathbf{w}_{i t}^{\prime} \gamma}
$$

where $\mathbf{w}$ is a vector of time-varying covariates and $\gamma$ is a vector of parameters to be estimated. Note that positive coefficients with respect to $\mathbf{w}$ imply a positive impact on $\lambda$ and, therefore, a negative impact on inefficiency. In contrast to the Battese and Coelli model, this specification does not impose any time structure on inefficiency and could therefore capture time-specific shocks on farm-level efficiency. However, by allowing for the time evolution of inefficiency to be completely random, it may produce very erratic results. From now on, this model will be called the "unstructured" model.

Moving to the dynamic efficiency specification, we specify a dynamic stochastic frontier by allowing for firm-specific efficiency scores to follow an autoregressive process. The inverse of the logistic function is used to transform $T E_{i t}$ so that we project it from the unit interval to the real line. More precisely, we define $s_{i t}=\log \left(\frac{T E_{i t}}{1-T E_{i t}}\right)$ as the latent-state variable and assume the following autoregressive process on $s_{i t}$ :

$$
\begin{gathered}
s_{i t}=\mathbf{z}_{i}^{\prime} \boldsymbol{\delta}+\rho s_{i, t-1}+\xi_{i t}, \quad \xi_{i t} \sim \mathscr{N}\left(0, \sigma_{\xi}^{2}\right) \\
s_{i 1}=\frac{\mathbf{z}_{i}^{\prime} \boldsymbol{\delta}}{1-\rho}+\xi_{i 1}, \quad \xi_{i 1} \sim \mathscr{N}\left(0, \sigma_{\xi 1}^{2}\right)
\end{gathered}
$$

where $\mathbf{z}$ is a vector of time-invariant covariates, $\boldsymbol{\delta}$ is a vector of parameters to be estimated, $\xi_{i t}$ is a two-sided error term that accounts for statistical noise and $\sigma_{\xi 1}^{2}=$ $\frac{\sigma_{\xi}^{2}}{1-\rho^{2}}$, due to stationarity. Stationarity of the $\mathbf{s}$ series assures that the expected value of $\mathbf{s}$ does not diverge to either positive or negative infinity and therefore, technical efficiency will not approach unity or zero. Furthermore, based on this specification, $\rho$ is an elasticity that measures the percentage change in the efficiency to inefficiency ratio that is carried from one period to the next. This inefficiency specification may be able to capture (persistent) time-specific efficiency shocks, as it does not specify a very restrictive time structure on inefficiency. Additionally, it could produce more reasonable results compared to models that allow the time evolution of efficiency scores to be completely random. 


\subsubsection{Measurement and decomposition of TFP growth}

After estimating the three alternative models, we can calculate and decompose TFP growth following Orea (2002) and Lovell (2003), who have extended the Malmquist productivity index introduced by Caves et al. (1982). The TFP growth rate is defined as the weighted growth rate of outputs minus the weighted growth rate of inputs, and can be written as:

$$
\frac{d \log T F P}{d t}=\sum_{m=1}^{M} \frac{\partial \log D_{0}}{\partial \log y_{m}} \hat{y}_{m}-\sum_{n=1}^{N} \frac{\epsilon_{n}}{\epsilon} \hat{x}_{n}
$$

where $\epsilon_{n}=\partial \log D_{0} / \partial \log x_{n}, \epsilon$ is the scale elasticity multiplied by minus 1 and a hat over a variable indicates growth rate. The weights that we use for outputs are the corresponding distance elasticities, and for inputs, the shares of distance elasticities in scale elasticity. Taking the logarithm of both sides of (4.2), totally differentiating with respect to time, and substituting in (4.10) yields:

$$
\frac{d \log T F P}{d t}=\frac{d \log T E}{d t}-\frac{\partial \log D_{0}(\mathbf{x}, \mathbf{y}, t)}{d t}-(\epsilon-1) \sum_{n=1}^{N} \frac{\epsilon_{n}}{\epsilon} \hat{x}_{n}
$$

Based on equation (4.11), we decompose productivity growth into three components: (i) technical efficiency change $\left(\frac{d \log T E}{d t}\right)$, (ii) technical progress $\left(-\frac{\partial \log D_{0}(\mathbf{x}, \mathbf{y}, t)}{d t}\right)$, and (iii) scale effect $\left(-(\epsilon-1) \sum_{n=1}^{N} \frac{\epsilon_{n}}{\epsilon} \hat{x}_{n}\right)$.

\subsection{Estimation approach}

\subsubsection{Empirical specification}

As mentioned before, calculation and decomposition of TFP growth is based on an output distance function. The use of a distance function is justified on the grounds of the multi-output (milk, meat etc.) nature of German dairy farms' production technology. We use an output distance function instead of an input distance function for the following reasons: (i) despite the restrictions on milk production from the milk quota system, German dairy farms can lease and purchase milk quota, (ii) given that the dynamic efficiency specification assumes that inputs like capital are considered as quasi-fixed, an input distance function may be an inappropriate specification tool. A translog specification of the output distance function is used as, in contrast to the Cobb-Douglas functional form, the translog is more flexible because it does not impose restrictions on substitution possibilities between inputs and outputs. Hence, the output distance function is specified as translog in inputs $(\boldsymbol{x})$, outputs $(\boldsymbol{y})$, and time 
trend $(t)$. Using the estimable form of equation (4.3), the output distance function is written as:

$$
\begin{aligned}
-\log y_{i t}^{m} & =\alpha_{0}+\sum_{k} \alpha_{k} \log x_{i t}^{k}+\sum_{l} \beta_{l} \log \left(\frac{y_{i t}^{l}}{y_{i t}^{m}}\right) \\
& +\frac{1}{2} \sum_{k} \sum_{r} \alpha_{k r} \log x_{i t}^{k} \log x_{i t}^{r} \\
& +\frac{1}{2} \sum_{l} \sum_{m} \beta_{l m} \log \left(\frac{y_{i t}^{l}}{y_{i t}^{m}}\right) \log \left(\frac{y_{i t}^{l}}{y_{i t}^{m}}\right) \\
& +\frac{1}{2} \sum_{k} \sum_{l} \zeta_{k l} \log x_{i t}^{k} \log \left(\frac{y_{i t}^{l}}{y_{i t}^{m}}\right) \\
& +\mu_{1} t+\mu_{2} t^{2}+\sum_{k} \gamma_{k} t \log x_{i t}^{k} \\
& +\sum_{l} \phi_{l} t \log \left(\frac{y_{i t}^{l}}{y_{i t}^{m}}\right)+v_{i t}-\log \left(T E_{i t}\right)
\end{aligned}
$$

A time trend is included in the specification to capture technological progress, while its interaction with outputs and inputs allows it to be nonneutral. Prior to estimation, the data for all outputs and inputs are normalized by their respective geometric means, so that the parameters associated with the first-order terms are directly interpretable as distance function elasticities, evaluated at the geometric mean of the data.

\subsubsection{Bayesian inference}

Bayesian techniques are used to estimate the three alternative models. For the Battese and Coelli (1992) model, we gather all structural parameters in a vector $\boldsymbol{\theta}_{1}=$ $\left[\boldsymbol{\beta}, \sigma_{v}, \eta, \lambda\right]$. The posterior distribution of the model can be written as follows:

$$
\pi\left(\boldsymbol{\theta}_{1},\left\{\mathbf{u}_{\mathbf{i}}\right\} \mid \mathbf{y}, \mathbf{X}\right) \propto p\left(\mathbf{y},\left\{\mathbf{u}_{i}\right\} \mid \boldsymbol{\theta}_{1}, \mathbf{X}\right) \times p\left(\boldsymbol{\theta}_{1}\right)
$$

where $\mathbf{y}$ is the stacked vector of the dependent variable over years and farms, and $\mathbf{X}$ is the matrix of variables in equation (4.4). The term $p\left(\mathbf{y},\left\{\mathbf{u}_{i}\right\} \mid \boldsymbol{\theta}_{1}, \mathbf{X}\right)$ corresponds to the complete data likelihood of the model, and $p\left(\boldsymbol{\theta}_{1}\right)$ is the prior density of the parameters. The following priors are imposed on the parameters:

- A multivariate normal density is used for the prior density of the vector $\boldsymbol{\beta}$. Prior means are set equal to zero while the prior covariance matrix is diagonal with a value of 1000 on the diagonal entries. This prior is conjugate.

- An Inverse-Gamma prior is used for $\sigma_{v}^{2}$ since this prior is conjugate. The shape 
and scale hyper-parameters are both set equal to 0.001 .

- A normal prior is used for the $\eta$ parameter with prior mean equal to zero and prior variance equal to 0.1 .

- A Gamma prior is used for the rate parameter $\lambda$. The typical approach is to set the shape parameter equal to unity and the scale parameter equal to $-\log \left(r^{*}\right)$, where $r^{*}$ is equal to the prior median efficiency (van den Broeck et al., 1994).

For the unstructured model, all structural parameters are gathered in a vector $\boldsymbol{\theta}_{2}=\left[\boldsymbol{\beta}, \sigma_{v}, \boldsymbol{\gamma}\right]$. The posterior density of this model is as follows:

$$
\pi\left(\boldsymbol{\theta}_{2},\left\{\mathbf{u}_{\mathbf{i}}\right\} \mid \mathbf{y}, \mathbf{X}, \mathbf{W}\right) \propto p\left(\mathbf{y},\left\{\mathbf{u}_{i}\right\} \mid \boldsymbol{\theta}_{2}, \mathbf{X}, \mathbf{W}\right) \times p\left(\boldsymbol{\theta}_{2}\right)
$$

where $p\left(\mathbf{y},\left\{\mathbf{u}_{i}\right\} \mid \boldsymbol{\theta}_{2}, \mathbf{X}, \mathbf{W}\right)$ is the complete data likelihood of the model, $\mathbf{W}$ is the matrix of covariates in equation (4.7), and $p\left(\boldsymbol{\theta}_{2}\right)$ corresponds to the prior density of the parameters. The following priors are specified for the parameters:

- We impose a multivariate normal prior density for the vector $\boldsymbol{\beta}$. Prior means equal to zero, and the prior covariance matrix is diagonal with the value of 1000 on the diagonal entries. This is a conjugate prior.

- We use an Inverse-Gamma prior for $\sigma_{v}^{2}$ as this prior is conjugate. Both shape and scale hyper-parameters are set equal to 0.001 .

- A multivariate normal density is imposed for the prior density of the vector $\boldsymbol{\gamma}$. Prior means are set equal to zero and the diagonal entries of the diagonal covariance matrix are set equal to 1000 . This is a non-conjugate prior.

For the dynamic efficiency model, we define $\mathbf{s}_{i}$ to be a $T \times 1$ vector of the latentstate variable of the transformed technical efficiency for firm $i$, where $T$ represents time periods, and we collect all structural parameters to be estimated in a vector $\boldsymbol{\theta}_{3}=\left[\boldsymbol{\beta}, \sigma_{v}, \boldsymbol{\delta}, \sigma_{\xi}, \rho\right]^{\prime}$. The model's posterior distribution can be written as follows:

$$
\pi\left(\boldsymbol{\theta}_{3},\left\{\mathbf{s}_{\mathbf{i}}\right\} \mid \mathbf{y}, \mathbf{X}, \mathbf{Z}\right) \propto p\left(\mathbf{y},\left\{\mathbf{s}_{i}\right\} \mid \boldsymbol{\theta}_{3}, \mathbf{X}, \mathbf{Z}\right) \times p\left(\boldsymbol{\theta}_{3}\right)
$$

where $p\left(\mathbf{y},\left\{\mathbf{s}_{i}\right\} \mid \boldsymbol{\theta}_{3}, \mathbf{X}, \mathbf{Z}\right)$ is the complete data likelihood, $\mathbf{Z}$ is the matrix of covariates in equations (4.8-4.9) and and $p\left(\boldsymbol{\theta}_{3}\right)$ is the prior density of the parameters. The priors that we impose on the parameters are as follows:

- A multivariate normal density is used for the prior density of the vector $\boldsymbol{\beta}$. Prior means are set equal to zero. The prior covariance matrix is diagonal with diagonal entries equal to 1000 . The prior is conjugate. 
- An Inverse-Gamma prior is used for $\sigma_{v}^{2}$. The shape and scale hyper-parameters are set equal to 0.001 . This prior is conjugate.

- A multivariate normal density is used for the prior density of the vector $\boldsymbol{\delta}$. As in the case of the $\boldsymbol{\beta}$ priors, prior means are set equal to zero and the diagonal entries of the diagonal covariance matrix are set equal to 1000. The prior is again conjugate.

- An Inverse-Gamma prior is used for $\sigma_{\xi}^{2}$ as this is conjugate. The shape and scale hyper-parameters are set equal to 0.1 and 0.01 respectively.

- A Beta prior is used for the inefficiency persistence parameter $\rho$ to restrict it in the unit interval $(\rho \sim \operatorname{Beta}(\alpha, \beta))$. The prior hyper-parameters $\alpha$ and $\beta$ are set equal to 4 and 2 respectively. This prior is non-conjugate.

The posterior moments of the three models' parameters are estimated using MCMC techniques (Koop et al. (1995) illustrate an application of MCMC in stochastic frontier models). Drawing samples from the posterior for the latent-state variables representing efficiency requires data augmentation techniques (see Tanner and Wong, 1987). Finally, Metropolis-Hastings updates are used for $\gamma, \mathbf{s}_{i}$, and $\rho$, as their complete conditionals do not belong to any known distributional family.

\subsubsection{Log-marginal likelihood and Bayes factors}

We compare the three alternative models using Bayes factors (Kass and Raftery, 1995). Considering two competing models $\mathscr{M}_{1}$ and $\mathscr{M}_{2}$, their relative posterior probability can be written as:

$$
\frac{p\left(\mathscr{M}_{1} \mid \mathscr{D}\right)}{p\left(\mathscr{M}_{2} \mid \mathscr{D}\right)}=\frac{p\left(\mathscr{D} \mid \mathscr{M}_{1}\right)}{p\left(\mathscr{D} \mid \mathscr{M}_{2}\right)} \frac{\operatorname{Prob}\left(\mathscr{M}_{1}\right)}{\operatorname{Prob}\left(\mathscr{M}_{2}\right)}
$$

where $\mathscr{D}$ represents the observed data, $p\left(\mathscr{D} \mid \mathscr{M}_{j}\right)$ is the density of the data given $\mathscr{M}_{j}$, and $\operatorname{Prob}\left(\mathscr{M}_{j}\right)$ is the prior probability of $\mathscr{M}_{j}$ being the true model. The marginal density of $p\left(\mathscr{D} \mid \mathscr{M}_{j}\right)$ with respect to the latent-state variables and parameters is written as:

$$
p\left(\mathscr{D} \mid \mathscr{M}_{j}\right)=\int p\left(\mathscr{D} \mid \theta_{j}, \mathscr{M}_{j}\right) \pi\left(\theta j \mid \mathscr{M}_{j}\right) d \theta_{j}
$$

where $\theta_{j}$ is the vector of parameters for model $j$ and $\pi\left(\theta_{j} \mid \mathscr{M}_{j}\right)$ is the prior density of $\theta_{j}$ under model $j$. The logarithm of the marginal density of the data with respect to the latent-state variables and parameters can be obtained using the Laplace-Metropolis estimator (Lewis and Raftery, 1997):

$$
\log \left[p\left(\mathscr{D} \mid \mathscr{M}_{j}\right)\right] \approx \frac{P}{2} \log [2 \pi]+\frac{1}{2} \log \left[\left|\mathbf{H}^{*}\right|\right]+\log \pi\left[\theta_{j}^{*}\right]+\log p\left[\mathscr{D} \mid \theta_{j}^{*}\right]
$$


where $P$ is the dimension of $\theta_{j}, \theta_{j}^{*}$ is the MCMC estimator of $\theta_{j}$ that maximizes the integrated likelihood $p\left(\mathscr{D} \mid \theta_{j}^{*}\right)$, and $\mathbf{H}$ is the Hessian of the integrated likelihood evaluated at $\theta_{j}^{*}$. Following the conventional practice of placing equal prior model probabilities, model comparison reduces to calculating Bayes factors. Assuming that the set of models considered is exhaustive, posterior model probabilities can be obtained using the posterior odds ratio and the fact that probabilities sum to unity.

\subsection{Data}

The data used in this application are obtained from the FADN ${ }^{1}$. The dataset contains farm-level information on physical units such as outputs and inputs, economic and financial data such as product-specific production costs and debts, geographical information, as well as characteristics relating to the farms' primary operators. The part of the dataset that is used here contains such information for German dairy farms and covers the period from 2001 to 2009. This study focuses on farms primarily engaged in dairy production, and for this purpose we have selected farms whose revenue from sales of cow's milk, beef, and veal comprise at least $66 \%$ of their total revenues, for every year the farm is observed. This is the classification that FADN uses to define specialized dairy farms. Furthermore, due to the dynamic nature of our modelling approach, we retained farms that are observed for nine consecutive years. The final dataset consists of a balanced panel of 706 farms with a total of 6,354 observations.

Two outputs are specified in the output distance function represented by equation (4.3):

1. Deflated revenues from sales of cow's milk (milk)

2. Deflated revenues plus change in valuation of beef and veal, pigmeat, sheep and goats, and poultry meat, plus deflated revenues from sales of other livestock and products (other)

The reported revenues are deflated with price indices obtained from EUROSTAT, using 2005 as the base year. Milk was deflated using its own price index, while, an aggregate price index of agricultural products was used to deflate the rest of the outputs.

Six input categories are specified in equation (4.3):

1. Buildings and machinery $(\mathrm{K})$ are measured in deflated book value. For each input subcategory (buildings and machinery), its own price index was retrieved from EUROSTAT and a Törnqvist index was constructed. The total reported value was then deflated using the Törnqvist index.

\footnotetext{
${ }^{1}$ Data source: EU-FADN - DG AGRI.
} 
2. Total labor (L) is measured in man-hours and consists of both family and hired labor.

3. Total utilized agricultural area (A) is measured in hectares and includes owned and rented land.

4. Materials and services (M) are measured in deflated value. This category of input is composed of ten other subcategories: seeds and plants, fertilizers, crop protection, energy, other livestock-specific costs, other crop-specific costs, forestryspecific costs, feed for pigs and poultry, contract work, and other direct inputs. For each input subcategories, the relevant price indices were obtained from EUROSTAT and a Törnqvist index was constructed. The total reported value was then deflated using the Törnqvist index.

5. Total livestock units $(\mathrm{S})$ is measured in livestock units and consists of the total number of equines, cattle, sheep, goats, pigs, and poultry of the holding.

6. Purchased feed $(\mathrm{F})$ is measured in deflated value. It includes concentrated feedingstuffs and coarse fodder for grazing stock. Feed produced within the farm is excluded. The variable was deflated based on its own price index obtained from EUROSTAT.

Dummy variables for eastern, western, northern, and southern (base category) Germany are included to capture differences in technology and climatic conditions across different regions in Germany. The $\mathbf{w}$ vector in equation (4.7) and the $\mathbf{z}$ vector in equations $(4.8-4.9)$ consist of the following variables: farms' economic size measured in hundreds of ESU, farms' specialization in milk production measured as the ratio of revenues from milk production to total revenues and farms' stock density, defined as the volume of livestock units per hectare. Operators that own large (in economic size) farms are expected to attain higher technical efficiency levels due to their higher managerial effort (Latruffe et al., 2008; Zhu et al., 2012). Higher specialization in milk production can increase a farm's efficiency due to farmers' higher level of experience when engaging in single production activities (Zhu et al., 2012; Sauer and LataczLohmann, 2015). Finally, higher stock density that is associated with the adoption of intensive production techniques can have a positive contribution on farms' technical efficiency (Alvarez and Corral, 2010). Imposing stationarity on the s series in equation (4.9) requires that the covariates in $\mathbf{z}$ are specified as time-invariant ${ }^{2}$. Summary statistics of the model's variables appear in Table 4.1.

\footnotetext{
${ }^{2}$ Variation of the variables over time is negligible. We derive farm-specific coefficients of variation for size, specialization, and stock density by dividing each farm's standard deviation in the respective variable by the farm's mean taken over time. Figure C.1 in Appendix C presents histograms of the coefficient of variation for size, specialization and stock density.
} 
Table 4.1: Summary statistics of the model's variables

\begin{tabular}{lcccc}
\hline Variable & Mean & Std. dev & $\mathbf{5 \%}$ & $\mathbf{9 5 \%}$ \\
\hline Revenues from cows' milk $(1,000 €)$ & 104.15 & 117.02 & 29.14 & 257.34 \\
Revenues from other output $(1,000 €)$ & 29.11 & 39.54 & 5.25 & 73.19 \\
Capital (1,000€) & 169.55 & 152.18 & 29.21 & 418.52 \\
Labor (1,000 man-hours) & 3.29 & 3.16 & 1.80 & 5.47 \\
Land (hectares) & 59.34 & 58.77 & 18.47 & 140.26 \\
Materials (1,000€) & 45.83 & 51.03 & 13.00 & 108.57 \\
Livestock (livestock units) & 92.58 & 83.59 & 32.69 & 212.65 \\
Purchased feed (1,000€) & 19.47 & 28.94 & 1.89 & 54.29 \\
Size (100 ESU) & 0.75 & 0.79 & 0.25 & 1.69 \\
Specialization (milk revenues/total revenues) & 0.73 & 0.11 & 0.54 & 0.89 \\
Density (livestock units/hectare) & 2.03 & 0.66 & 1.13 & 3.19 \\
\hline
\end{tabular}

\subsection{Results and discussion}

The results reported in this section are based on 120,000 draws from the posterior distribution of the parameters for each model. A burn-in of 50,000 iterations is used to remove the influence of the initial values, while every one in ten draws is retained to mitigate potential autocorrelation of the draws. The full set of results from the three alternative models is provided in Appendix C in Tables C.1, C.2 and C.3. Table 4.2 reports the parameter estimates of the first-order terms, and the rest of the parameters from the three alternative models ${ }^{3}$.

The point estimates of the distance function elasticities across the three specifications differ slightly in magnitude. This results in different estimates for the scale elasticities (RTS). However, the distance elasticities have the expected signs and their 95\% credible intervals do not include zero (only the elasticity with respect capital in the Battese and Coelli (1992) model is significant at the $90 \%$ credible interval $)^{4}$. The positive sign of the distance function elasticity with respect to other output means that a potential increase in output, other than milk, will cause an increase in the distance function and farms will move closer to the frontier. On the other hand, the negative signs of the distance function elasticities with respect to inputs imply that increases in inputs push the frontier outwards and farms become less efficient. All three models suggest that German dairy farms experience technological progress since the frontier moves outwards with the passage of time.

Concerning the Battese and Coelli model, the negative sign of $\eta$ implies that farms

\footnotetext{
${ }^{3}$ Since the main objective of the paper is to compare the results from the three alternative specifications, the determinants of efficiency in the unstructured and the dynamic models are not discussed but are presented in Tables C.4 and C.5 in Appendix C. Note that all estimates have the expected signs and their corresponding $95 \%$ credible intervals do not contain zero.

${ }^{4}$ Credible intervals are presented in Tables C.1, C.2 and C.3 in Appendix C.
} 
Table 4.2: Posterior summaries of the first-order terms and the parameters in the three $\boldsymbol{\theta}$ vectors

\begin{tabular}{|c|c|c|c|c|c|c|}
\hline & \multicolumn{2}{|c|}{ BC92 } & \multicolumn{2}{|c|}{ Unstructured } & \multicolumn{2}{|c|}{ Dynamic } \\
\hline Variable & Mean & Std. dev. & Mean & Std. dev. & Mean & Std. dev. \\
\hline intercept & 0.276 & 0.011 & -0.108 & 0.007 & -0.524 & 0.040 \\
\hline $\log _{-} \mathrm{y} 2$ & 0.191 & 0.005 & 0.233 & 0.005 & 0.146 & 0.005 \\
\hline log_K & -0.008 & 0.005 & -0.060 & 0.004 & -0.021 & 0.005 \\
\hline $\log _{-} L$ & -0.014 & 0.011 & -0.084 & 0.009 & -0.049 & 0.011 \\
\hline $\log _{-} A$ & -0.080 & 0.013 & -0.048 & 0.010 & -0.103 & 0.016 \\
\hline $\log _{-} M$ & -0.261 & 0.010 & -0.315 & 0.008 & -0.199 & 0.010 \\
\hline $\log _{-} \mathrm{S}$ & -0.371 & 0.015 & -0.312 & 0.012 & -0.279 & 0.017 \\
\hline $\log _{-} F$ & -0.219 & 0.006 & -0.177 & 0.005 & -0.191 & 0.005 \\
\hline trend & -0.015 & 0.001 & -0.025 & 0.001 & -0.023 & 0.001 \\
\hline$\sigma_{v}$ & 0.106 & 0.001 & 0.136 & 0.002 & 0.082 & 0.001 \\
\hline$\eta$ & -0.018 & 0.004 & - & - & - & - \\
\hline$\lambda$ & 3.334 & 0.165 & - & - & - & - \\
\hline$\sigma_{\xi}$ & - & - & - & - & 0.125 & 0.007 \\
\hline$\rho$ & - & - & - & - & 0.940 & 0.005 \\
\hline RTS & \multicolumn{2}{|c|}{0.953} & \multicolumn{2}{|c|}{0.997} & \multicolumn{2}{|c|}{0.840} \\
\hline
\end{tabular}

Note: BC92 refers to the Battese and Coelli (1992) inefficiency specification.

become less efficient as time progresses. The Battese and Coelli model produces an average efficiency score of $76 \%$, the unstructured model a score of $92 \%$, and the dynamic efficiency model an estimate of $60 \%$. These big differences are due to the completely different inefficiency structure that is imposed in each of the three models. The Battese and Coelli model produces a moderate efficiency score. This is because the restrictive structure that is imposed on inefficiency smooths out big efficiency changes. For instance, in contrast to the unstructured and dynamic efficiency models, the Battese and Coelli specification can't capture steep efficiency changes between 2007 and 2009; this will become obvious below. On the other hand, the unstructured and the dynamic efficiency models are able to capture these efficiency changes, with the former producing more extreme results that are reflected in the high average efficiency score. Furthermore, inefficiency is highly autocorrelated and the dynamic efficiency model produces an estimate for $\rho$ of $94 \%$. This result is consistent with the high inefficiency persistence found by Emvalomatis et al. (2011) for the case of German dairy farms. Additionally, it adds credibility to the adjustment cost theory, which states that under the existence of high adjustment costs, the optimal decision for farms is to remain inefficient in the future.

Moving to the TFP growth rate and its decomposition into technical progress, technical efficiency change, and scale effect, Table 4.3 reports the corresponding estimates for each of the three models. All three models suggest that technical progress 
is the main driver of TFP growth. This result is in accordance with the findings of Brümmer et al. (2002), Emvalomatis (2012b), and Sauer and Latacz-Lohmann (2015) for the case of German dairy farms. Technical progress is rather stable in the Battese and Coelli case, decreasing in the unstructured model and increasing in the dynamic efficiency model. On average, the scale effect contributes very little to TFP growth under all specifications. Overall, the Battese and Coelli model produces an average TFP growth estimate of approximately 1\%, while the other two models produce an estimate of around $2.5 \%$. This is in line with previous empirical studies that have reported average TFP growth rates of German dairy farms of above $1 \%$.

Table 4.3: TFP growth rate and decomposition (\%)

\begin{tabular}{|c|c|c|c|c|}
\hline Year & Technical progress & TE change & Scale effect & TFP growth \\
\hline \multicolumn{5}{|l|}{ BC92 } \\
\hline 2001-2002 & 1.419 & -0.462 & 0.090 & 1.047 \\
\hline $2002-2003$ & 1.442 & -0.471 & 0.166 & 1.137 \\
\hline 2003-2004 & 1.490 & -0.480 & -0.139 & 0.871 \\
\hline 2004-2005 & 1.540 & -0.489 & 0.084 & 1.135 \\
\hline $2005-2006$ & 1.549 & -0.498 & 0.159 & 1.210 \\
\hline $2006-2007$ & 1.608 & -0.507 & 0.160 & 1.261 \\
\hline $2007-2008$ & 1.634 & -0.517 & -0.271 & 0.846 \\
\hline 2008-2009 & 1.576 & -0.527 & 0.063 & 1.112 \\
\hline Average & 1.532 & -0.494 & 0.039 & 1.077 \\
\hline \multicolumn{5}{|c|}{ Unstructured } \\
\hline 2001-2002 & 3.296 & 0.451 & 0.005 & 3.752 \\
\hline 2002-2003 & 2.959 & -0.620 & 0.011 & 2.350 \\
\hline 2003-2004 & 2.812 & 0.507 & -0.008 & 3.311 \\
\hline 2004-2005 & 2.658 & -0.845 & 0.005 & 1.818 \\
\hline 2005-2006 & 2.538 & -0.231 & 0.011 & 2.318 \\
\hline 2006-2007 & 2.358 & 0.795 & 0.012 & 3.166 \\
\hline 2007-2008 & 2.196 & -4.200 & -0.020 & -2.024 \\
\hline 2008-2009 & 1.924 & 3.905 & 0.002 & 5.831 \\
\hline Average & 2.593 & -0.030 & 0.002 & 2.565 \\
\hline \multicolumn{5}{|l|}{ Dynamic } \\
\hline 2001-2002 & 1.889 & 0.238 & 0.246 & 2.373 \\
\hline 2002-2003 & 1.950 & 0.195 & 0.551 & 2.696 \\
\hline 2003-2004 & 2.110 & 0.688 & -0.478 & 2.320 \\
\hline 2004-2005 & 2.268 & -0.353 & 0.294 & 2.209 \\
\hline 2005-2006 & 2.441 & -0.337 & 0.500 & 2.604 \\
\hline 2006-2007 & 2.589 & -0.559 & 0.482 & 2.512 \\
\hline 2007-2008 & 2.744 & -2.152 & -0.870 & -0.278 \\
\hline 2008-2009 & 2.860 & 1.765 & 0.201 & 4.826 \\
\hline Average & 2.356 & -0.064 & 0.116 & 2.408 \\
\hline
\end{tabular}

Note: BC92 refers to the Battese and Coelli (1992) inefficiency specification.

The reason why the average TFP growth estimate in the unstructured and dy- 
namic models is almost twice the estimate produced by the Battesse and Coelli model is twofold: (i) the average estimate of the main contributor (technical progress component) of TFP growth in the Battesse and Coelli model is smaller. This result should not be surprising as the estimate with respect to the trend variable in the distance function specification of the Battesse and Coelli model is deflated because the trend variable appears also in the specification of inefficiency, (ii) the average technical efficiency change estimate is much smaller in the Battesse and Coelli specification as it is restricted to be only decreasing. This results in a further deflation of average TFP growth.

Striking differences in the time variation of TFP growth across the three specifications are observed. This is due to the differences in the technical efficiency change component. In the Battese and Coelli case, efficiency is, on average, slightly decreasing over time. However, since the unstructured and the dynamic efficiency models do not restrict efficiency to be either only increasing or decreasing, they allow for efficiency changes to either directions. Besides, in contrast to the Battese and Coelli model, they can capture steep efficiency changes. These changes are observed during the period that milk price changes have occurred in the German dairy sector. More specifically, a big efficiency change occurs between the period of 2007-2008. The milk price peak of $35.01 € / 100 \mathrm{~kg}$ in 2008 is accompanied by an almost $2.2 \%$ decrease in average technical efficiency in the dynamic efficiency model, and a $4.2 \%$ decrease in the unstructured model. In both specifications, this results in a steep decline in TFP growth. High milk prices motivate farmers to increase their short-run production so that they can take advantage of the associated profits. To raise production in the short-run, farmers need to increase the use of variable inputs. However, since farmers are probably experienced in employing a particular range of variable inputs, a rapid increase in their use that goes beyond their comfort zone may make them prone to committing mistakes. For instance, farmers may overuse inputs such as feedingstuffs or labor, which will result in increased production but inefficient use of these inputs.

On the other hand, an average efficiency increase of approximately $1.8 \%$ in the dynamic efficiency model and 3.9\% in the unstructured model is observed from 2008 to 2009 , which is the period where prices plummeted from $35.01 € / 100 \mathrm{~kg}$ to $25.25 € / 100 \mathrm{~kg}$. This efficiency increase results in a high TFP growth rate under both models. A logical consequence of such a price fall is that farmers are no longer motivated to increase production, since the associated profit gains are smaller. On the contrary, given the price decrease, farmers are more motivated to produce less by returning to their normal range of variable input use. This return may decrease short-run production, but farmers will probably make a more efficient use of their variable inputs which will compensate for the lower profits associated with the milk price fall. 
As expected, the Battese and Coelli model is not able to capture these efficiency changes that may result from the milk price volatility which occurred during the period of our study. On the other hand, the unstructured and dynamic efficiency models are more flexible, and therefore able to capture such efficiency changes. However, in contrast to the dynamic efficiency model, the unstructured model produces very erratic results due to the complete absence of a time structure for inefficiency. To offer a clearer picture of the differences in efficiency change and TFP growth volatility between the three models, Figure 4.1 presents the evolution of the components of TFP growth. While the technical change component and particularly the scale effect com-

Technical change effect

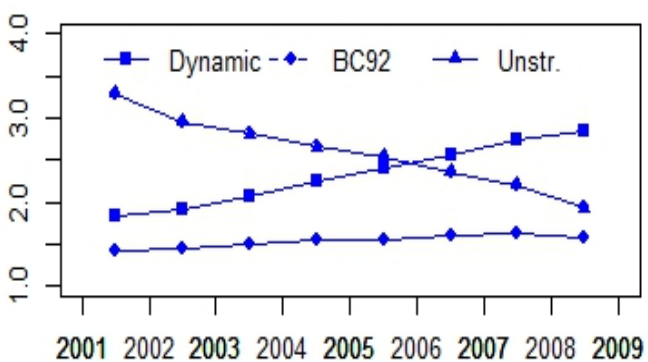

200120022003200420052006200720082009

Scale effect

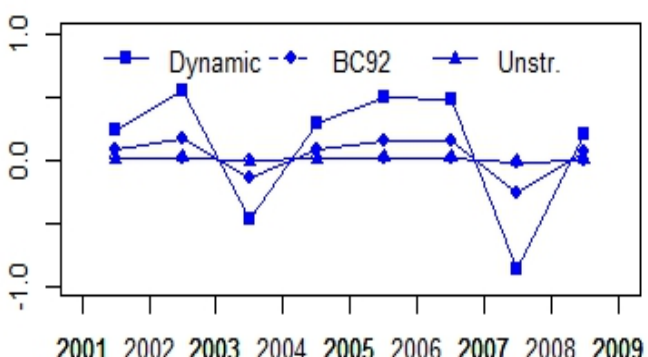

DTE effect

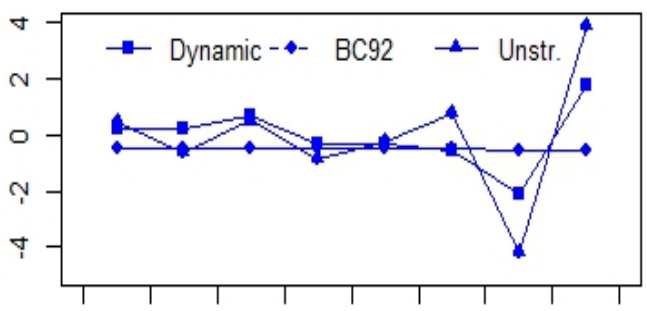

200120022003200420052006200720082009
TFP growth

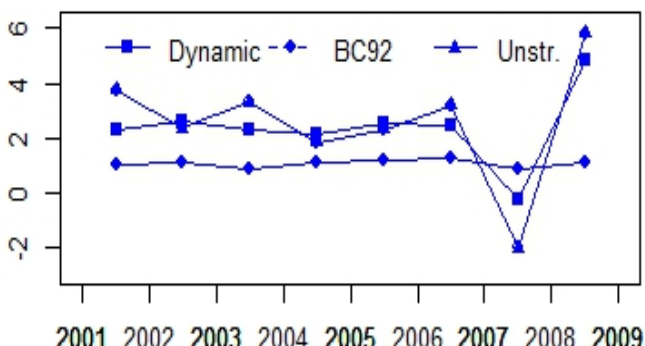

Figure 4.1: Decomposition of TFP growth under the three alternative models Note: BC92 refers to the Battese and Coelli (1992) inefficiency specification and Unstr. to the unstructured model.

ponent vary little across each model, striking differences across the three alternative specifications are observed for the period 2007-2009 in the technical efficiency change component (DTE effect) and in TFP growth. These two components are rather stable in the Battese and Coelli model, while the dynamic efficiency and unstructured models indicate sharp efficiency and TFP growth changes in the period 2007-2009. The magnitude of these changes is much larger in the unstructured model. 
A more formal model comparison is performed to infer which of the three models fits the data better. Note that the same dependent variable is used in all three specifications, while the prior model probability of $1 / 3$ is placed in each of the three models. Table 4.4 reports the estimates of the marginal log-likelihood and the posterior model probabilities.

Table 4.4: Marginal log-likelihoods and posterior model probabilities

\begin{tabular}{lcc}
\hline Model & Marginal log-likelihood & Posterior probability \\
\hline BC92 & 1411.77 & 0.000 \\
Unstructured & 2157.58 & 0.000 \\
Dynamic & 4153.17 & 1.000 \\
\hline
\end{tabular}

Note: BC92 refers to the Battese and Coelli (1992) inefficiency specification.

The dynamic efficiency model is favored by the data as, on the one hand, it imposes a less restrictive time structure on inefficiency compared to the Battese and Coelli specification, while, on the other hand, it does not allow efficiency scores to evolve completely arbitrarily over time as the unstructured efficiency model does.

\subsection{Conclusions}

This article estimates and decomposes TFP growth of German dairy farms for the period between 2001 and 2009. The study period is characterized by steep milk price changes that took place toward the end of the period. Such a shock motivates the measurement of efficiency and TFP growth and their expected time variation. However, detection of efficiency and TFP growth shocks depends on the modelling approach followed. Most studies that have examined TFP growth have relied on models that specify inefficiency as a deterministic function of time, with the most popular one being that of Battese and Coelli (1992). Additionally, models that do not impose any time structure on efficiency may be able to capture efficiency shocks, but are likely to produce very erratic results. We argue that a dynamic inefficiency specification that allows for inefficiency scores to be autocorrelated, allows for a more flexible time structure that can account for (persistent) efficiency shocks that may be induced by the high milk price volatility observed during our study period, without producing erratic results.

Although all three models produce an average TFP growth rate above $1 \%$, large discrepancies are observed in the grow rate's evolution over time. While the technical change components and particularly the scale components do not vary significantly over time, important differences occur in the efficiency change components. On the one hand, in the Battese and Coelli model, efficiency is only slightly decreasing over 
time. This is something to be expected, as this approach restricts inefficiency to be either only increasing or only decreasing with the passage of time. Furthermore, it is unable to capture steep efficiency changes because it considers inefficiency as a deterministic function of time. On the other hand, in the unstructured and the dynamic efficiency models, the direction of efficiency change is stochastic and can reveal time-specific efficiency shocks. However, the unstructured model produces very erratic results, since it does not impose any time structure on the efficiency scores.

The efficiency shocks occur when steep milk price changes were taking place in German dairy farming. In particular, the peak of milk prices in 2008 coincides with a sharp efficiency decrease that is only captured by the unstructured and the dynamic efficiency specifications. Since high milk prices offer the potential of making high profits, farmers are motivated to increase the short-run production of milk. To achieve this, they need to increase the use of variable inputs beyond the traditional level, running the risk of making mistakes, such as overusing them. This results in the inefficient use of resources which is evident in the observed efficiency decrease. However, the following year, the decrease in milk price is accompanied by an efficiency increase, that again, only the unstructured and dynamic efficiency models can capture. Farmers no longer have the incentive to produce high amounts of milk, as its low price will now result in relatively smaller profit gains. This implies that farmers are probably using their variable inputs in a more parsimonious way that increases efficiency and compensates for the profit loss compared to the year before.

The results confirm that the detection of sharp efficiency and TFP growth changes heavily dependents on the specification of inefficiency. Models such as the Battese and Coelli (1992) that consider the evolution of inefficiency as a deterministic function of time are not able to capture efficiency shocks. Models that do not impose any time structure on efficiency scores are able to account for period-specific efficiency shocks, but can produce very erratic results. The dynamic efficiency model belongs to the category of models that impose a time structure on efficiency scores, but not a very restrictive one. Such a model can account for period-specific efficiency shocks without running the risk of producing very erratic results, which is evident in our study. Additionally, the dynamic efficiency model is favored by our data when tested against the Battese and Coelli specification and a model that imposes no time structure on efficiency. 


\section{Chapter 5}

\section{General Conclusions}

\subsection{Summary of findings}

This dissertation is built on the recognition that firms are not perfect decision-making units. Producers may fail to meet their objectives due to governmental intervention or due to the stochastic environment in which they operate. The deviation between optimal and observed production is quantified by means of efficiency measurement. Additionally, stochastic events such as price volatility motivate the measurement and the identification of shocks in firms' TFP growth, which serves as an indicator of the competitiveness of a sector. This dissertation departs from the vast literature on efficiency and productivity measurement by recognizing that firms' decisions are dynamic in nature with today's actions affecting future production possibilities. Decision-making units may choose to remain inefficient in the short-run because this is the optimal strategy to meet their long-run objective. The costly adjustment of quasi-fixed factors of production can justify such a decision. Long-run efficiency takes into account the long-run objective of firms while measuring their failure to optimize their present production processes.

The German dairy sector appears to be an interesting case for measuring efficiency and TFP growth. Measurement of the former is motivated by the intensive policy intervention that took place in the sector over the last decades. In particular, the transition from coupled to decoupled CAP subsidies and the associated efficiency effects are of great interest. Furthermore, the sector's fast technological progress and the increasing use of capital stock justify the dynamic framework used. Measurement of TFP growth is interesting for two main reasons. Firstly, TFP growth is an important indicator that reflects the potential of a sector to survive in an environment that is characterized by both domestic and international competition. Secondly, the high milk price volatility that took place in the German dairy sector during the first decade of the $21^{\text {st }}$ century may result in steep changes in efficiency and TFP growth of German dairy farms. Examining this issue can reveal important information concerning the way that farmers react to such a shock.

The main objective of this dissertation is to extend and estimate the few existing parametric dynamic efficiency and TFP models to answer three research questions. 
The first research question is concerned with whether heterogeneity exists in the longrun technical efficiency of German dairy farms. To answer this research question the parametric dynamic efficiency model is extended in Chapter 2 to allow for the long-run technical efficiency of farms to be dependent on farm-specific characteristics and varying degrees of their inefficiency persistence. The farm-specific characteristics included consist of the economic size of farms, measured in ESU, and the amount of subsidies that farms receive. Furthermore, a hierarchical structure for the inefficiency persistence component is used that allows for variation across farms. The results provide evidence of substantial heterogeneity in the long-run technical efficiency of German dairy farms ranging from approximately 50\% to $98 \%$. This result indicates that the assumption of previous studies of a common long-run technical efficiency score for all firms should be relaxed. Heterogeneity in the long-run technical efficiency of German dairy farms is mostly due to differences in farm-specific factors and, to a lesser extent, due to discrepancies in farms' inefficiency persistence. Farm size exerts a positive impact on the long-run technical efficiency of farms, while subsidies are negatively related to farms' long-run technical efficiencies. Inefficiency persistence is found to be very high, ranging from $88 \%$ to $98 \%$.

The second research question is tackled in Chapter 3 and seeks farm-specific characteristics which may influence farms' technical inefficiency persistence. A meticulous literature review is conducted to identify those farm-specific characteristics that are related to adjustment costs. Based on this review, subsidies are related to external adjustment costs, while the farmer's age is associated with internal adjustment costs. Given that adjustment costs cause high inefficiency persistence, this study tests for the impact of these farm-specific characteristics on inefficiency persistence. The inefficiency persistence parameter is projected from the unit interval to the real line, and covariates are allowed to have an impact on it. The empirical findings suggest a high degree of inefficiency persistence, with subsidies and age having a statistically significant impact on it. Specifically, subsidies have a positive effect on inefficiency persistence, while older farmers exhibit higher persistence of technical inefficiency when compared to younger farmers.

The third research question is concerned with the ability of the dynamic efficiency specification to capture time-specific technical efficiency and TFP growth shocks that may have been induced by the high milk price volatility that took place in the German dairy sector. In Chapter 4, TFP growth is decomposed into three components: (i) technical progress, (ii) technical efficiency change and (iii) scale effect. Apart from the dynamic efficiency specification, two further models are considered: one which imposes a very restrictive time structure on efficiency and one which does not impose any time structure on efficiency scores. The results confirm that the dynamic efficiency specifi- 
cation is able to capture time-specific technical efficiency and TFP growth shocks in German dairy farming. In addition, formal model comparisons are performed showing that the dynamic efficiency specification is favored by the data when compared with the two alternative efficiency specifications.

\subsection{Limitations}

In this dissertation, some limitations exist particularly with respect to the inefficiency persistence component. In Chapters 2 and 3, heterogeneity in this persistence is quite low. One would expect that, to a certain extent, farms would exhibit quite different degrees of inefficiency persistence. This is because some farms may tend to adopt new technologies quicker than others, or because some farm operators may be able to learn quicker due to their higher cognitive capacity or experience. A possible explanation for this low heterogeneity in inefficiency persistence is the following: since inefficiency is an unobserved quantity, initializing the autoregressive process of the inefficiency scores requires a distribution for inefficiency in the initial period. This is achieved by imposing stationarity on the autoregressive series. Stationarity restricts the inefficiency persistence parameter on the unit interval. A natural consequence of finding a mean value for inefficiency persistence close to unity, while restricting it to the unit interval, is that this parameter will not vary a lot around the mean.

In Chapter 3, while the determinants of inefficiency persistence are statistically significant, their economic significance is negligible. However, this study has provided a novel way to allow the inclusion and impact testing of farm-specific characteristics on the persistence of technical inefficiency. Besides, in the case where the determinants of inefficiency persistence were also economically significant, one would not be able to intuitively interpret their magnitude. This is because inefficiency persistence is an elasticity that measures the percentage change in the efficiency to inefficiency ratio that is carried from one period to the next, and therefore lacks units of measurement. For instance, interpretation of the magnitude of the determinants of efficiency is much more intuitive, as it measures the deviation of firms from the production frontier.

Additionally, the study in Chapter 3 fails to include indicators that are directly related to external adjustment costs. Subsidies are indirectly related to these costs, as they can simply ameliorate farmers' financial situation and allow them to adopt new technologies. Examples of more relevant variables are financial indicators such as debts. However, the lack of variation in the available financial indicators has prevented their use as explanatory factors of inefficiency persistence. In terms of internal adjustment costs, several additional covariates such as education or the presence of a successor could further help in explaining the persistence of technical inefficiency. 
However, these information were not available in the dataset.

Finally, in Chapter 4, it was assumed that time-specific shocks in efficiency and TFP growth of German dairy farms may occur because of the high milk price volatility that took place during the study period. The dynamic efficiency specification was used to capture such shocks. Despite the fact that this specification revealed steep efficiency and TFP growth changes that coincide with the volatility in milk prices, this study does not empirically test for the relationship between milk prices and efficiency or TFP growth. This is due to the unavailability of milk prices in the dataset. Furthermore, even if milk prices could be retrieved from an alternative data source, they could not be used as determinants of efficiency. This is because the need of imposing stationarity, requires that the determinants of efficiency are specified as time-invariant. This requirement cannot be satisfied due to milk prices varying significantly over time.

All in all, despite the aforementioned limitations of this dissertation, the answers to the three research questions were not affected.

\subsection{Synthesized Results}

Although the objective of each of the three chapters was different, all three studies used the dynamic efficiency specification with minor differences related to the modelling of the inefficiency persistence component. In all three studies, inefficiency persistence of German dairy farms was found to be very high. Table 5.1 summarizes the average inefficiency persistence estimates in Chapters 2-4. The estimates of average inefficiency persistence are quite similar across the three chapters.

Table 5.1: Summary of average inefficiency persistence scores by chapters

\begin{tabular}{lc}
\hline Chapter & Average inefficiency persistence \\
\hline 2. Long-run technical efficiency heterogeneity & $95 \%$ \\
3. Determinants of inefficiency persistence & $97 \%$ \\
4. Dynamic efficiency and TFP growth & $94 \%$ \\
\hline
\end{tabular}

With respect to the efficiency scores, the long-run efficiency estimates are only reported in Chapter 2 as this was the primary objective of the study. However, the average short-run technical efficiency scores are reported in every chapter, and similar estimates are found ranging from $60 \%$ to $70 \%$.

All three chapters estimated efficiency using an output distance function. A translog specification was used with the same outputs and inputs. The distance function elasticities with respect to outputs and inputs are rather similar across all three chapters and German dairy farms are found to operate under the decreasing returns to scale part of the technology. Additionally, the three studies provide evidence that Ger- 
man dairy farms face technological progress, as the frontier moves outwards as time progresses.

The results in Chapters 3 and 4 provide evidence that specialization in milk production, higher stock density, and bigger economic farm size are all positively related to technical efficiency. Specialization of farmers in a single production activity makes them more experienced and skillful, resulting in higher technical efficiency. Higher stock density is associated with intensive production techniques that result in higher technical efficiency at the farm-level. Finally, farms with a large economic size are probably more business oriented and use more mental labor which consequently increases their technical efficiency. The results in Chapter 2 further suggest that the positive impact of the economic size of farms on technical efficiency is also present in the long-run.

Finally, all three chapters departed from the static efficiency framework by using the dynamic efficiency specification, recognizing that farms' decision making processes are dynamic in nature. In Chapters 2 and 3, formal comparison tests between static and dynamic efficiency models were not conducted. However, in Chapter 4 a formal comparison test using Bayes factors was performed to compare two static efficiency specifications with the dynamic efficiency model. The results suggest that the dynamic efficiency specification outperforms the static efficiency models. Since the dynamic efficiency specification is rather similar across all three chapters, this provides evidence in favor of moving from a static to a dynamic framework in this dissertation.

\subsection{Policy Implications}

The results from Chapter 2 point out that CAP subsidies have a negative impact on the long-run technical efficiency of farms. Several empirical studies including Hadley (2006), Zhu and Oude Lansink (2010) and Bojnec and Latruffe (2013) have concluded that CAP subsidies are negatively related to short-run technical efficiency. In all cases, decoupled payments comprise a very large share of these CAP subsidies. Their negative impact on technical efficiency stems from the fact that farmers perceive these kinds of subsidies as an additional income source and are, therefore, less motivated to work efficiently. Based on the results from Chapter 2, this negative effect is also present in the long-run. This result informs policy-makers that there is a long-term negative impact of CAP subsidies on farms' technical efficiency.

Chapters 3 and 4 further indicate that specialization in milk production and higher stock density can increase farms' short-run technical efficiency. This is consistent with the empirical findings reported by Latruffe et al. (2008), Alvarez and Corral (2010), and Zhu et al. (2012). This implies that any policy encouraging specialization in a single 
production activity or adoption of intensive production techniques should positively contribute to the technical efficiency of farms.

The results in all three chapters suggest that technical inefficiency is highly persistent across time. This result is consistent with the high inefficiency persistence reported by Emvalomatis et al. (2011) for the case of German dairy farms. Farms are inefficient today and this inefficiency does not disappear as time progresses. Shocks such as the introduction of innovative technologies do not allow farms to become fully efficient because of the existence of high adjustment costs. Lately, the CAP reforms tend to give particular emphasis to sustainability matters. In the dairy sector, particular attention is paid to animal health and welfare, public health risks related to the use of antibiotics, and emission of nutrients and greenhouse gases. Farmers are required to invest in improved animal housing systems or more environmentally friendly management practices (Stehfest et al., 2013). However, the results from this dissertation point out that farmers face high adjustment costs that prevent them from instantaneously investing in new equipment. In this case, this implies that a farmer's optimal decision may be to remain environmentally inefficient because of the high adjustment costs related to the construction of a new animal housing system or the adoption of an environmentally friendly production technology. Consequently, policy makers should be aware of the constraints that adjustment costs impose on farmers. If short-run environmental efficiency is imperative, then faster implementation of environmentallyfriendly practices could be achieved by the distribution of subsidies among investments that could make the dairy sector more sustainable.

With reference to the above discussion, the results from Chapter 3 show that CAP payments are most probably perceived as an additional income source and not as a tool for investing in new technologies. This results in higher inefficiency persistence for farms. The cause lies with the fact that the share of subsidies on investment when compared to the total amount of subsidies that farms receive is negligible. The results further indicate that young farmers are more prone to investing in new technologies compared to very old farmers. This result suggests that if policy makers are interested in promoting the use of new technologies, they should provide young people with incentives to undertake the management of farms.

Finally, the results in Chapter 4 suggest that TFP growth of German dairy farms is particularly sensitive to shocks that may be outside the control of the producers. TFP growth is a very important indicator that determines whether a sector will persist or perish in an environment that is characterized by both domestic and international competition. Given this high importance of TFP growth and its sensitivity with respect to exogenous shocks, policy-makers should focus on minimizing these shocks so that they can ensure that the sector is competitive and able to survive. 


\subsection{Suggestions for Future Research}

This dissertation has focused on extending the few existing parametric dynamic efficiency models. The analysis of the determinants of inefficiency persistence has been constrained by the lack of variation in the financial indicators and the absence of additional potentially relevant variables. Based on the modelling approach proposed in Chapter 3, future research can be conducted on examining the impact of financial indicators such as debts on the persistence of inefficiency. Additionally, datasets that contain information on farmers' education and/or presence of a successor could help to explain better the persistence of inefficiency. Finally, provided that a certain share of total subsidies consists of subsidies on investment, an interesting exercise would be to differentiate between decoupled payments and subsidies on investments, as opposite effects on inefficiency persistence are expected.

Furthermore, given that data on environmental indicators are available, another interesting direction is the application of the dynamic framework to environmental efficiency analysis. As mentioned before, recent reforms to the CAP require farmers to invest in environmentally friendly production techniques. However, financial constraints or learning costs may prevent or delay farmers' investment in environmentally friendly technologies. This may imply that the environmental inefficiency of farms may persist over time, justifying the use of a dynamic framework.

A large number of efficiency measurement studies has recently focused on spatial dependence between the decision-making units. This spatial dependence may arise because farmers located in close proximity may communicate with each other, raising awareness of the existence of new technologies. This may be particularly relevant when dynamic efficiency analysis is concerned because farmers' investment decisions may be affected by their neighbors' decisions. Two relevant extensions of the dynamic efficiency model are possible. The first combines the specification of a lag efficiency component with a spatial efficiency term. This specification allows efficiency to be dependent not only on past efficiency but also on neighbors' efficiency. The second extension could take the direction of including neighbors' individual characteristics as determinants of a farm's inefficiency persistence. If communication between farmers exists, then neighbors' characteristics should play a role in a farm's investment decisions and, therefore, in its inefficiency persistence. 


\section{Appendix A}

Table A.1: Parameterization of priors

\begin{tabular}{lccc}
\hline Parameter & Distribution Probability density function & Hyper-priors \\
\hline$\beta$ & $\mathrm{N}(\mathrm{b}, \mathrm{S})$ & $\frac{|S|^{-\frac{1}{2}}}{(2 \pi)^{\frac{K}{2}}} \exp \left\{-\frac{(\beta-b)^{\prime} S^{-1}(\beta-b)}{2}\right\}$ & $\mathrm{b}=0_{K}, S=1,000 \times I_{K}$ \\
$\tau \equiv \frac{1}{\sigma_{v}^{2}}$ & Gamma(a,b) & $\frac{b^{a}}{\Gamma(\alpha)} \tau^{\alpha-1} e^{-b \tau}$ & $\mathrm{a}=0.001, \mathrm{~b}=0.001$ \\
$\delta$ & $\mathrm{N}(\mathrm{d}, \mathrm{P})$ & $\frac{|P|^{-\frac{1}{2}}}{(2 \pi)^{\frac{L}{2}}} \exp \left\{-\frac{(\delta-d)^{\prime} P^{-1}(\delta-d)}{2}\right\}$ & $\mathrm{d}=0_{L}, P=1,000 \times I_{L}$ \\
$\phi \equiv \frac{1}{\sigma_{\xi}^{2}}$ & $\mathrm{Gamma}(\mathrm{a}, \mathrm{b})$ & $\frac{b^{a}}{\Gamma(\alpha)} \phi^{\alpha-1} e^{-b \phi}$ & $\mathrm{a}=0.01, \mathrm{~b}=0.01$ \\
$\mu$ & $\mathrm{N}(\mathrm{m}, \mathrm{t})$ & $\left(2 \pi t_{m}^{2}\right)^{-\frac{1}{2}} \exp \left\{-\frac{\left(\delta-m_{\mu}\right)^{2}}{2 t_{m}^{2}}\right\}$ & $\mathrm{m}=2.3, \mathrm{t}=10$ \\
$\psi \equiv \frac{1}{\sigma_{\omega}^{2}}$ & $\mathrm{Gamma}(\mathrm{a}, \mathrm{b})$ & $\frac{b^{a}}{\Gamma(\alpha)} \psi^{\alpha-1} e^{-b \psi}$ & $\mathrm{a}=0.1, \mathrm{~b}=0.01$ \\
\hline
\end{tabular}

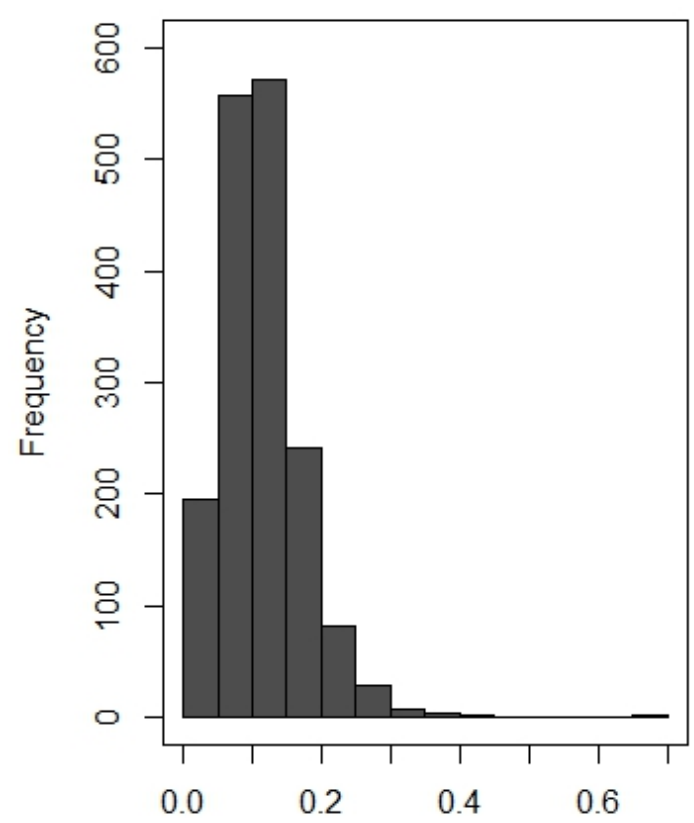

coefficient of variation ESU

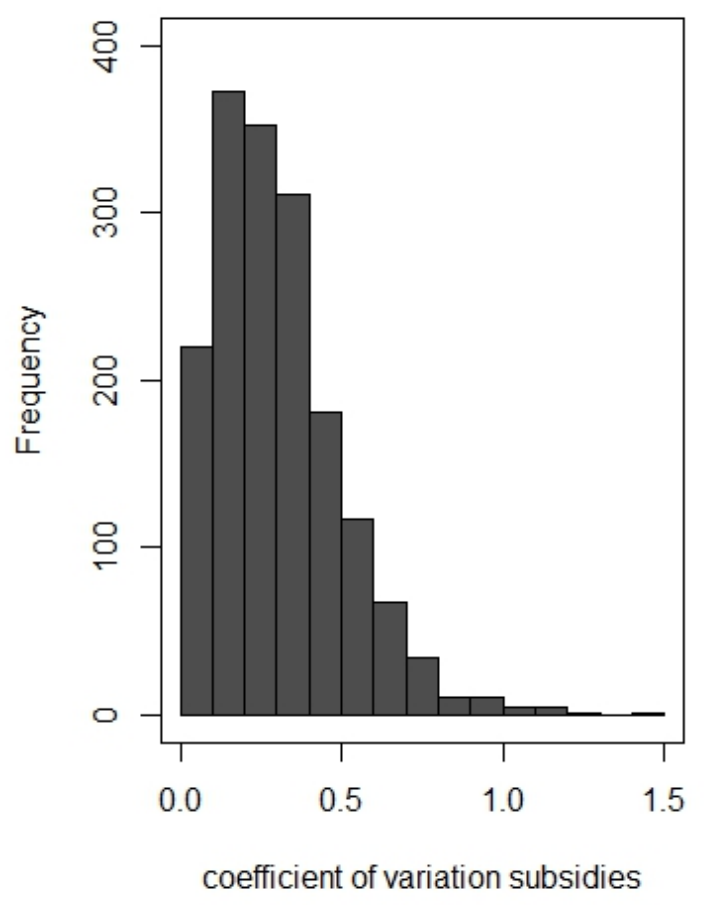

Figure A.1: Coefficient of variation for European Size Units and subsidies 
Table A.2: Estimates of the model's parameters

\begin{tabular}{|c|c|c|c|}
\hline Variable & Mean & Std. dev. & 95\% Credible Interval \\
\hline intercept & -0.464 & 0.030 & {$[-0.542,-0.415]$} \\
\hline $\log _{-} y 2$ & 0.121 & 0.003 & {$[0.116,0.127]$} \\
\hline $\log _{-} \mathrm{K}$ & -0.007 & 0.004 & {$[-0.015,0.000]$} \\
\hline $\log _{-} L$ & -0.053 & 0.008 & {$[-0.068,-0.038]$} \\
\hline log_A & -0.078 & 0.009 & {$[-0.097,-0.060]$} \\
\hline $\log _{-} M$ & -0.114 & 0.007 & {$[-0.128,-0.100]$} \\
\hline $\log _{-} \mathrm{S}$ & -0.446 & 0.012 & {$[-0.469,-0.422]$} \\
\hline $\log _{-} F$ & -0.180 & 0.004 & {$[-0.188,-0.172]$} \\
\hline trend & -0.022 & 0.001 & {$[-0.023,-0.020]$} \\
\hline east & 0.029 & 0.014 & {$[0.001,0.057]$} \\
\hline west & -0.036 & 0.011 & {$[-0.059,-0.014]$} \\
\hline north & 0.029 & 0.010 & {$[0.009,0.050]$} \\
\hline log_KK & 0.009 & 0.002 & {$[0.005,0.013]$} \\
\hline log_KL & -0.011 & 0.009 & {$[-0.028,0.005]$} \\
\hline log_KA & -0.019 & 0.010 & {$[-0.039,0.000]$} \\
\hline log_KM & 0.045 & 0.008 & {$[0.030,0.061]$} \\
\hline log_KS & -0.028 & 0.012 & {$[-0.050,-0.005]$} \\
\hline $\log \_K F$ & -0.001 & 0.004 & {$[-0.007,0.006]$} \\
\hline $\log _{-} L L$ & 0.016 & 0.011 & {$[-0.005,0.037]$} \\
\hline $\log \_L A$ & 0.028 & 0.018 & {$[-0.008,0.064]$} \\
\hline log_LM & 0.006 & 0.016 & {$[-0.026,0.038]$} \\
\hline $\log _{-} L S$ & -0.037 & 0.023 & {$[-0.082,0.007]$} \\
\hline $\log _{-} L F$ & 0.024 & 0.008 & {$[0.008,0.040]$} \\
\hline $\log _{-} A A$ & 0.012 & 0.014 & {$[-0.016,0.040]$} \\
\hline log_AM & 0.033 & 0.018 & {$[-0.002,0.068]$} \\
\hline $\log \_A S$ & -0.078 & 0.027 & {$[-0.131,-0.025]$} \\
\hline $\log _{-} A F$ & 0.025 & 0.008 & {$[0.008,0.041]$} \\
\hline log_MM & 0.004 & 0.009 & {$[-0.013,0.022]$} \\
\hline log_MS & -0.161 & 0.022 & {$[-0.204,-0.118]$} \\
\hline $\log _{-} M F$ & 0.030 & 0.007 & {$[0.016,0.043]$} \\
\hline $\log _{-} \mathrm{SS}$ & 0.122 & 0.022 & {$[0.078,0.166]$} \\
\hline $\log _{-} \mathrm{SF}$ & 0.029 & 0.011 & {$[0.007,0.050]$} \\
\hline $\log _{-} F F$ & -0.040 & 0.001 & {$[-0.043,-0.037]$} \\
\hline $\log _{-} y 2 y 2$ & 0.029 & 0.001 & {$[0.027,0.031]$} \\
\hline trend2 & 0.000 & 0.000 & {$[0.000,0.000]$} \\
\hline
\end{tabular}




\begin{tabular}{lccc} 
log_Ky2 & -0.002 & 0.003 & {$[-0.007,0.004]$} \\
log_Ly2 & -0.008 & 0.006 & {$[-0.020,0.003]$} \\
log_Ay2 & -0.029 & 0.006 & {$[-0.041,-0.017]$} \\
log_My2 & 0.049 & 0.006 & {$[0.037,0.061]$} \\
log_Sy2 & 0.010 & 0.009 & {$[-0.007,0.027]$} \\
log_Fy2 & -0.008 & 0.003 & {$[-0.014,-0.003]$} \\
trend_log_K & 0.000 & 0.001 & {$[-0.002,0.002]$} \\
trend_log_L & -0.005 & 0.002 & {$[-0.008,-0.002]$} \\
trend_log_A & 0.004 & 0.002 & {$[0.000,0.007]$} \\
trend_log_M & 0.009 & 0.002 & {$[0.006,0.013]$} \\
trend_log_S & -0.009 & 0.002 & {$[0.000,0.003]$} \\
trend_log_F & 0.002 & 0.001 & {$[0.006,0.009]$} \\
trend_log_y2 & 0.008 & 0.001 & {$[0.000,0.017]$} \\
\hline s & & & {$[0.028,0.044]$} \\
\hline intercept & 0.009 & 0.004 & {$[0.087,-0.024]$} \\
ESU & 0.035 & 0.004 & {$[0.132,0.162]$} \\
subsidies & -0.033 & 0.005 & {$[2.884,3.178]$} \\
\hline$\sigma_{v}$ & 0.089 & 0.001 & $0.439]$ \\
$\sigma_{\xi}$ & 0.148 & 0.008 & 0.030 \\
$\sigma_{\omega}$ & 0.380 & 0.075 & \\
$\mu$ & 3.032 & & \\
\hline
\end{tabular}

Table A.3: Determinants of transformed efficiency s

\begin{tabular}{lccc}
\hline Variable & Mean & Std. dev. & $\mathbf{9 5 \%}$ Credible Interval \\
\hline intercept & 0.009 & 0.004 & {$[0.000,0.017]$} \\
ESU & 0.035 & 0.004 & {$[0.028,0.044]$} \\
subsidies & -0.033 & 0.005 & {$[-0.043,-0.024]$} \\
\hline
\end{tabular}




\section{Appendix B}

Table B.1: Parameterization of priors

\begin{tabular}{lccc}
\hline Parameter & Distribution Probability density function & Hyper-priors \\
\hline$\beta$ & $\mathrm{N}(\mathrm{b}, \mathrm{S})$ & $\frac{|S|^{-\frac{1}{2}}}{(2 \pi)^{\frac{K}{2}}} \exp \left\{-\frac{(\beta-b)^{\prime} S^{-1}(\beta-b)}{2}\right\}$ & $\mathrm{b}=0_{K}, S=1,000 \times I_{K}$ \\
$\tau \equiv \frac{1}{\sigma_{v}^{2}}$ & Gamma(a,b) & $\frac{b^{a}}{\Gamma(\alpha)} \tau^{\alpha-1} e^{-b \tau}$ & $\mathrm{a}=0.001, \mathrm{~b}=0.001$ \\
$\delta$ & $\mathrm{N}(\mathrm{q}, \mathrm{P})$ & $\frac{|P|^{-\frac{1}{2}}}{(2 \pi)^{\frac{L}{2}}} \exp \left\{-\frac{(\omega-q)^{\prime} P^{-1}(\omega-q)}{2}\right\}$ & $\mathrm{q}=0_{L}, P=1,000 \times I_{L}$ \\
$\phi \equiv \frac{1}{\sigma_{\xi}^{2}}$ & Gamma(a,b) & $\frac{b^{a}}{\Gamma(\alpha)} \tau^{\alpha-1} e^{-b \tau}$ & $\mathrm{a}=0.01, \mathrm{~b}=0.01$ \\
$\eta$ & $\mathrm{N}(\mathrm{e}, \mathrm{R})$ & $\frac{|R|^{-\frac{1}{2}}}{(2 \pi)^{\frac{M}{2}}} \exp \left\{-\frac{(\eta-e)^{\prime} R^{-1}(\eta-e)}{2}\right\}$ & $\mathrm{e}=0_{M}, R=1,000 \times I_{L}$ \\
$\psi \equiv \frac{1}{\sigma_{\lambda}^{2}}$ & Gamma(a,b) & $\frac{b^{a}}{\Gamma(\alpha)} \psi^{\alpha-1} e^{-b \psi}$ & $\mathrm{a}=0.1, \mathrm{~b}=0.01$ \\
\hline
\end{tabular}

Table B.2: Parameter estimates from the three alternative inefficiency specifications

\begin{tabular}{lcccccc}
\hline & \multicolumn{2}{c}{ BC92 } & \multicolumn{2}{c}{ Emvalomatis et al. (2011) } & \multicolumn{2}{c}{ Current paper } \\
\hline Parameter & Mean & Std. dev. & Mean & Std. dev. & Mean & Std. dev. \\
\hline intercept & 0.225 & 0.009 & -0.445 & 0.019 & -0.417 & 0.029 \\
log_other & 0.184 & 0.003 & 0.140 & 0.003 & 0.125 & 0.003 \\
log_K & -0.021 & 0.004 & -0.015 & 0.004 & -0.017 & 0.004 \\
log_L & -0.045 & 0.008 & -0.049 & 0.007 & -0.051 & 0.007 \\
log_A & -0.021 & 0.009 & -0.070 & 0.009 & -0.087 & 0.010 \\
log_M & -0.192 & 0.008 & -0.146 & 0.007 & -0.162 & 0.007 \\
log_S & -0.506 & 0.011 & -0.502 & 0.011 & -0.422 & 0.012 \\
log_F & -0.213 & 0.004 & -0.192 & 0.004 & -0.175 & 0.004 \\
trend & -0.017 & 0.001 & -0.019 & 0.000 & -0.020 & 0.000 \\
\hline average TE & \multicolumn{2}{c}{0.770} & & 0.661 & & 0.700 \\
$\rho$ & & - & 0.991 & 0.971 \\
\hline
\end{tabular}

Note: BC92 refers to the Battese and Coelli (1992) inefficiency specification.

Table B.3: Estimates of the model's parameters

\begin{tabular}{lccc}
\hline Variable & Mean & Std. dev. & 95\% Credible Interval \\
\hline intercept & -0.417 & 0.029 & {$[-0.480,-0.370]$} \\
log_other & 0.125 & 0.003 & {$[0.119,0.130]$} \\
log_K & -0.017 & 0.004 & {$[-0.024,-0.010]$} \\
log_L & -0.051 & 0.007 & {$[-0.064,-0.037]$} \\
log_A & -0.087 & 0.010 & {$[-0.106,-0.067]$}
\end{tabular}




\begin{tabular}{|c|c|c|c|}
\hline log_M & -0.162 & 0.007 & {$[-0.175,-0.148]$} \\
\hline log_S & -0.422 & 0.012 & {$[-0.445,-0.399]$} \\
\hline $\log _{-} F$ & -0.175 & 0.004 & {$[-0.182,-0.167]$} \\
\hline trend & -0.020 & 0.000 & {$[-0.021,-0.019]$} \\
\hline east & 0.060 & 0.015 & {$[0.030,0.089]$} \\
\hline west & 0.002 & 0.010 & {$[-0.018,0.022]$} \\
\hline north & 0.055 & 0.010 & {$[0.036,0.074]$} \\
\hline log_KK & 0.008 & 0.002 & {$[0.004,0.012]$} \\
\hline log_KL & -0.014 & 0.009 & {$[-0.031,0.003]$} \\
\hline log_KA & -0.013 & 0.009 & {$[-0.030,0.005]$} \\
\hline log_KM & 0.047 & 0.007 & {$[0.033,0.062]$} \\
\hline $\log K S$ & -0.033 & 0.011 & {$[-0.054,-0.012]$} \\
\hline log_KF & 0.001 & 0.003 & {$[-0.006,0.007]$} \\
\hline $\log _{-} L L$ & 0.022 & 0.013 & {$[-0.004,0.048]$} \\
\hline $\log _{-} L A$ & 0.014 & 0.020 & {$[-0.025,0.053]$} \\
\hline $\log \_\mathrm{LM}$ & 0.003 & 0.018 & {$[-0.031,0.038]$} \\
\hline $\log _{-} L S$ & -0.037 & 0.024 & {$[-0.085,0.010]$} \\
\hline $\log _{-} L F$ & 0.027 & 0.009 & {$[0.010,0.044]$} \\
\hline $\log _{-} A A$ & 0.017 & 0.014 & {$[-0.011,0.045]$} \\
\hline $\log _{-} A M$ & 0.019 & 0.018 & {$[-0.016,0.055]$} \\
\hline $\log _{-} A S$ & -0.070 & 0.026 & {$[-0.122,-0.018]$} \\
\hline $\log _{-} A F$ & 0.033 & 0.008 & {$[0.017,0.049]$} \\
\hline log_MM & 0.009 & 0.009 & {$[-0.009,0.027]$} \\
\hline log_MS & -0.154 & 0.022 & {$[-0.198,-0.109]$} \\
\hline log_MF & 0.024 & 0.007 & {$[0.009,0.038]$} \\
\hline log_SS & 0.135 & 0.022 & {$[0.093,0.177]$} \\
\hline $\log _{-} \mathrm{SF}$ & 0.006 & 0.011 & {$[-0.015,0.027]$} \\
\hline $\log _{2} F F$ & -0.037 & 0.001 & {$[-0.039,-0.034]$} \\
\hline log_other2 & 0.031 & 0.001 & {$[0.029,0.033]$} \\
\hline trend2 & 0.000 & 0.000 & {$[0.000,0.000]$} \\
\hline log_K_other & -0.010 & 0.003 & {$[-0.015,-0.004]$} \\
\hline log_L_other & -0.002 & 0.007 & {$[-0.015,0.011]$} \\
\hline log_A_other & -0.031 & 0.006 & {$[-0.044,-0.019]$} \\
\hline log_M_other & 0.062 & 0.006 & {$[0.050,0.075]$} \\
\hline log_S_other & 0.008 & 0.009 & {$[-0.009,0.025]$} \\
\hline log_F_other & -0.015 & 0.003 & {$[-0.021,-0.009]$} \\
\hline trend_log_K & -0.003 & 0.001 & {$[-0.004,-0.001]$} \\
\hline trend_log_L & -0.006 & 0.001 & {$[-0.009,-0.003]$} \\
\hline
\end{tabular}




\begin{tabular}{lccc} 
trend_log_A & 0.006 & 0.001 & {$[0.003,0.009]$} \\
trend_log_M & 0.001 & 0.001 & {$[-0.002,0.004]$} \\
trend_log_S & -0.001 & 0.002 & {$[-0.005,0.003]$} \\
trend_log_F & 0.003 & 0.001 & {$[0.001,0.004]$} \\
trend_log_other & 0.004 & 0.001 & {$[0.003,0.005]$} \\
\hline$\sigma_{v}$ & 0.105 & 0.001 & {$[0.103,0.107]$} \\
$\sigma_{\xi}$ & 0.086 & 0.010 & {$[0.066,0.106]$} \\
$\sigma_{\lambda}$ & 0.340 & 0.029 & {$[0.282,0.395]$} \\
\hline
\end{tabular}

Table B.4: Determinants of transformed efficiency (s)

\begin{tabular}{lccc}
\hline Variable & Mean & Std. dev. & 95\% Credible Interval \\
\hline intercept & -0.059 & 0.013 & {$[-0.088,-0.036]$} \\
size & 0.011 & 0.002 & {$[0.007,0.017]$} \\
specialization & 0.087 & 0.022 & {$[0.052,0.132]$} \\
density & 0.005 & 0.002 & {$[0.003,0.009]$} \\
\hline
\end{tabular}

Table B.5: Determinants of transformed inefficiency persistence (h)

\begin{tabular}{lccc}
\hline Variable & Mean & Std. dev. & 95\% Credible Interval \\
\hline intercept & 3.487 & 0.238 & {$[3.041,3.976]$} \\
subsidies & 0.087 & 0.027 & {$[0.039,0.140]$} \\
age $<65$ & -0.095 & 0.034 & {$[-0.161,-0.029]$} \\
\hline
\end{tabular}



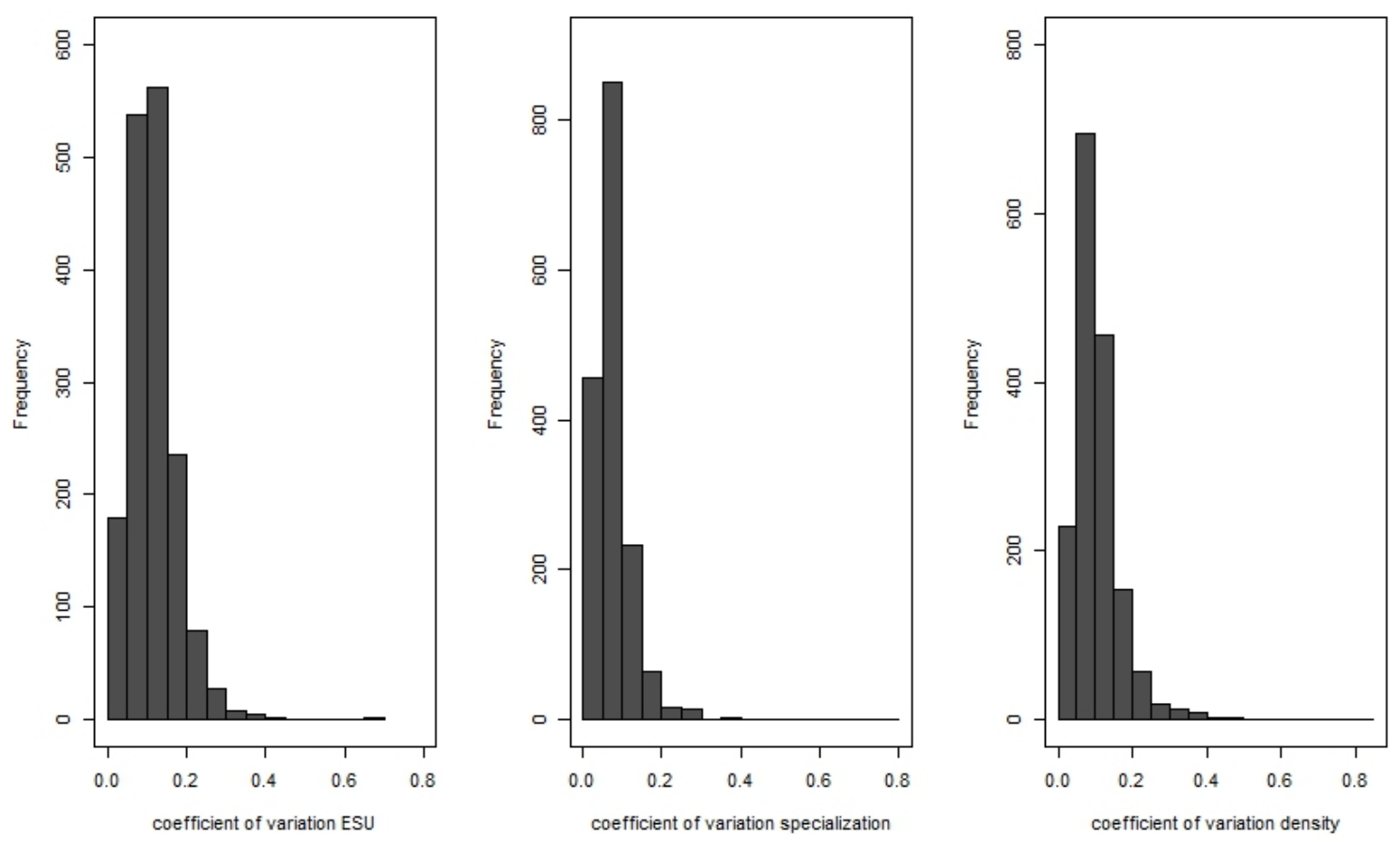

Figure B.1: Coefficient of variation for ESU, specialization, and density

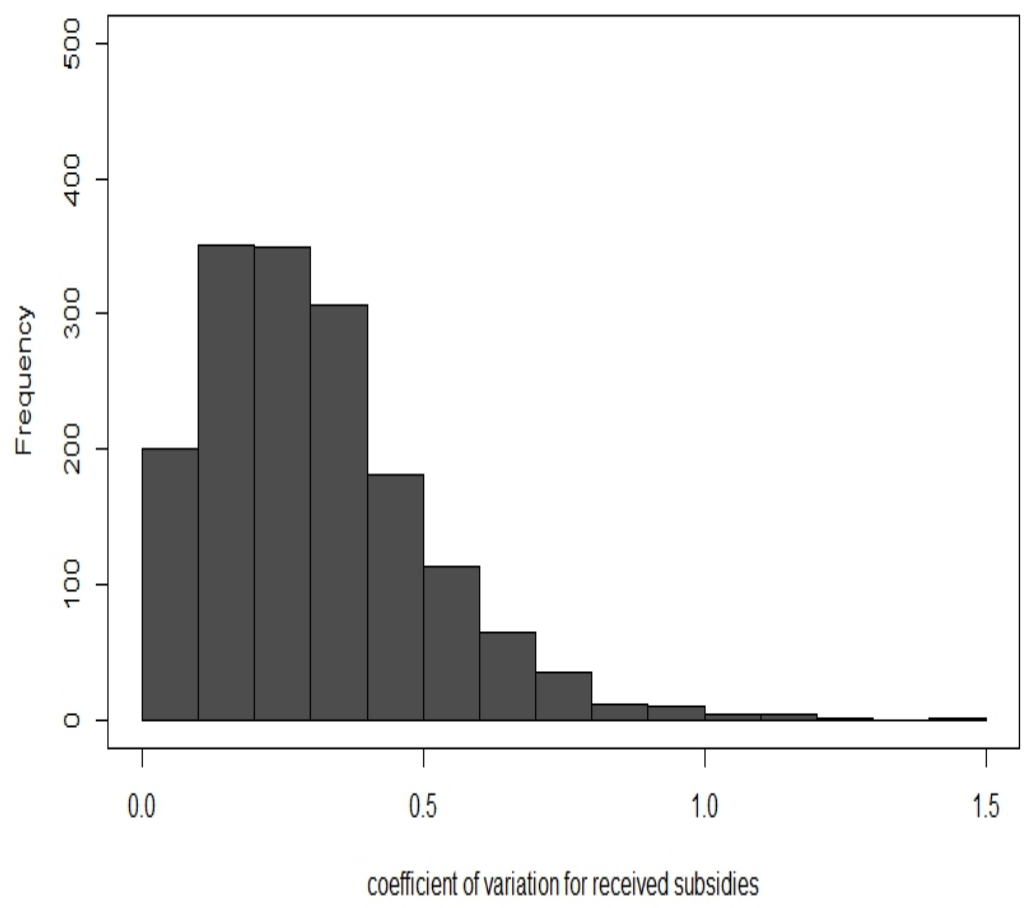

Figure B.2: Coefficient of variation for received subsidies 


\section{Appendix $\mathrm{C}$}

Table C.1: Estimates of the parameters from the Battese and Coelli (1992) model

\begin{tabular}{|c|c|c|c|}
\hline Variable & Mean & Std. dev. & 95\% Credible Interval \\
\hline intercept & 0.276 & 0.011 & {$[0.256,0.298]$} \\
\hline $\log _{-} y 2$ & 0.191 & 0.005 & {$[0.181,0.200]$} \\
\hline log_K & -0.008 & 0.005 & {$[-0.017,0.002]$} \\
\hline $\log _{-} L$ & -0.014 & 0.011 & {$[-0.035,0.007]$} \\
\hline $\log _{-} A$ & -0.080 & 0.013 & {$[-0.104,-0.055]$} \\
\hline log_M & -0.261 & 0.010 & {$[-0.282,-0.240]$} \\
\hline $\log _{-} S$ & -0.371 & 0.015 & {$[-0.400,-0.342]$} \\
\hline $\log _{-} F$ & -0.219 & 0.006 & {$[-0.231,-0.208]$} \\
\hline trend & -0.015 & 0.001 & {$[-0.018,-0.013$} \\
\hline east & -0.042 & 0.035 & {$[-0.104,0.031]$} \\
\hline west & -0.011 & 0.016 & {$[-0.041,0.021]$} \\
\hline north & 0.033 & 0.015 & {$[0.004,0.064]$} \\
\hline log_KK & 0.016 & 0.003 & {$[0.011,0.022]$} \\
\hline log_KL & -0.023 & 0.013 & {$[-0.048,0.002]$} \\
\hline log_KA & 0.011 & 0.013 & {$[-0.015,0.038]$} \\
\hline $\log \_K M$ & 0.027 & 0.010 & {$[0.007,0.047]$} \\
\hline $\log K S$ & -0.030 & 0.015 & {$[-0.060,-0.001]$} \\
\hline $\log \_K F$ & -0.002 & 0.005 & {$[-0.011,0.008]$} \\
\hline log_LL & 0.016 & 0.021 & {$[-0.024,0.057]$} \\
\hline $\log _{L} L A$ & -0.043 & 0.032 & {$[-0.106,0.020]$} \\
\hline $\log L \mathrm{LM}$ & 0.044 & 0.027 & {$[-0.009,0.098]$} \\
\hline $\log _{-} L S$ & -0.008 & 0.039 & {$[-0.083,0.068]$} \\
\hline $\log _{-} L F$ & 0.027 & 0.013 & {$[0.002,0.052]$} \\
\hline $\log _{-} A A$ & -0.037 & 0.022 & {$[-0.079,0.006]$} \\
\hline log_AM & -0.021 & 0.027 & {$[-0.074,0.033]$} \\
\hline log_AS & -0.035 & 0.040 & {$[-0.115,0.044]$} \\
\hline log_AF & 0.060 & 0.011 & {$[0.038,0.082]$} \\
\hline $\log$ MM & 0.056 & 0.015 & {$[0.027,0.085]$} \\
\hline log_MS & -0.224 & 0.033 & {$[-0.289,-0.159]$} \\
\hline log_MF & 0.026 & 0.010 & {$[0.005,0.046]$} \\
\hline log_SS & 0.200 & 0.030 & {$[0.141,0.260]$} \\
\hline
\end{tabular}




\begin{tabular}{|c|c|c|c|}
\hline log_SF & -0.050 & 0.014 & {$[-0.078,-0.022]$} \\
\hline $\log _{-} F F$ & -0.042 & 0.002 & {$[-0.046,-0.038]$} \\
\hline $\log _{-} \mathrm{y} 2 \mathrm{y} 2$ & 0.048 & 0.002 & {$[0.044,0.052]$} \\
\hline $\log \mathrm{Ky} 2$ & -0.025 & 0.004 & {$[-0.033,-0.017]$} \\
\hline log_Ly2 & -0.022 & 0.012 & {$[-0.045,0.001]$} \\
\hline log_Ay2 & -0.016 & 0.012 & {$[-0.039,0.007]$} \\
\hline log_My2 & 0.086 & 0.010 & {$[0.067,0.105]$} \\
\hline log_Sy2 & 0.016 & 0.015 & {$[-0.013,0.045]$} \\
\hline $\log \_\mathrm{Fy} 2$ & -0.027 & 0.005 & {$[-0.036,-0.018]$} \\
\hline trend2 & 0.000 & 0.000 & {$[0.000,0.000]$} \\
\hline trend_log_K & 0.000 & 0.001 & {$[-0.001,0.002]$} \\
\hline trend_log_L & -0.007 & 0.002 & {$[-0.011,-0.003]$} \\
\hline trend_log_A & 0.012 & 0.002 & {$[0.008,0.016]$} \\
\hline trend_log_M & -0.018 & 0.002 & {$[-0.022,-0.014]$} \\
\hline trend_log_S & 0.010 & 0.003 & {$[0.004,0.015]$} \\
\hline trend_log_F & 0.002 & 0.001 & {$[0.000,0.004]$} \\
\hline trend_log_y2 & -0.001 & 0.001 & {$[-0.003,0.001]$} \\
\hline$\sigma_{v}$ & 0.106 & 0.001 & {$[0.104,0.108]$} \\
\hline$\eta$ & -0.018 & 0.004 & {$[-0.026,-0.009]$} \\
\hline$\lambda$ & 3.334 & 0.165 & {$[3.020,3.665]$} \\
\hline
\end{tabular}

Table C.2: Estimates of the parameters from the unstructured model

\begin{tabular}{lccc}
\hline Variable & Mean & Sd.dev. & 95\% Credible Interval \\
\hline intercept & -0.108 & 0.007 & {$[-0.119,-0.097]$} \\
log_y2 & 0.233 & 0.005 & {$[0.225,0.241]$} \\
log_K & -0.060 & 0.004 & {$[-0.067,-0.054]$} \\
log_L & -0.084 & 0.009 & {$[-0.100,-0.069]$} \\
log_A & -0.048 & 0.010 & {$[-0.064,-0.032]$} \\
log_M & -0.315 & 0.008 & {$[-0.329,-0.301]$} \\
log_S & -0.312 & 0.012 & {$[-0.332,-0.292]$} \\
log_F & -0.177 & 0.005 & {$[-0.185,-0.169]$} \\
trend & -0.025 & 0.001 & {$[-0.026,-0.024]$} \\
east & 0.017 & 0.014 & {$[-0.006,0.039]$} \\
west & -0.011 & 0.007 & {$[-0.022,0.000]$} \\
north & 0.031 & 0.007 & {$[0.020,0.042]$}
\end{tabular}




\begin{tabular}{|c|c|c|c|}
\hline log_KK & -0.001 & 0.003 & {$[-0.005,0.004]$} \\
\hline log_KL & -0.004 & 0.012 & {$[-0.024,0.016]$} \\
\hline log_KA & -0.006 & 0.012 & {$[-0.026,0.013]$} \\
\hline $\log \_\mathrm{KM}$ & 0.045 & 0.011 & {$[0.026,0.064]$} \\
\hline $\log _{-} K S$ & -0.010 & 0.015 & {$[-0.035,0.015]$} \\
\hline log_KF & -0.011 & 0.005 & {$[-0.020,-0.002]$} \\
\hline log_LL & -0.014 & 0.017 & {$[-0.042,0.015]$} \\
\hline $\log _{-} L A$ & -0.056 & 0.030 & {$[-0.105,-0.007]$} \\
\hline log_LM & 0.102 & 0.031 & {$[0.051,0.152]$} \\
\hline log_LS & -0.019 & 0.038 & {$[-0.082,0.044]$} \\
\hline $\log _{-} L F$ & 0.015 & 0.013 & {$[-0.005,0.036]$} \\
\hline log_AA & 0.029 & 0.017 & {$[0.001,0.056]$} \\
\hline log_AM & -0.081 & 0.029 & {$[-0.128,-0.034]$} \\
\hline log_AS & -0.009 & 0.037 & {$[-0.071,0.052]$} \\
\hline $\log _{-} \mathrm{AF}$ & 0.030 & 0.012 & {$[0.011,0.050]$} \\
\hline $\log _{-} \mathrm{MM}$ & 0.021 & 0.017 & {$[-0.006,0.049]$} \\
\hline log_MS & -0.177 & 0.034 & {$[-0.232,-0.121]$} \\
\hline log_MF & 0.036 & 0.011 & {$[0.017,0.054]$} \\
\hline $\log _{-} \mathrm{SS}$ & 0.169 & 0.033 & {$[0.114,0.223]$} \\
\hline $\log _{-} \mathrm{SF}$ & -0.016 & 0.017 & {$[-0.044,0.012]$} \\
\hline $\log _{-} F F$ & -0.036 & 0.002 & {$[-0.040,-0.033]$} \\
\hline $\log =\mathrm{y} 2 \mathrm{y} 2$ & 0.057 & 0.002 & {$[0.053,0.061]$} \\
\hline $\log \_\mathrm{Ky} 2$ & -0.003 & 0.005 & {$[-0.011,0.006]$} \\
\hline log_Ly2 & -0.029 & 0.013 & {$[-0.050,-0.008]$} \\
\hline log_Ay2 & -0.048 & 0.013 & {$[-0.069,-0.027]$} \\
\hline log_My2 & 0.004 & 0.012 & {$[-0.016,0.024]$} \\
\hline $\log _{-} \mathrm{Sy} 2$ & 0.086 & 0.017 & {$[0.059,0.114]$} \\
\hline $\log \_\mathrm{Fy} 2$ & -0.015 & 0.006 & {$[-0.024,-0.006]$} \\
\hline trend2 & 0.000 & 0.000 & {$[-0.000,0.000]$} \\
\hline trend_log_K & 0.000 & 0.001 & {$[-0.002,0.002]$} \\
\hline trend_log_L & -0.004 & 0.003 & {$[-0.009,0.000]$} \\
\hline trend_log_A & 0.006 & 0.003 & {$[0.001,0.011]$} \\
\hline trend_log_M & -0.016 & 0.003 & {$[-0.021,-0.011]$} \\
\hline trend_log_S & 0.009 & 0.004 & {$[0.003,0.016]$} \\
\hline trend_log_F & 0.005 & 0.001 & {$[0.003,0.007]$} \\
\hline trend_log_y2 & 0.002 & 0.001 & {$[-0.000,0.0004]$} \\
\hline$\sigma_{v}$ & 0.136 & 0.002 & {$[0.132,0.140]$} \\
\hline
\end{tabular}


Table C.3: Estimates of the parameters from the dynamic model

\begin{tabular}{|c|c|c|c|}
\hline Variable & Mean & Std. dev. & 95\% Credible Interval \\
\hline intercept & -0.522 & 0.035 & {$[-0.583,-0.469]$} \\
\hline $\log _{-} y 2$ & 0.146 & 0.005 & {$[0.138,0.154]$} \\
\hline $\log _{-} K$ & -0.021 & 0.005 & {$[-0.029,-0.012]$} \\
\hline $\log _{-} L$ & -0.049 & 0.011 & {$[-0.067,-0.031]$} \\
\hline log_A & -0.103 & 0.016 & {$[-0.129,-0.077]$} \\
\hline $\log _{-} M$ & -0.199 & 0.010 & {$[-0.215,-0.182]$} \\
\hline $\log _{-} S$ & -0.279 & 0.017 & {$[-0.307,-0.251]$} \\
\hline $\log _{-} F$ & -0.191 & 0.005 & {$[-0.199,-0.182]$} \\
\hline trend & -0.023 & 0.001 & {$[-0.025,-0.022]$} \\
\hline east & -0.023 & 0.026 & {$[-0.066,0.018]$} \\
\hline west & 0.011 & 0.013 & {$[-0.011,0.033]$} \\
\hline north & 0.056 & 0.013 & {$[0.035,0.077]$} \\
\hline log_KK & 0.006 & 0.003 & {$[0.001,0.012]$} \\
\hline $\log K L$ & 0.001 & 0.013 & {$[-0.020,0.023]$} \\
\hline $\log K A$ & -0.001 & 0.015 & {$[-0.025,0.023]$} \\
\hline log_KM & 0.026 & 0.011 & {$[0.009,0.044]$} \\
\hline log_KS & -0.006 & 0.017 & {$[-0.033,0.021]$} \\
\hline $\log _{-} K F$ & -0.003 & 0.005 & {$[-0.011,0.006]$} \\
\hline $\log _{L} L L$ & -0.008 & 0.018 & {$[-0.038,0.023]$} \\
\hline $\log _{L} L A$ & -0.015 & 0.032 & {$[-0.067,0.038]$} \\
\hline log_LM & 0.034 & 0.027 & {$[-0.010,0.078]$} \\
\hline log_LS & -0.002 & 0.037 & {$[-0.062,0.059]$} \\
\hline $\log _{-} L F$ & 0.016 & 0.013 & {$[-0.005,0.037]$} \\
\hline $\log _{-} \mathrm{AA}$ & -0.023 & 0.021 & {$[-0.059,0.012]$} \\
\hline log_AM & -0.024 & 0.027 & {$[-0.069,0.020]$} \\
\hline $\log _{-} \mathrm{AS}$ & -0.012 & 0.041 & {$[-0.078,0.055]$} \\
\hline $\log _{-} A F$ & 0.052 & 0.012 & {$[0.032,0.072]$} \\
\hline log_MM & 0.017 & 0.014 & {$[-0.006,0.039]$} \\
\hline log_MS & -0.133 & 0.032 & {$[-0.185,-0.081]$} \\
\hline log_MF & 0.021 & 0.010 & {$[0.005,0.038]$} \\
\hline $\log _{-} S S$ & 0.087 & 0.033 & {$[0.033,0.141]$} \\
\hline $\log _{-} \mathrm{SF}$ & -0.011 & 0.015 & {$[-0.037,0.014]$} \\
\hline $\log _{-} F F$ & -0.040 & 0.002 & {$[-0.044,-0.037]$} \\
\hline $\log _{-} y 2 y 2$ & 0.034 & 0.002 & {$[0.031,0.037]$} \\
\hline
\end{tabular}




$\begin{array}{lccc}\text { log_Ky2 } & -0.016 & 0.005 & {[-0.024,-0.009]} \\ \text { log_Ly2 } & -0.027 & 0.011 & {[-0.045,-0.009]} \\ \text { log_Ay2 } & -0.017 & 0.011 & {[-0.035,0.001]} \\ \text { log_My2 } & 0.067 & 0.010 & {[0.051,0.082]} \\ \text { log_Sy2 } & 0.012 & 0.014 & {[-0.012,0.035]} \\ \text { log_Fy2 } & -0.015 & 0.004 & {[-0.023,-0.008]} \\ \text { trend2 } & -0.001 & 0.000 & {[-0.001,-0.001]} \\ \text { trend_log_K } & -0.001 & 0.001 & {[-0.002,0.001]} \\ \text { trend_log_L } & -0.006 & 0.002 & {[-0.010,-0.002]} \\ \text { trend_log_A } & 0.010 & 0.003 & {[0.006,0.014]} \\ \text { trend_log_M } & -0.014 & 0.003 & {[0.0018,-0.010]} \\ \text { trend_log_S } & 0.007 & 0.003 & {[0.0013]} \\ \text { trend_log_F } & 0.000 & 0.001 & {[0.004,0.007]} \\ \text { trend_log_y2 } & 0.005 & 0.001 & {[0.114,0.137]} \\ & & & {[0.931,0.949]} \\ \sigma_{v} & 0.082 & 0.001 & \\ \sigma_{\xi} & 0.125 & 0.007 & 0.005 \\ \rho & 0.940 & 0.005 & \end{array}$

Table C.4: Determinants of efficiency in the unstructured model

\begin{tabular}{lccc}
\hline Variable & Mean & Sd.dev. & 95\% Credible Interval \\
\hline intercept & 2.622 & 0.114 & {$[2.441,2.814]$} \\
size & 0.529 & 0.071 & {$[0.416,0.649]$} \\
specialization & 1.483 & 0.156 & {$[1.230,1.743]$} \\
density & 1.069 & 0.099 & {$[0.909,1.234]$} \\
\hline
\end{tabular}

Table C.5: Determinants of transformed efficiency $\mathrm{s}$ in the dynamic efficiency model

\begin{tabular}{lccc}
\hline Variable & Mean & Std. dev. & 95\% Credible Interval \\
\hline intercept & 0.050 & 0.007 & {$[0.039,0.062]$} \\
size & 0.025 & 0.004 & {$[0.019,0.032]$} \\
specialization & 0.078 & 0.010 & {$[0.063,0.094]$} \\
density & 0.021 & 0.004 & {$[0.015,0.028]$} \\
\hline
\end{tabular}



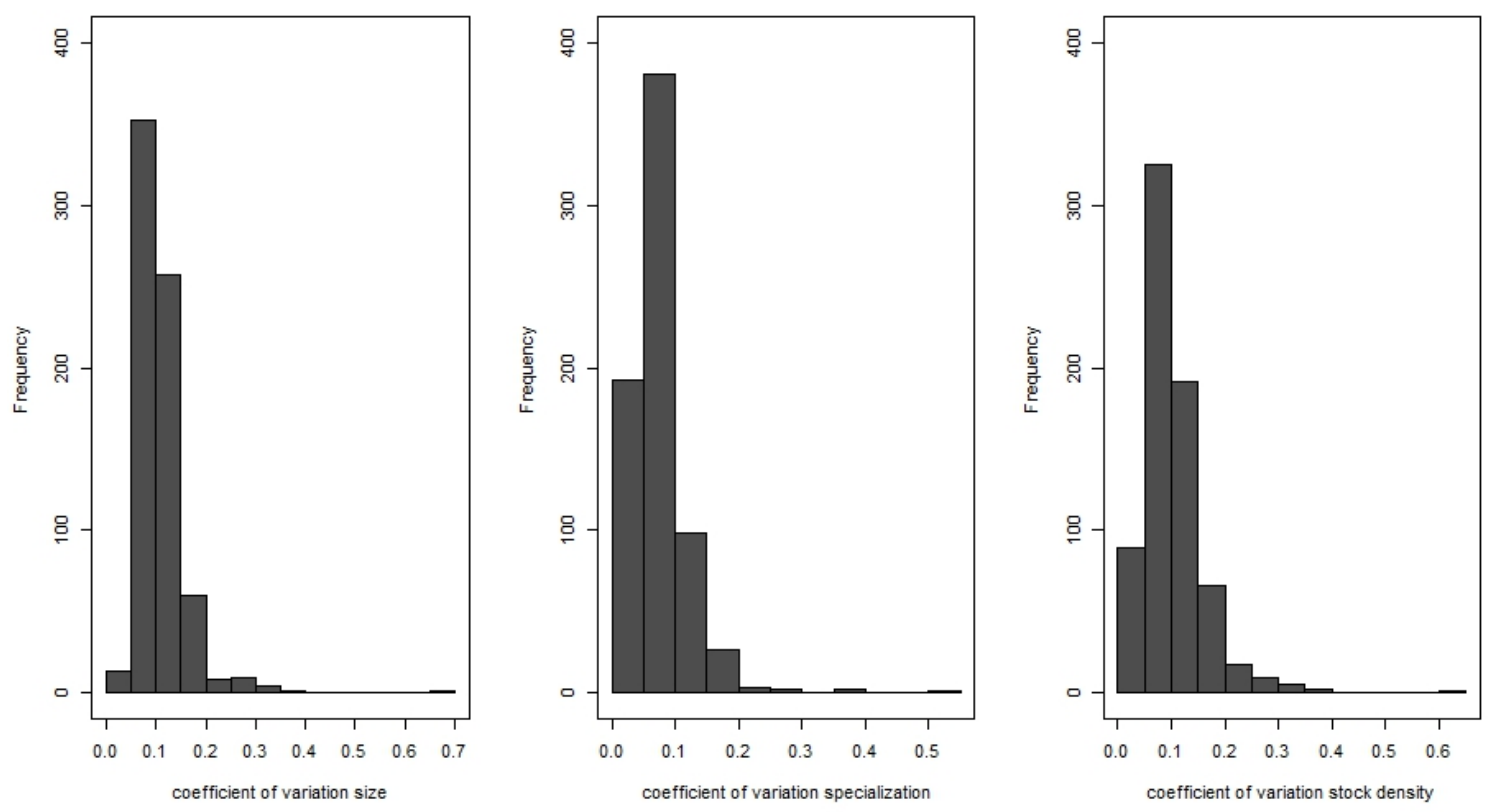

Figure C.1: Coefficient of variation for size, specialization and stock density 


\section{Bibliography}

Abdulai, A. and Tietje, H. (2007). Estimating technical efficiency under unobserved heterogeneity with stochastic frontier models: application to northern German dairy farms. European Review of Agricultural Economics 34 (3): 393-416.

Ahn, S. C. and Sickles, R. C. (2000). Estimation of long-run inefficiency levels: a dynamic frontier approach. Econometric Reviews 19 (4): 461-492.

Aigner, D., Lovel, C. A. K., and Schmidt, P. (1977). Formulation and estimation of stochastic frontier production function models. Journal of Econometrics 6 (1): 2137.

Alvarez, A. and Corral, J. del (2010). Identifying different technologies using a latent class model: extensive versus intensive dairy farms. European Review of Agricultural Economics 37 (2): 231-250.

Badunenko, O. and Kumbhakar, S. C. (2016). When, where and how to estimate persistent and transient efficiency in stochastic frontier panel data models. European Journal of Operational Research 255 (1): 272-287.

Battese, G. E. and Coelli, T. J. (1992). "Frontier Production Functions, Technical Efficiency and Panel Data: With Application to Paddy Farmers in India". International Applications of Productivity and Efficiency Analysis: A Special Issue of the Journal of Productivity Analysis. Dordrecht: Springer Netherlands, 149-165.

Battese, G. E. and Coelli, T. J. (1995). A model for technical inefficiency effects in a stochastic frontier production function for panel data. Empirical Economics 20 (2): 325-332.

Bojnec, S. and Latruffe, L. (2009). Determinants of technical efficiency of Slovenian farms. Post-Communist Economies 21 (1): 117-124.

Bojnec, S. and Latruffe, L. (2011). Farm size and efficiency during transition: insights from Slovenian farms. Transformation in Business Economics 10 (3): 104-116.

Bojnec, S. and Latruffe, L. (2013). Farm size, agricultural subsidies and farm performance in Slovenia. Land Use Policy 32: 207-217.

Brady, M., Kellermann, K., Sahrbacher, C., and Jelinek, L. (2009). Impacts of decoupled agricultural support on farm structure, biodiversity and landscape mosaic: some EU results. Journal of agricultural economics 60 (3): 563-585.

Brümmer, B. (2001). Estimating confidence intervals for technical efficiency: the case of private farms in slovenia. European Review of Agricultural Economics 28 (3): $285-306$. 
Brümmer, B., Glauben, T., and Thijssen, G. (2002). Decomposition of Productivity Growth Using Distance Functions: The Case of Dairy Farms in Three European Countries. American Journal of Agricultural Economics 84 (3): 628-644.

Caves, D. W., Christensen, L. R., and Diewert, W. E. (1982). The economics theory of index numbers and the measurement of input, output, and productivity. Econometrics 50 (6): 1393-1414.

Cechura, L., Grau, A., Hockmann, H., Levkovych, I., and Kroupova, Z. (2016). Catching Up or Falling Behind in European Agriculture: The Case of Milk Production. Journal of Agricultural Economics. DOI: 10.1111/1477-9552.12193.

Ciaian, P. and Swinnen, J. F. M. (2009). Credit Market Imperfections and the Distribution of Policy Rents. American Journal of Agricultural Economics 91 (4): 11241139.

Cochrane, W. W. (1958). Farm prices: myth and reality. Minneapolis, Minnesota: U of Minnesota Press.

Coelli, T. and Fleming, E. (2004). Diversification economies and specialisation efficiencies in a mixed food and coffee smallholder farming system in Papua New Guinea. Agricultural Economics 31 (2-3): 229-239.

Cornwel, C., Schmidt, P., and Sickles, R. C. (1990). Production frontiers with crosssectional and time-series variation in efficiency levels. Journal of Econometrics 46 (1): 185-200.

Davidova, S. and Latruffe, L. (2007). Relationships between Technical Efficiency and Financial Management for Czech Republic Farms. Journal of Agricultural Economics 58 (2): 269-288.

Debreu, G. (1951). The Coefficient of Resource Utilization. Econometrica 19 (3): 273292.

Eisner, R., Strotz, R. H., and Post, G. R. (1963). Determinants of business investment. Englewood Cliffs, New Jersey: Prentice Hall.

Emvalomatis, G. (2012a). Adjustment and unobserved heterogeneity in dynamic stochastic frontier models. Journal of Productivity Analysis 37 (1): 7-16.

Emvalomatis, G. (2012b). Productivity Growth in German Dairy Farming using a Flexible Modelling Approach. Journal of Agricultural Economics 63 (1): 83-101.

Emvalomatis, G., Stefanou, S. E., and Oude Lansink, A. (2011). A Reduced-Form Model for Dynamic Efficiency Measurement: Application to Dairy Farms in Germany and The Netherlands. American Journal of Agricultural Economics 93 (1): $161-174$.

European Commission (2016). Accessed: 25/11/2016. URL: http ://ec.europa.eu/ agriculture/healthcheck. 
EUROSTAT (2016). Accessed: 07/11/2016. URL: http://ec .europa.eu/eurostat/ web/agriculture/data/database.

Fallah-Fini, S., Triantis, K., and Johnson, A. L. (2014). Reviewing the literature on non-parametric dynamic efficiency measurement: state-of-the-art. Journal of Productivity Analysis 41 (1): 51-67.

Farrell, M. J. (1957). The Measurement of Productive Efficiency. Journal of the Royal Statistical Society. Series A (General) 120 (3): 253-290.

Filippini, M. and Greene, W. (2016). Persistent and transient productive inefficiency: a maximum simulated likelihood approach. Journal of Productivity Analysis 45 (2): $187-196$.

Filippini, M. and Hunt, L. C. (2015). Measurement of energy efficiency based on economic foundations. Energy Economics 52: S5-S16.

Galán, S. E., Veiga, H., and Wiper, M. P. (2015). Dynamic effects in inefficiency: Evidence from the Colombian banking sector. European Journal of Operational Research 240 (2): 562-571.

Gardebroek, C. and Oude Lansink, A. (2004). Farm-specific Adjustment Costs in Dutch Pig Farming. Journal of Agricultural Economics 55 (1): 3-24.

Geylani, P. C. and Stefanou, S. E. (2013). Linking investment spikes and productivity growth. Empirical Economics 45 (1): 157-178.

Hadley, D. (2006). Patterns in Technical Efficiency and Technical Change at the Farmlevel in England and Wales, 1982-2002. Journal of Agricultural Economics 57 (1): $81-100$.

Kapelko, M., Oude Lansink, A., and Stefanou, S. E. (2015). Analyzing the impact of investment spikes on dynamic productivity growth. Omega 54: 116-124.

Karagiannis, G. and Tzouvelekas, V. (2005). Explaining output growth with a heteroscedastic non-neutral production frontier: the case of sheep farms in Greece. European Review of Agricultural Economics 32 (1): 51-74.

Kass, R. E. and Raftery, A. E. (1995). Bayes Factors. Journal of the American Statistical Association 90 (430): 773-795.

Kleinhanß, W., Offermann, F., and Ehrmann, M. (2010). Evaluation of the impact of milk quota - case study Germany. Braunschweig.

Koop, G., Osiewalski, J., and Steel, M. F. (1997). Bayesian efficiency analysis through individual effects: Hospital cost frontiers. Journal of Econometrics 76 (1-2): 77105.

Koop, G., Steel, M. F. J., and Osiewalski, J. (1995). Posterior analysis of stochastic frontier models using Gibbs sampling. Computational Statistics 10: 353-373.

Koopmans, T. C. (1951). Activity analysis of production and allocation. 13. New York: Wiley. 
Kumbhakar, S. C. (1990). Production frontiers, panel data, and time-varying technical inefficiency. Journal of Econometrics 46 (1): 201-211.

Kumbhakar, S. C. and Bokusheva, R. (2009). Modelling farm production decisions under an expenditure constraint. European Review of Agricultural Economics 36 (3): 343-367.

Latruffe, L., Balcombe, K., Davidova, S., and Zawalinska, K. (2004). Determinants of technical efficiency of crop and livestock farms in Poland. Applied Economics 36 (12): 1255-1263.

Latruffe, L., Balcombe, K., Davidova, S., and Zawalinska, K. (2005). Technical and scale efficiency of crop and livestock farms in Poland: does specialization matter? Agricultural Economics 32 (3): 281-296.

Latruffe, L., Davidova, S., and Balcombe, K. (2008). Application of a double bootstrap to investigation of determinants of technical efficiency of farms in Central Europe. Journal of Productivity Analysis 29 (2): 183-191.

Lee, Y. H. and Schmidt, P. (1993). A production frontier model with flexible temporal variation in technical efficiency. The measurement of productive efficiency: Techniques and applications: 237-255.

Lewis, S. M. and Raftery, A. E. (1997). Estimating Bayes Factors via Posterior Simulation With the Laplace-Metropolis Estimator. Journal of the American Statistical Association 92 (438): 648-655.

Lovell, C. (2003). The decomposition of Malmquist productivity indexes. Journal of Productivity Analysis 20 (3): 437-458.

Luh, Y. H. and Stefanou, S. E. (1993). Learning-by-doing and the sources of productivity growth: A dynamic model with application to U.S. agriculture. Journal of Productivity Analysis 4 (4): 353-370.

Malmquist, S. (1953). Index numbers and indifference surfaces. Trabajos de Estadistica 4 (2): 209-242.

Meeusen, W. and van den Broeck, J. (1977). Efficiency Estimation from Cobb-Douglas Production Functions with Composed Error. International Economic Review 18 (2): 435-444.

Nemoto, J. and Goto, M. (1999). Dynamic data envelopment analysis: modeling intertemporal behavior of a firm in the presence of productive inefficiencies. Economics Letters 64 (1): 51-56.

Nemoto, J. and Goto, M. (2003). Measurement of Dynamic Efficiency in Production: An Application of Data Envelopment Analysis to Japanese Electric Utilities. Journal of Productivity Analysis 19 (2): 191-210. 
Newman, C. and Matthews, A. (2007). Evaluating the Productivity Performance of Agricultural Enterprises in Ireland using a Multiple Output Distance Function Approach. Journal of Agricultural Economics 58 (1): 128-151.

Orea, L. (2002). Parametric Decomposition of a Generalized Malmquist Productivity Index. Journal of Productivity Analysis 18 (1): 5-22.

Penrose, E. T. (1959). The theory of the growth of the firm. New York, New York: Wiley.

Rizov, M., Pokrivcak, J., and Ciaian, P. (2013). CAP Subsidies and Productivity of the EU Farms. Journal of Agricultural Economics 64 (3): 537-557.

Sauer, J. and Latacz-Lohmann, U. (2015). Investment, technical change and efficiency: empirical evidence from German dairy production. European Review of Agricultural Economics 42 (1): 151-175.

Shephard, R. W. (1970). The theory of cost and production functions, Princeton, New Jersey. New Jersey: Princeton University Press.

Silva, E. and Stefanou, S. E. (2007). Dynamic Efficiency Measurement: Theory and Application. American Journal of Agricultural Economics 89 (2): 398-419.

Stefanou, S. E. (2009). A Dynamic Characterization of Efficiency. Agricultural Economics Review 10 (1): 18-33.

Stefanou, S. E. and Saxena, S. (1988). Education, Experience, and Allocative Efficiency: A Dual Approach. American Journal of Agricultural Economics 70 (2): 338-345.

Stehfest, E., van den Berg, M., Woltjer, G., Msangi, S., and Westhoek, H. (2013). Options to reduce the environmental effects of livestock production - Comparison of two economic models. Agricultural Systems 114: 38-53.

Tanner, M. A. and Wong, W. H. (1987). The Calculation of Posterior Distributions by Data Augmentation. Journal of the American Statistical Association 82 (398): $528-540$.

Tsionas, E. G. (2006). Inference in dynamic stochastic frontier models. Journal of Applied Econometrics 21 (5): 669-676.

Tsionas, E. G. and Kumbhakar, S. C. (2014). Firm heterogeneity, persistent and transient technical inefficiency: a generalized true random-effects model. Journal of Applied Econometrics 29 (1): 110-132.

van den Broeck, J., Koop, G., Osiewalski, J., and Steel, M. F. J. (1994). Stochastic frontier models: A Bayesian perspective. Journal of Econometrics 61 (2): 273-303.

Wooldridge, J. M. (2005). Simple solutions to the initial conditions problem in dynamic, nonlinear panel data models with unobserved heterogeneity. Journal of Applied Econometrics 20 (1): 39-54. 
Zhu, X., Demeter, R., and Oude Lansink, A. (2012). Technical efficiency and productivity differentials of dairy farms in three EU countries: the role of CAP subsidies. Agricultural Economics Review 13 (1): 66-92.

Zhu, X., Karagiannis, G., and Oude Lansink, A. (2011). The Impact of Direct Income Transfers of CAP on Greek Olive Farms' Performance: Using a Non-Monotonic Inefficiency Effects Model. Journal of Agricultural Economics 62 (3): 630-638.

Zhu, X. and Oude Lansink, A. (2010). Impact of CAP Subsidies on Technical Efficiency of Crop Farms in Germany, the Netherlands and Sweden. Journal of Agricultural Economics 61 (3): 545-564. 


\section{CURRICULUM VITAE}

\section{Ioannis Skevas}

February 2017

\section{Contact Information}

Address: Department of Agricultural Economics and Rural Development Georg-August-Universität Göttingen

Platz der Göttinger Sieben 5

Göttingen, D-37073

Germany

Tel: $\quad$ +49 (0) 551394800

Email: $\quad$ iskevas@gwdg.de

\section{Personal Information}

Born: $\quad$ Alexandroupolis, Greece, 28 April 1987

Nationallity: Hellenic

\section{Education}

PhD Georg-August-Universität Göttingen, Germany

November 2013 - February 2017

Chair for Statistics - RTG 1644 "Scaling Problems in Statistics" Department of Agricultural Economics and Rural Development Thesis Title: "A Bayesian approach to dynamic efficiency and productivity measurement"

MSc: $\quad$ Wageningen University, Netherlands, August 2013

Environmental Economics and Natural Resources Group

Thesis Title: "Direction of efficiency and the impact of policy instruments on farmer's performance: The case of Dutch dairy farms"

BSc \& MSc: Aristotle University of Thessaloniki, Greece, February 2011 
Department of Agricultural Economics

Thesis Title: "The role of agriculture in the economic development of Greece"

\section{Languages}

Greek: Mother tongue

English: Fluent - Certificate of Proficiency

German: Beginner - Certificate of A1.1 - A1.3

\section{Professional Experience}

Research Scholar: University of Dundee, United Kingdom

September 2015 - April 2016

Economic Studies

Researcher: $\quad$ CPB Netherlands Bureau for Economic Policy Analysis

Netherlands

April - June, 2013

Climate and Regional Economics

Internship MSc: CPB Netherlands Bureau for Economic Policy Analysis Netherlands

August - December, 2012

Climate and Regional Economics

Internship BSc: Greek Ministry of Rural Development and Food Greece

July - August, 2009

\section{Specialties \& Research Interests}

- Statistics and Applied Econometrics

- Production Economics, Efficiency \& Productivity Measurement

- Agricultural \& Environmental Economics

\section{Publications}

1. T. Skevas., E. Kikulwe., H. Papadopoulou., I. Skevas., and J. Wesseler, 2012. Do European union farmers reject genetically modified maize? Farmer prefer- 
ences for genetically modified maize in Greece. AgBioForum, 15(3):242-256.

\section{Work in Progress}

1. I. Skevas., G. Emvalomatis., and B. Brümmer. The effect of farm characteristics on the persistence of technical inefficiency: A case study in German dairy farming. (In European Review of Agricultural Economics, $3^{\text {rd }}$ round).

2. I. Skevas., G. Emvalomatis., and B. Brümmer. Heterogeneity of long-run technical efficiency of German dairy farms: a Bayesian approach. (In Journal of Agricultural Economics, $2^{\text {nd }}$ round.)

3. I. Skevas., G. Emvalomatis., and B. Brümmer. Productivity growth under a dynamic inefficiency specification: the case of German dairy farms. (In Journal of Productivity Analysis, under review).

4. I. Skevas., X. Zhu., V. Shestalova., and G. Emvalomatis. The impact of agrienvironmental policies and production intensification on the environmental performance of Dutch dairy farms. (In Journal of Agricultural and Resource Economics, under review.)

5. T. Skevas., I. Skevas., and S. Swinton. Do spatial interdependencies affect the decision to make land available for bioenergy crops? (In Journal of Agricultural Economics, under review.)

\section{Presentations at Professional Meetings}

- Paper presentation at the $146^{\text {th }}$ EAAE seminar: Technology transfer as a driver of innovative entrepreneurship in agriculture and the agri-food industry, July 1416, 2015, Chania, Greece. Title: Dynamic efficiency analysis under a Bayesian framework.

- Paper presentation at the $14^{\text {th }}$ European Workshop on Efficiency and Productivity Analysis, June 15-18, 2015, Helsinki, Finland. Title: Heterogeneity of 
inefficiency persistence under a Bayesian framework.

- Poster presentation at the EAAE 2014 International Congress, August 26-29, 2014, Ljubljana, Slovenia. Title: An examination of the impact of agri-environmental policies and intensification on the hyperbolic efficiency of Dutch dairy farms.

\section{Teaching Experience}

- Efficiency and Productivity Analysis - Stochastic Approaches. February 2015.

Ph.D course of the Doctoral Certificate Program in Agricultural Economics.

Georg-August-Universität Göttingen

- Microeconomics (Teaching Assistant). September 2015 - December 2015. B.Sc. course.

University of Dundee.

- Applied Business Statistics (Teaching Assistant). January 2016 - March 2016.

M.Sc. course.

University of Dundee.

\section{Professional Associations}

European Association of Agricultural Economists (EAAE)

Agricultural Economics Society (AES)

\section{Journal Reviewer}

Agricultural Economics

\section{References}

1. Bernhard Brümmer, Professor, Department of Agricultural Economics and Rural Development, Georg-August-Universität Göttingen, Platz der Goettinger Sieben 5, D-37073, Goettingen, Germany, e-mail: bbruemm@gwdg.de 
2. Grigorios Emvalomatis, Senior Lecturer, Business, University of Dundee, 3 Perth Rd, DD14HN, Dundee, United Kingdom, e-mail: g.emvalomatis@dundee.ac.uk

3. Thomas Kneib, Professor, Chair of Statistics and Econometrics, Georg-AugustUniversität Göttingen, Humboldtallee 3, D-37073, Goettingen, Germany, email: tkneib@uni-goettingen.de

4. Hassan Molana, Professor, Business, University of Dundee, 3 Perth Rd, DD14HN, Dundee, United Kingdom, e-mail: h.h.molana@dundee.ac.uk 